University of Louisville

ThinkIR: The University of Louisville's Institutional Repository

Electronic Theses and Dissertations

$12-2019$

\title{
Brokering words and work: complexities of literacy sponsorship in the oilfields of south Texas.
}

Jennifer L. Marciniak

University of Louisville

Follow this and additional works at: https://ir.library.louisville.edu/etd

Part of the Rhetoric and Composition Commons

\section{Recommended Citation}

Marciniak, Jennifer L., "Brokering words and work: complexities of literacy sponsorship in the oilfields of south Texas." (2019). Electronic Theses and Dissertations. Paper 3332.

https://doi.org/10.18297/etd/3332

This Doctoral Dissertation is brought to you for free and open access by ThinkIR: The University of Louisville's Institutional Repository. It has been accepted for inclusion in Electronic Theses and Dissertations by an authorized administrator of ThinkIR: The University of Louisville's Institutional Repository. This title appears here courtesy of the author, who has retained all other copyrights. For more information, please contact thinkir@louisville.edu. 


\title{
BROKERING WORDS AND WORK:
}

COMPLEXITIES OF LITERACY SPONSORSHIP IN THE OILFIELDS OF SOUTH TEXAS

\author{
by \\ Jennifer L. Marciniak \\ B.A., Stephen F. Austin State University, 2000 \\ M.A., Texas A\&M University - Corpus Christi, 2009

\begin{abstract}
A Dissertation
Submitted to the Faculty of the

College of Arts and Sciences of the University of Louisville

in Partial Fulfillment of the Requirements

for the Degree of
\end{abstract} \\ Doctor of Philosophy in \\ English/Rhetoric and Composition \\ Department of English \\ University of Louisville \\ Louisville, Kentucky
}

December 2019 
Copyright 2019 by Jennifer L. Marciniak

\section{All Rights Reserved}





\title{
BROKERING WORDS AND WORK: \\ COMPLEXITIES OF LITERACY SPONSORSHIP IN THE OILFIELDS OF SOUTH TEXAS
}

\author{
by \\ Jennifer L. Marciniak \\ B.A., Stephen F. Austin State University, 2000 \\ M.A., Texas A\&M University - Corpus Christi, 2009
}

A Dissertation Approved on

November 15, 2019

by the following Dissertation Committee:

Bronwyn Williams, Ph.D. (Co-Director)

Stephen Schneider, Ph.D. (Co-Director)

Beth Boehm, Ph.D.

Glynis Ridley, Ph.D.

Michael Pennell, Ph.D. 


\section{DEDICATION}

This dissertation is dedicated to

\section{Talulah}

my constant companion and best friend for 10 years

who crossed the rainbow bridge before we could finish the journey together. 


\section{ACKNOWLEDGMENTS}

First and foremost, I would like to thank the rig and service workers in the Eagle Ford Shale who made this study possible. They took time out of their busy days and nights to meet me in bars, restaurants, their places of work, and their homes. They are some of the most intelligent, yet misunderstood, folks I have ever known. While some are

lifelong friends and others acquaintances, they all remind me what it means to be a proud, working-class South Texan, which is a part of my identity that will always drive my work inside and outside of academia.

Thanks to my father, Allen Wayne Marciniak, for the stories and the sacrifices that made me feel like his experiences, as well as Manuel's, Joseph's, Ben's, and Sarah's, needed a voice in literacy studies.

Thanks to Niki Bertrand (soon to be Ph.D.), Dr. Sandi Nenga, Dr. Leslie OrtquistAhrens, and Dr. K. Shannon Howard. Your support and advice has been much appreciated and needed throughout this process. Also, many thanks to my friends and family who supported me by respecting my wishes NOT talk about the dissertation or answer questions about it.

I owe a substantial amount of gratitude to my "accountabili-buddies" without whom I would never have completed this project. First, thanks to Aubrie Cox at the University of Louisville Virtual Writing Center for spending more than 40 writing center sessions talking out and reading drafts over the past year. Her questions and responses to 
my ideas kept me from going down numerous "rabbit holes," which is one of my biggest challenges as a writer. Second, thanks to Emily Sydnor, John Ross, Luis Romero, and Erin Taylor, my colleagues in the Junior Faculty Research Group at Southwestern University for keeping me on track and pushing me to take control of the process instead of letting it take control of me. Also, I need to thank all my writing partners at Focusmate, a dynamic community of people from around the world, who, like me, need to be immediately responsible to someone to get writing done.

Lastly, I would like to thank my committee for agreeing to read the stories of these workers and other sponsors of literacy in the South Texas oil and gas industry. Special thanks to Dr. Bronwyn Williams for providing much needed support, especially during the final year or writing. It took a lot longer than I anticipated, but this hitch is done. 


\section{ABSTRACT \\ BROKERING WORDS AND WORK: \\ COMPLEXITIES OF LITERACY SPONSORSHIP IN THE OILFIELDS OF SOUTH TEXAS \\ Jennifer L. Marciniak}

November 15, 2019

This research is an investigation of workforce recruitment language as the "leading edge" of literacy sponsorship as it pertains to blue-collar rig and service workers in the South Texas oilfields. Using Deborah Brandt's Literacy in American Lives as a framework for this study, I conducted interviews with 10 rig and service workers and labor market intermediary administrators about the perceptions and expectations of literacy use in oilfield work. My inquiry begins by first learning about workers' experiences with recruitment into the industry. Then, to understand more about how the industry communicates literacy expectations to these workers, I look at recruitment rhetoric via a rhetorical analysis of job advertisements for oil and gas positions. Finally, I examine the role of job market labor market intermediaries (LMIs), or temp agencies, and the role they play in potential oil and gas workers coming into the industry.

The results of this research are what make up my dissertation "Brokering Words and Work: Complexities of Literacy Sponsorship in the Oilfields of South Texas" in which I argue that literacy use is influenced by two significant factors. The first factor is 
the cultural and technological shift in the industry as it pertains to the 2012-13 hydraulic fracturing boom in the Eagle Ford Shale region of South Texas. This particular boom aligns with the Great Crew Change, the mass retirement of workers from oil and gas positions, creating a need for more workers at all levels of the industry, including workers with advanced technical skills and academic education. To recruit for these new literacies and skills, the industry communicates needs through job advertisements, which, I argue, are as much gatekeepers as they are matchmakers between work and workers for reasons related to access. The second factor is the normalizing of literacy-based processes by the in industry, especially as it pertains to workforce materials, such as reading and interpreting job advertisements, filling out job applications, and resume work. As the culture shifts from networking to the utilization of online job applications and materials, workers and/or applicants not familiar with these genres need assistance navigating the literacy expectations required to use them. To assist in labor market education practices, the industry utilizes the services of labor market intermediaries, which, I argue, are used to bridge literacy and accessibility gaps between worker and industry. 
TABLE OF CONTENTS

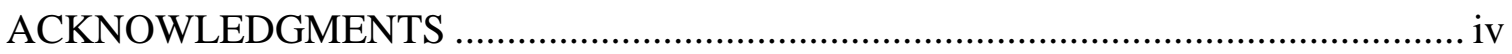

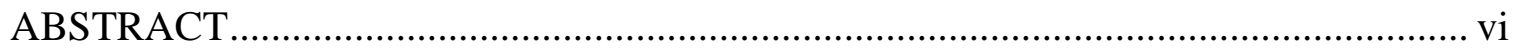

CHAPTER ONE: BROKERING WORDS AND WORK: COMPLEXITIES OF

LITERACY SPONSORSHIP IN THE OILFIELDS OF SOUTH TEXAS ......................... 1

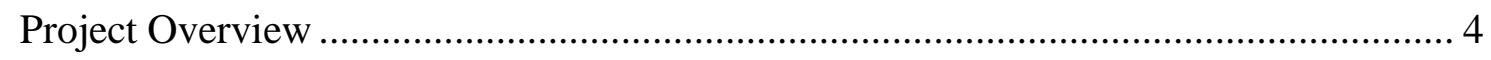

Literacy Sponsorship in the Workplace: A Literature Review ....................................... 7

Venues of Workplace Education and Literacy ..................................................... 8

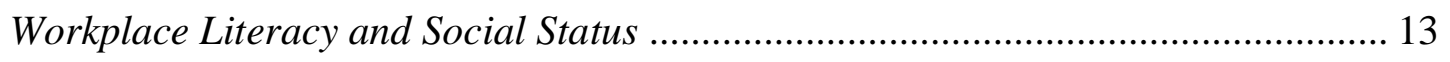

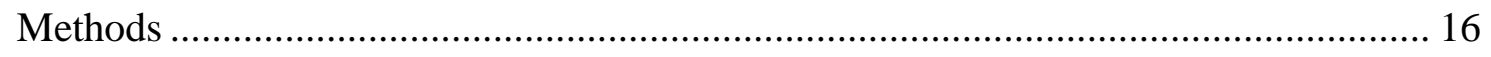

CHAPTER TWO: COMMUNITIES OF PRACTICES AND LITERACY

PERCEPTIONS IN THE OILFIELDS OF SOUTH TEXAS ......................................... 31

Section 1: Recruitment Experiences of South Texas Oilfield Workers (1990s-2000s) 33

Section II: Ways of Learning and Literacy Work in the South Texas Oilfield ............. 41

Situated learning and "doing” knowledge............................................................... 43

Literacy-based learning and 'doing' knowledge ..................................................... 49

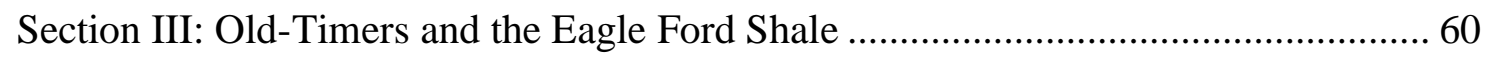

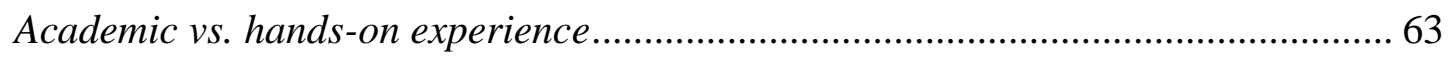


Technology and the changing oilfield . 68

Conclusion 70

\section{CHAPTER THREE: OIL AND GAS INDUSTRY AS LITERACY SPONSOR: JOB}

ADVERTISEMENTS ANALYSIS

Section I: The Eagle Ford Shale and the Great Crew Change.................................... 74

Culture and Tech Shift Impact on Current Oilfield Workers ..................................... 76

Section II: Job Advertisements as Evidence of Literacy Sponsorship: Methodology .. 80

Section III: Job Advertisement Results and Analysis .............................................. 83

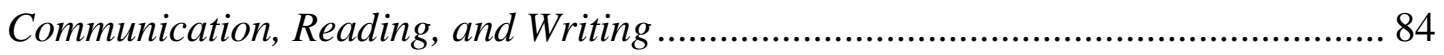

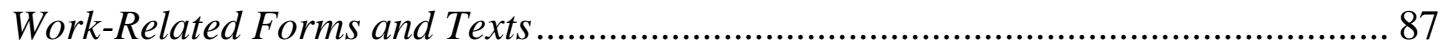

Academic and Non-Academic Education and Training .......................................... 92

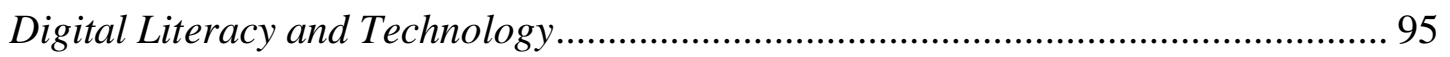

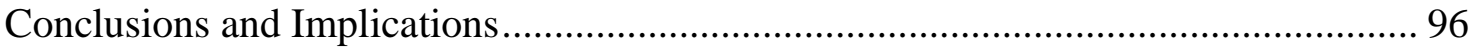

\section{CHAPTER FOUR: LABOR MARKET INTERMEDIARIES AS LITERACY}

SPONSORS IN THE SOUTH TEXAS OILFIELD …………………...................... 100

Two Types of Labor Market Intermediaries.............................................................. 102

Texas Workforce Solutions of the Coastal Bend.................................................... 107

South Texas Oil and Gas Industry Hiring Challenges ................................................. 110

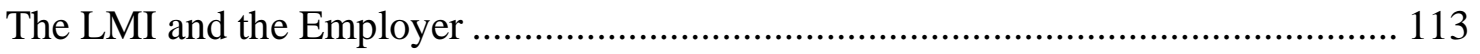

Assisting in Writing and Revising Job Advertisements .......................................... 113

WorkInTexas as Human Resources ..................................................................... 115

Marketing Job Availability to the Local Community ………….............................. 117

The LMI and the Worker.................................................................................. 121 
Understanding the Application Process ……………………………………...... 122

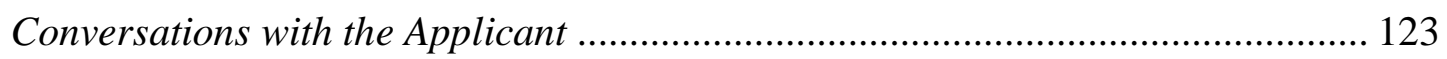

Career Readiness Resources and Educational Opportunities .................................. 124

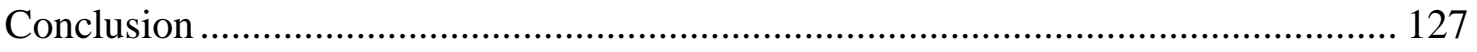

CHAPTER FIVE: CONCLUSIONS AND FUTURE RESEARCH ………................. 130

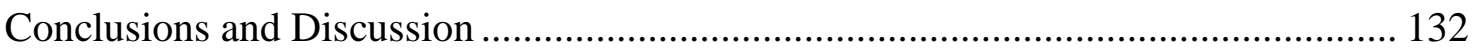

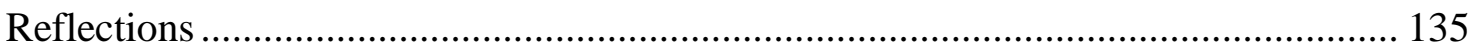

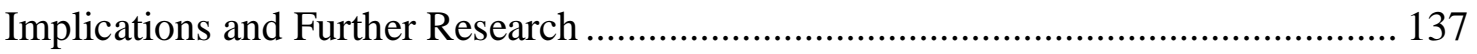

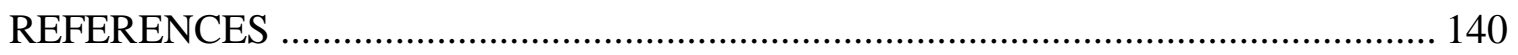

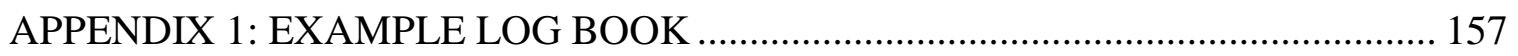

APPENDIX 2: RELIABLE STAFFING WEB PAGE ................................................ 158

APPENDIX 3: RELIABLE STAFFING WEB PAGE 2 ………………................... 159

APPENDIX 4: PARTICIPANT INTERVIEW QUESTIONS ....................................... 160

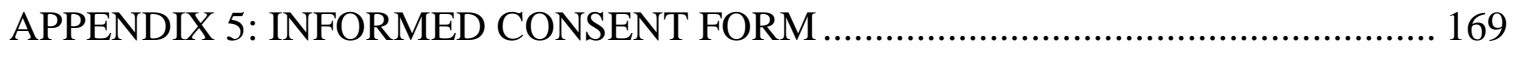

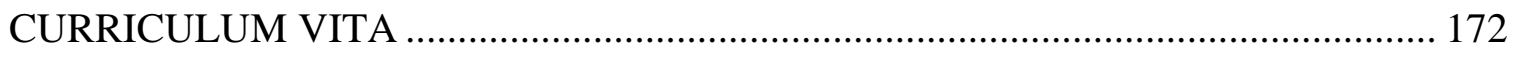




\section{CHAPTER ONE}

\section{BROKERING WORDS AND WORK: COMPLEXITIES OF LITERACY SPONSORSHIP IN THE OILFIELDS OF SOUTH TEXAS}

Growing up in South Texas meant, to some extent, growing up in the oilfield. If family members were not involved in some aspect of rig or refinery work, friends' families were. Everywhere in rural South Texas there were reminders of the local economy's reliance on the oil and gas industry. Large white, mud-spattered pick-up trucks - the company vehicle of so many oilfield men - were everywhere. They packed the parking lot of the lone gas station in town at 6am, getting their coffee and taquitos to start the day, or end it, depending on their shift. These same trucks, with sometimes equally dirty men clad in oil-stained coveralls, would line up to drop off their kids at school at 6:45am. This was an hour earlier than the first bell, because the men had to drive to work at the rig yards or the refineries, which were an hour away, or more. These symbols of the oilfield were a constant on the highways, small rural roads, and packed driveways in and outside of town, sometimes three or four trucks to a house.

When I was kid, my father was an electrician for the oilfield. He wasn't a refinery worker or a driller, so he didn't drive one of those white company vehicles. Instead, he drove a little blue Toyota pick-up truck that he still drives today. It was the 1980s, and the oilfield was not in the best of shape. The industry, in the middle of a bust, was 
continuing to squeeze everything it could from the region, but the rig counts kept dropping. Because of this shortage, my father, a contractor for the moderately-sized wireline service company Dresser Atlas, had a hard time finding stable work. My mother didn't work as she was raising two kids and had no real marketable skills or education, so we relied solely on my father's paycheck. At one point, to keep his job, he was required to go to several months of training in Houston. Houston was four hours away from where we lived, so he stayed in a motel during the week while attending classes and would come home on the weekends. When he came home on the weekends all he did was sleep.

For a long time during my childhood the oilfield took our father away from us. Certification programs were one thing, but the daily grind of shiftwork in the oilfield was another. The reality of shiftwork was one that most oilfield families shared. The labor was so demanding that going home at the end of the day. Since shifts were sometimes 12 hours long and way out in rural areas, rig workers were required to stay in "man camps" around the rigs or yards. The rigor of the work allowed only enough time for working, sleeping, and grabbing a meal in between. Ask any rig worker and they will tell you the same -- this kind of life was not sustainable. The physical and mental stress takes a toll on the worker and the worker's family; at some point, it's time to move on.

At 43 , my father reached that point. It was the early ' 90 s, and Dresser Atlas had been bought and sold several times. He had survived rounds of layoffs. It was exhausting for everyone not knowing if they were going to have a job the next day. After a long application and interview process in a different industry, he took a new job at a medicine refinery about 45 minutes away. It paid better and had benefits, but it was still shiftwork. 
Most of his time was spent on the graveyard shift, so again, we did not see him as much. But at least it was stable.

Now, you may be wondering why I am telling you my family's story and what, if anything, it must do with literacy. I didn't realize it at the time (I mean, I was in elementary school!), but my father's job involved quite a bit of reading and writing. When he was home, he was surrounded by technical manuals. Getting in his truck required moving a bunch of tally books - or log books - he had stacked in the front seat and stuck between the dashboard and the windshield. The shelves next to the telephone in the kitchen were cluttered with three-ring binders full of formulas, definitions, and technical processes. His toolshed/workshop had notes tacked the walls with drawings, numbers, and words related to engine parts he was rebuilding or rewiring. When he was home, sometimes my mother would send me out to the shed to get him for dinner or a phone call, and he would be bent over his bench working on some motor or part that looked like a rusty hunk of metal with wires coming out it. He would hook up his meters to the wires and adjust something on the part. The little needle in the meter would move or make a ticking noise. He would then analyze the meter and scribble something in one of his many notepads. He would do this repeatedly until he got the outcome he wanted. And if he didn't - well, all I'm going to say is there were some auto parts, as well as some choice words, thrown around that shed.

These notepads of his were full of scribbles -- words I did not understand, and acronyms I really did not understand. In between these scribbles were lists, equations, drawings, and numbers, a language that really meant nothing to me other than to serve as a version of post-traumatic stress regarding my own algebra homework. The fact was my 
father's oilfield job required a range of literacy practices, tools, and artifacts. $\mathrm{He}$ participated in a career's worth of literacy events and activities. And, as this dissertation will show, literacy plays a similar role in the lives of other oilfield rig and service jobs. Even now, many of these literacy practices and problem solving systems are too complicated for me, an academically educated adult with (almost) three degrees, to wrap my head around. The complexity of the literacy systems used in the blue-collar, or vocational, sector of the oil and gas industry is what makes this project so important and the people who practice these literacies integral to literacy studies scholarship. Literacy practices related to the oilfield worker identities are valuable because to certain sects of society, including academia, where exist stigma that blue-collar workers like my father are unintelligent, illiterate, and uneducated. Through this dissertation, I aim to further conversations in workplace literacy and literacy studies that argue nothing is further from the truth. I do this by starting at the beginning - with recruitment.

\section{Project Overview}

The aim of this dissertation is to fill gaps in literacy studies scholarship surrounding pre-employment literacy expectations in vocational job sectors through the study of a largely ignored but increasingly complex blue-collar area of the oil and gas industry. As my review of the literature will show, much of the existing literacy studies scholarship situated in vocational workplaces focuses on the activities surrounding knowledge use and practice. As a workplace literacy scholarship has noted quite frequently (Gee, Hull, Rose, Barton and Hamilton, New London Group, Brandt, Graff, Darrah), complications related to literacy use arise frequently in the workplace due to a variety of factors, such as language difference, class, education, and culture shifts. 
However, little attends to the processes by which workers find their way into a position in which these challenges and complications arise. Understanding the choices these workers make when looking for a job in the oilfield, where and how are they looking for these positions can help us understand more about the value of certain literacies communicated - or not -- to potential workers. How companies use language to recruit certain workers also spotlights how an industry itself views the shifting relationship between literacies and competencies. This relationship, as this dissertation shows, can sometimes at odds with the values of the workers, which this dissertation illustrates through stories told by oil and gas workers.

An investigation of recruitment language, especially towards literacy expectations, will help expose what I call the "leading edge" of literacy sponsorship as it pertains to the workforce. This inquiry begins by first learning about workers' experiences with recruitment into the industry, including their use of certain literacy artifacts, such as applications and resumes. The discussion uncovers questions and concerns raised by workers surrounding literacy sponsorship in the oil and gas industry. What do workers in the field think about the state of literacy in the industry? What is the industry communicating to them about valued literacy practices, and why does that matter? To answer these questions, I break down the recruitment rhetoric via a rhetorical analysis of job advertisements for oil and gas positions. Considering the rhetoric of job advertisements, how and what do words like "required skills" and "qualifications" translate to job seekers across social groups? These forms of textual rhetoric tell potential workers what skills are valuable, as well as trainable, and it is usually from that literacy event that potential workers decide to either apply or walk away. Finally, I examine the 
role of job market labor market intermediaries (LMIs), or temp agencies, and the role they play in potential oil and gas workers coming into the industry. The literature tells us that labor market intermediaries value an already established set of skills and as these institutions recruit for these established skills, so what message do their recruitment strategies send to the local populations about the value of certain literacies over others? Further, what, if anything, are these labor market intermediaries doing to help educate workers on valued literacies?

I choose these three areas as discussion points because all view, use, and consider literacy in complex ways. Understanding the complexity of these literacy practices and systems will provide rhetoric and composition and literacy studies scholars with a critical example of the conflict between hands-on and academic learning, value, and the perceptions of intelligence. This focus of the rest of this chapter is to map out how I will answer these questions. It is important to note that this dissertation, except for labor market intermediaries, does not discuss literacy sponsorship or practices that manifest in these programs outside the literature review. However, acknowledgement of the work conducted in terms of literacy in these vocational areas is important as they have greatly shaped our knowledge of workplace literacy and created a niche for this project.

In this chapter, I first review the conversation in literacy studies scholarship related to literacy sponsorship in the workplace, specifically how sponsors act as gatekeepers in control of "trade routes" (Brandt). I next review sponsorship as it relates to workplace education and literacy. This is followed by a discussion of community colleges and job training programs as venues of literacy sponsorship. I also introduce the role of a lesser known, particularly significant sponsor of literacy, the labor market 
intermediary1. After reviewing the literature, I lay out my methodology, including the reasoning behind my choice and the ethical implications of such methods. Finally, I end this chapter with overviews for the chapters that follow.

\section{Literacy Sponsorship in the Workplace: A Literature Review}

In Literacy in American Lives (2001), Deborah Brandt designates sponsors as "delivery systems for the economies of literacy," frequently reminding us that access to reading and writing requires "permission, sanction, assistance, coercion, or at minimum, contact with existing trade routes" (p. 19). Brandt's definition of literacy sponsorship employs a variety of actions that sponsors undergo to "deliver" reading and writing to their clients. Sponsors, or agents, of literacy learning are gatekeepers in that their privileged status gives them the power to allow, or disallow, their learners access to reading and writing, as well as sources of reading and writing learning. Sponsors can also tighten their hold on the learner through, as Brandt discusses, "suppressing, or withholding" reading and writing alternatives, and maneuvering the learner through dominant, sponsor-supported literacy practices, such as those learned in formal schooling, as well as job training programs and vocational education courses.

Sponsors also control what Brandt calls "trade routes," or uses and movements of different types of literacies within different communities. The trade routes in which certain literacy practices are established and/or governed are constantly moving, fluctuating with the socio-political and socio-economic pressures of capitalism. Depending on how literacy is viewed by the sponsor, it may be regarded as moving

1 Labor market intermediaries are the focus of Chapter 4 
"forward" along the trade route, meaning that the user has been granted access to literacy by the sponsor, such as reading and writing in schools and workplace initiative programs.

In industrial settings, workforce administration is considered a sponsor, or regulator, of the literacy skills deemed necessary for efficient performance and production. Workforce administration includes managers, supervisors, and trainers, as well as those more distanced from the central workplace, such as presidents and chief executive officers. The administration offers streamlined work training programs and classes based on technical skills the industry has deemed necessary for the job. Worker progress during the course is oftentimes evaluated through standardized testing procedures. In other words, the "trade value" of certain literacies is decided by how well workers can score on standardized tests, and other assessment practices.

\section{Venues of Workplace Education and Literacy}

Previous arguments in workplace literacy scholarship focus mostly on the content of training programs, as well as work's connection to formal education. As mentioned earlier, while this dissertation does not focus on training programs, it is important to acknowledge that these programs do exist and their history is extensive. In the mid-to-late 20 th century, the place and function of literacy in the workplace was still a point of contention. Reports, including Workforce 2000, and Investing in People: A Strategy to Address America's Workforce Crisis detailed the employment emergency in the 1980s, including a call to action for schools to offer vocational programs and applied instructional programs that "emphasized transferable academic skills," which included reading, math, science, communication, and problem solving (Commission on Workforce Quality, p. 10, as cited in Jury, 1997, pg. 214-215). This emphasis on education as a 
precursor to workplace success can be traced back to the 19th century, where the ability to read and write was debated as a factor in whether a worker could perform to standards in the workplace. Graff (1995) argues that education in the $19_{\text {th }}$ century was revealed to be more about the teaching of morality and discipline than it was about the teaching of reading and writing as a job-related practice. His point is that industry, skill, and wealth could be obtained without formal education. However, Graff does suggest that the growth of education was due to extensive arguments by political leaders of the time who viewed education "as central to the development and the maintenance of the economic system, as it was to the social order," therefore producing the claim that, "educated and literate labour was more productive and of more benefit to both society and individual" (p. 176). This correlation between formal literacy education and production continues to be widely acknowledged as a determining factor in workforce hiring and training, and as we will see in Chapter 2, much to the displeasure of the rig and service workers, the oil and gas industry is no exception.

One of the most widely recognized venues for academic literacy education as it relates to today's blue-collar workforce is the community college. Termed the "middleman" of education, community colleges are positioned between secondary school and four-year institutions of higher education (Pennell, 2011; Carnevale and Desrochers, 2002; Grubb, 1996; Kintzer, 1973). Community colleges have commonly been affiliated with the idea of transfer -- preparing students to move from two-year to four-year institutions by focusing on core education (Grubb, 1996; Kintzer, 1973.) However, Pennell (2011) points out that community colleges are also playing the role of middleman, or type of trader to the workforce, constantly "draw[ing] from and 
respond[ing] to the middle of the labor market" by focusing on those coming from the sub-baccalaureate level of academic education or mid-skilled vocational levels (p. 315). Furthermore, the community college is a local 2 learning institution; therefore, it targets local students, as well as local businesses, creating a relationship of literacy and employment. The sub-baccalaureate labor market resides within the local, and, as a result, when searching for workers, businesses advertise locally. If these businesses establish relations with any educational providers like community colleges or vocational programs, they do so within the local community (Grubb, 1996). It is important to mention that community colleges in South Texas began adding petroleum and process technology certificates and associate degrees in 2010 due to the increased need for certifications and education in the oil and gas industry. However, considering the scope of this dissertation, these programs and their role in literacy sponsorship will not be discussed.

In addition to formal academic education, job training programs - whether it be on the job or in streamlined certification programs - have sponsored solutions to local unemployment and the shifting economic structures of industry since the 1990s. Merrifield (1997) describes the job training mentality as one of "if we build it, they will come," which she says "applies not just to baseball fields but also to high-skill workforce" (p. 276). This "good jobs will follow good skills" mentality is driven by a goal of economic efficiency; therefore, job training programs usually focus more on acquiring and maintaining skills believed to be directly related to the industry as opposed to fully utilizing the workers' existing academic, home, or other personal literacies

2 Local is defined as belonging to a community defined by region, such as a neighborhood, town, or segment of a city. 
(Pastor et al, 2003; Darrah, 1997; Hart-Landsberg and Reder, 1997; Grubb, 1997;

Merrifield, 1997; D'Amico and Schnee, 1997). Job training is based on the concept of "skill requirements," which focuses on the implicit understanding that workers are hired for the skills they possess related to the work they are required to do. However, this concept, as Darrah (1997) points out, "fails to provide neutral discourse for analyzing work since it rests upon tacit assumptions that mold how we see work, workers, and workplaces" (pp. 252-253).

As discussed in the introduction to this project, by requiring the assessment of a narrow set of technical skills deemed important to job performance, workforce administration may be implying (or possibly ignoring) the value of social skills to workforce efficiency. Darrah's study of the factory floor at Kramden Computers exemplifies the social nature of work as a subversion of individualized skill competencies. While workers were hired for a specific technical skill set, it quickly became apparent that skills in communication and teamwork were needed even more, and many workers had a hard time adapting (p. 262). While workplace training programs are tasked with providing workers the skills that administrators/employers believe to be necessary, studies show little correlation between the skills workers may be trained in and those necessary on the job (Hart-Landsberg and Reder; 1997, p 352; citing Balfanz, 1991; Hull, 1993; Darrah 1992; Gowen 1992; Schultz, 1992). In addition, Darrah's (1997) study shows the need to reevaluate how managers and trainers define and gauge not just standards of workplace literacy, but concepts of literacy. Therefore, this proposed project's analysis of the variety of job advertisements that lead potential workers into certain positions they may or may not be prepared for will arguably shed light on what 
concepts of literacy are valued/devalued in potential workers. There is further interest in whether specific literacies - such as communication, teamwork, and multitasking - are now being categorized as "technical" skills in recruitment literature. In terms of the oil and gas industry job training programs have a considerable history in Texas. However, due to the scope of the dissertation, job training programs are not included in the primary research for this project.

Like job training programs, labor market intermediaries, or LMIs, foster targeted alliances with industry. However, these entities recruit for achieved skills, not necessarily trainability. LMIs are agencies that hire contingent, or temporary or temporary-to-hire labor, varying from entry-level positions to management. Kelly Services, Spherion, Manpower, and LK Jordan are examples of for-profit LMIs. Non-profit LMIs include adult learning centers and state-funded workforce commissions. Much like community college vocational programs and job training programs, LMIs work with the local. Pennell (2007) writes that LMIs "reflect, foster, and respond to actual and perceived shifts" in America's employment process, and have been doing so for decades. However, what is most significant is how these institutions "highlight the influential role literacy, and the places of literacy, play in economic shifts" (p. 369). Positioning LMIs within literacy studies, Pennell identifies the LMI system as an agent that capitalizes on the movement of literacy from workplace to workplace. He says that literacy for the workplace has become a "brokered good -- a good that is being assessed, traded and sold by more than educational institutions," and that the term literacy has become "outdated in a 'jobless but not workless' society of dislocated 3 free agents" (p. 349). These "free

3 By “dislocated," Pennell means unemployed. See p. 349. 
agents," as Pennell points out are akin to James Paul Gee's idea of the "portfolio people." Gee (2000) argues a diverse range of knowledge lends itself to the new capitalist idea of the individual as a "portfolio," or collection of "rearrangeable" skills, abilities, and identities we have acquired "inside and outside the workplace," as opposed to the linear progression "up a career ladder" (p. 51). In other words, workers are a complex network of multiple identities developed through an engagement with other people and places, skills and abilities that are engaged in and fought against inside and outside school and the workplace (Gee, 200; Lave; 1996; also see Bauman, 2007; Sennett, 2006, 1998).

The above-mentioned strategies (and tactics) these LMIs use to recruit workers may vary from those used by job training programs and other educational institutions as their goal is to identify workers with a defined set of skills. What is of high interest in this project is how the LMI goes about "brokering" workers they find suitable for the fracking industry, what literacies are "worth more" to these institutions, and what drives that worth. The role of the LMI is in oil and gas industry recruitment and literacy sponsorship is significant. In Chapter 4, I articulate the critical role of one state-run labor market, or workforce intermediary, Texas Workforce Solutions, and the experience one oilfield worker had as he was recruited and hired through the organization.

\section{Workplace Literacy and Social Status}

The value of certain literacies as ascertained by the workforce correlates to what community college programs are offered, the curriculum of job training programs, and how LMIs negotiate a worker's worth to the buyer. However, society's perception of what literacy "is" and the employers' expectations of a certain level of traditional reading and writing skills impact how certain social groups view the workforce. Heath's (1983) 
study of the oral and literate communication practices in the African American community of "Trackton" shows that millwork jobs, which required little to no writing or reading skill, paid equal to or more than professional jobs requiring formal education. Thus, completion of advanced schooling or improved test scores would not necessarily have had a socioeconomic impact on the worker's lives (p. 369). Ogbu (1983) argues that a "traditional" socio-economic positioning of African Americans as a "caste-like minority" consigned to occupy low-wage, dead-end jobs does not encourage them to "achieve their maximum." Since these jobs usually do not require or reward formal education, there is a significant impact on literacy learning as measured by lack of school completion, as well as poor performance on standardized tests (p. 236).

Studies of literacy and gender report similar findings. Castellano (1997) and Merrifield (1997) focus on how workplace literacy and standardized testing impact efficiency and marketability of skills for women. Castellano's (1997) study of a job training program for women in the skilled trades emphasizes that a school-based literacy such as standardized testing "does not predict future performance so much as assess applicants' exposure to a certain set of experiences and their ability to display it in a testing situation" (pp. 192-193). Like Darrah's (1997) questioning 4 of the value of the social nature of communication versus the individualized use of technical skills on the factory floor, Castellano considers the contradictions of testing, which requires one to work alone, compared to the social nature of the "real job situation," which necessitates workplace learning to move beyond a testable standard set of skill requirements (p. 193).

4 These studies also question literacy testing in the skilled trades: Hart-Landsberg and Reder, 1997; Shuman, 1983; Fingeret, 1983; Keder and Green 1983. 
Thus, assessing workers by tests rather than performance closes doors rather than opens them for disadvantaged and minority job applicants whose experience lies within their ability to negotiate workplace literacies as opposed to school-based literacies, like testing. Workers may feel polarized by testing procedures, as it exemplifies a literacy they are uncomfortable or unfamiliar with, and therefore the fear of failure becomes reason not to work toward advancement. Castellano concludes that standardized testing of skill requirements has "outlived life predictors of job performance and have become a justification for maintaining the status quo" (p. 207). Merrifield (1997) focuses on workforce training of displaced female textile workers. Results showed that increased literacy learning "did not get those who trained more jobs, better-paying jobs, jobs with benefits, or even for the most part, jobs they had trained for" (p. 289).

While this dissertation does not formally study the intersections of race and gender in the oil and gas industry, the literature does parallel class-based concerns raised by workers regarding negotiation of academic vs. non-academic literacies and the value to the industry has started placing on academic literacies in a historically blue-collar sector of the industry. The divisiveness created by this shift towards a more academically educated blue-collar workforce is one of the main topics of Chapter 2, and tensions created by this shift reverberate throughout the whole project.

As the scholarship on literacy sponsorship has shown, there is a significant correlation between literacy education and/or training and the social and economic anxieties related to efficiency and production. These tensions are rooted within conflicting ideas of what literacy "is," and the relation of these ideas to workforce production and training. There certainly is an acknowledgement by local educational 
institutions that certain literacies are desired, trainable, and marketable within certain industries. However, what needs further investigation is how these institutions market for certain literacies and trainable skillsets deemed necessary for the workforce. What has not been considered in the literature is the blue-collar worker perceptions of literacy in their industry versus that of the industry as it pertains to literacy requirements before hiring occurs. Therefore, it is within this process of workforce recruitment and hiring, and the literacies related to each, that I situate my project. Ultimately, this project aims to advances studies of literacy sponsorship by considering how an understanding of what literacy "is" affects how new industry and educational/training institutions recruit, broker, and/or sponsor workforce literacy.

In the next section, I outline my research methodology designed specifically to answer the above questions. Centering this project within the oil and gas industry creates potential for an analysis that will help literacy scholars better understand the complex nature of literacy in the blue-collar oil and gas industry, worker perceptions of literacy in their respective fields, and how the shifting nature of the field in terms of education and literacy expectations is shaping the way the industry is sponsoring literacy practices to the current workforce and the larger community.

\section{Methods}

For this study, I have chosen to investigate how the oil and gas industry communicates the value of literacy to potential workers and the perception of said literacies of the current (as of 2013) blue-collar workforce. I frame this study with Brandt's theory of literacy sponsorship, which allows for a fruitful discussion of the relationship between power, education, and class in South Texas. I chose this lens for 
several reasons. First it provides a clear foundation for looking at the complexities between class, literacy, and culture shift in the workplace, especially a workplace as complex in terms of literacy and competency as the oilfield. Pennell (2007) argues that literacy researchers must "investigate and uncover" the places where literacy happens. It is within the local connections - between industry, education, and community -- where "hope for change and a just society exist" (p. 370, emphasis author). A type of change, or shift, related to culture and literacy is currently occurring in the oil and gas industry, which makes the moment ripe for study.

Secondly, literacy sponsorship provides context for hiring practices. One of the many ways Brandt (2001) defines sponsors of literacy is "any agents, local or distant, concrete or abstract, who enable support, teach, and model, as well as recruit, regulate, suppress, or withhold literacy - and gain advantage by it in some way" (p. 19). Sponsors can be teachers, parents, governing officials, and work supervisors - anyone in a position of power to make decisions regarding the definition of "acceptable" competencies and/or literacy skills. They can also be viewed as literacy "gatekeepers" in that their privileged status gives them the power to allow, or disallow, learner access to reading and writing, as well as sources of reading and writing attainment. In the workplace, we see this gatekeeping as it manifests in hiring and training decisions by the worker, as well as the employer. The gatekeeping aspect is of interest in this study, as it, and its hidden implications to employment, are comment threads throughout the chapters.

The third reason is the alignment of sponsorship with the act of buying and selling workers as products or tools. While the term "sponsorship" generally defines an institution or person's relationship to literacy, the way oil and gas companies and third 
party labor market intermediaries negotiate the value of literacy can be more clearly defined through the term "brokering." The act of buying and selling work and workers plays a significant role access to literacy and competency building in the oilfield. Pennell (2007) describes literacy is a "brokered good," being bought and sold by consumers. For example, colleges and universities use recruitment materials such as job advertisements, videos, and brochures to sell the promise of literacy (thus, jobs) to specific groups. The placement of these materials in specific venues - such as the newspaper, television, and internet - appeals to certain groups who have access to these spaces. However, it can also deny access to certain groups, regardless of intention. While Pennell is specifically describing brokerage between businesses and colleges and universities, the same types of relationships are prevalent in the oil and gas industry, specifically between companies and labor market intermediaries, or temp agencies. By utilizing specific venues, these brokers act as literacy gatekeepers in that their privileged status gives them the power to allow, or disallow, certain groups rights to the specific literacies being offered. Meaning, what happens if workers with the needed skill and literacies do not inhabit, visit, or have knowledge of these spaces? Brokers, like sponsors, grant or deny permission, whether they know it or not. They have the power to provide or withhold assistance depending on the type of literacy the client wants or needs. In this project, an analysis of recruitment materials and services will identify how the industry brokers specific literacies to specific social groups and its current and potentially future implications for the industry.

I focus this study within South Texas for several reasons. First, it is a region that has historically supported by the oil and gas industrial economy. Second, the discovery of the Eagle Ford Shale in 2008 and the ensuing boom required the use of new technology, 
specifically for hydraulic fracturing. New technology aligning with the boom created a trickle-down effect in terms of literacy expectations in the industry, specifically those related to the use of digital technology and willingness to further academic education. Third, at the time of data gathering, September 2013, the Eagle Ford Shale was at the height of its boom. Therefore, industry literature used in the study, such as job advertisements, and workers conducting workplace literacy practices in the oil and gas industry, were abundant. In addition, the Eagle Ford Shale region of Texas is my home. This personal connection to the region and people within the industry allowed me to tap multiple sources for information.

Perhaps the most significant reason for choosing the South Texas oilfield is that it is a complex site of communities of practice. The term community of practice is rooted in concepts introduced by Lave and Wenger (1991) related to situated learning, the process of learning in the environment in which the skills and literacies will be learned, practiced, and, eventually, mastered. For a community of practice to work, those involved must share common goals and desires. Wenger (2001) outlines the structural characteristics of a community of practice as having three main components: domain, community, and practice. Becoming part of a community of practices hinges on the development of literacies and competencies through repeated performance. Competencies, which can be fostered through literacy practice, are sponsored, albeit fostered or denied, within these communities of practice. In the oilfield, these competencies can include elements of being a communicative driller, a hard-working floorhand, a top-rated equipment sales person, or a truck driver with a record of efficient delivery and safe driving. They can 
also be an old floorhand questioned by a new engineer, or a driller shouting at a new floorhand for not pulling his hands away from the tongs quick enough.

While each rig or service position includes standard requirements set forth by the industry at a global level, Wenger (2000) says that the competence to actually do the work in practice is defined at the community level, defined by how a worker interacts with others in the community. These interactions create the bonds that hold communities together. These practices are defined and redefined over the days, months, and years. As illustrated throughout the chapters, literacy's role in building these competencies is sometimes more visible than others.

Primary data was collected from two main sources: Interviews with rig and service works and labor market intermediary administrators and recruiters, online and printed job advertisements. First were interviews with rig and service workers. Interviews with workers were integral to this project as they provided contextual evidence for problems within the job application process. Halbritter and Lindquist (2012) argue that interviews can be rich "scenes of production" as they are "necessarily rhetorical" in nature (p. 175). Meaning, interviews are supposed to capture and frame the voice and assertions of the research subject, and it is up to the researcher to recreate the narrative responsibly. Also, my personal connection to the area made the process of recruiting interviewees easier as I knew several people working in rig and service in the Eagle Ford Shale. Given much of the focus of the project stems from perceptions of workplace literacy and competencies, it was important that the voices of the workers take precedence to my own. I modeled interview practices and style featured of Brandt's Literacy in American Lives and thick description from Mike Rose's The Mind at Work. 
Other similar ethnographic or empirical studies such as Heath, Barton and Hamilton, and Scribner and Cole were influential to the study as they used interview to provide a variety of examples of how to frame to showcase subject voice in specific cultural contexts. This framing included the use interview content in addition to or instead of ethnographic description. Krippendorff (2004) argues that content analysis is an advisable approach when an ethnographic approach is not possible. In addition, interviews can be created, or sequenced, in a way that elicits certain reactions. As I was not able to visit oil and gas rig yards during the data collection process, content analysis was the preferred method used for this project.

Even though the above examples of ethnographic and interview content analysis were helpful, I could not help but note the standard of academic language used throughout the studies. For this particular project, I wanted to prioritize the ease of use for a wider audience, one that extended outside of academia. To do this, I felt obliged to create descriptions and discussions in a more accessible voice. While I understand the initial audience for this project is my dissertation committee, I felt it necessary to create a balance of language accessible for academic and non-academic readers, as I am writing about a non-academic demographic. Therefore, I actively tried to model the narrative and descriptive style of Mike Rose, specifically his balance between description, reflection, and subject voice as evidenced in Lives on the Boundary and The Mind at Work. In addition, the oral histories in Studs Terkel's Working and Bobby Weaver's Oilfield Trash: Life and Labor in the Oil Patch provided a model of the type of voice I wanted to afford my interviewees. Both Terkel and Weaver get out of the way and let the interviewee tell the story. It is important for this dissertation to use the space to create a 
discussion with the workers, not a complicated analysis of their stories and perceptions. As a demographic that is already wary of higher education, I did not want this study to be another example of why folks in the oilfield felt silenced by the academy.

Recruitment of workers and labor market intermediary administrators for interview took place over the summer of 2013 and interviews were conducted in September of 2013 in various places in South Texas. I recruited 10 oil and gas workers and two (2) recruiters from labor market intermediaries from a variety of areas in the Eagle Ford Shale region of the Coastal Bend. All but three of the oil and gas workers grew up with me and were from my same small town in South Texas. Since the workers either knew me or knew my father, the conversations were relaxed and open. Worker interviews took place at a variety of locations including a bar, a family home, a worker's office, over the phone, and in a café during the lunch rush. The labor market intermediary recruiter interview was with two recruitment managers from the same organization Texas Workforce Solutions. This interview, which was conducted with with both managers, was much more formal, and took place in the headquarters office in downtown Corpus Christi, TX. All interviewees read and signed the consent forms mandated by the Institutional Review Board (IRB) with no questions.

There were a few limitations to note regarding the interviews. First, as I mentioned above, it was easier for me to find workers because of my personal relationship to the region. However, easier does not necessarily mean it was easy. My goal was to recruit 15 oilfield and service workers, which did not happen. Complications included issues with scheduling, such as workers being called in to work the day of the interview. While most contacted me if they needed to cancel, it was not always the case. 
One day I drove two hours to meet a worker at a coffee shop in San Antonio for an interview, but they did not show up, nor did they return correspondence. Trust was another challenge. Reasons from workers who turned down my requests for an interview cited suspicion related to my academic status. Meaning, they did not trust the reasoning behind my research. Several workers were wary and asked if I was going to focus on environmental impacts of drilling. I had to assure a few workers several times that was not my intention, and that I was interested in reading and writing practices at work. Others flat out said no, citing they did not want to go on record, regardless. Some of these workers who turned down requests for an interview were friends or acquaintances of mine since grade school.

Secondly, I noted two challenges with the interviews that I found linked to ethics. The first was my personal relationship with some of the interview subjects. As noted earlier, several of the workers interviewed were personal friends or acquaintances. While this made the conversations easier, it created a need to consider other implications related to using friends and acquaintances as research subjects. Yuan (2014) reflects on the values and challenges of using friends as subjects instead of a random sampling for research on museum artifacts and de-contextualization. Yuan said his worries were "linked with the tradition of studying and representing 'others,' which requires the researcher to keep a distance from the subject of the research in order to achieve an unbiased view" (p. 95, emphasis author's). While his worries were valid, he found that the quality and narrative style of the information he was looking for relied on stories rather than a group of what he calls "analyses based on controllable variants" (p. 95). Meaning, the thick description, perceptions, and reflective nature of his subjects' 
experiences in the museums were what was valuable to the study as opposed to quantitative outcomes. Thus, his familiarity with his research subjects created a much looser and informal environment for such narrative to emerge.

Like Yuan, I was concerned that my relationship with the oilfield workers would violate the need for objectivity as a researcher. However, like Yuan, I found that the relationships were extremely valuable for getting the heart of problems and concerns the workers had with literacy, education, and shifts in the industry itself. It also allowed me more freedom to ask more pointed questions about language and vocabulary they used to describe their work processes, as many times concepts were foreign to me and procedures were highly mathematical and complex. These questions asked for illustrations and examples of processes to help me understand and can articulate and narrate their experiences responsibly.

The second ethical challenge I encountered was how trust manifested itself in the interview process. Working with friends and acquaintances already implies a certain level of trust has already been established. In my situation, this was certainly the case as I grew up with most my subjects. While this allowed for informality and richer narratives, it also created opportunities for going down rabbit holes about certain subjects. Interviews with friends sometimes lasted upwards of three hours, while acquaintance and administrative interviews were closer to one or two hours. Yuan (2014) had similar challenges with using his friends as subjects, especially when and how to keep a balance between flexibility and control: "Though 'flexibility' is valuable in a piece of narrative research and some of the content of such casual chatting may contribute to the study, I found it necessary to steer the course carefully to prevent conversations from 'running wild"' (pp 
97-98). I understand Yuan's concerns about taking care with flexibility and control as I had to negotiate similar challenges throughout my interview process. In the case of this project, I felt it necessary to allow more leeway with my subjects to go off the beaten path of the interview questions a bit. I did this because even though we were friends or acquaintances, there was still hesitancy on their part due to a long-standing distrust of academics by the working class in the oil and gas industry. This distrust has become more complicated with the rise in anti-drilling and anti-fracking rhetoric in the media.

Oftentimes information at the core of this rhetoric is attributed to academic sources and activism. Thus, these workers see themselves and their jobs as being victimized from multiple angles. So, even though several friends agreed to be interviewed, just as many declined for reasons related to distrust of the academy. A few who consented to the interview still required me to clarify what I was writing about and expressed concern that I was going to write about their industry and the environment. One pulled out of the process the day of the scheduled interview with the reasoning that they just did not feel comfortable having their thoughts and stories in a text related to the academy.

It is also important to note that as a researcher interviewing friends, there is always a potential for bias. Loyalty towards friends, especially when coding interviews and framing dialogue that might not show them in a positive light, can cloud judgment. As a researcher, I anticipated the possibility of this issue with two of the workers. Therefore, I was extra cautious when using their narratives, making sure that concerns were correctly interpreted and voices framed in in the context of the correct conversations. 
Another challenge related to trust was demonstrated in the labor market intermediary managers interview. One manager asked several questions regarding my intentions for publication. I explained my purpose was to highlight and advocate for blue collar workers in the industry in terms of literacy. They said, "Okay, well we will help you out if you help us out," which I understood to mean that they expected my work to advocate for them as well as the workers. I am not sure exactly if their response is an example of a limitation or a way of demonstrating trust would be to enter a contract of some type of forced collaboration.

The second data source was job advertisements for rig and service positions. These were collected during the same period I was conducting the interviews. As job advertisements are created by the industry and/or labor market intermediaries, this genre is a credible source of information for articulating industry support for worker literacy requirements. It is important to note that I refer to job advertisements as sponsors or literacy and literacy artifacts throughout the research. I do this because job advertisements are written by a variety of professionals who might be directly (company human resources professionals) or indirectly (labor market intermediary recruiters) related to the industry. The author's varying relationships to the industry complicate such an active role in sponsoring literacy. This includes communicating, and in some cases miscommunicating literacy and competency expectations. However, as it can be transformed, revised, or edited by non-industry officials, the outcome of the genre is also that of an artifact, a product of what the industry needs or feels are important characteristics for one to join the respective community of practice the advertisement represents. 
Overall, I collected 30 job advertisements for a rig and service positions from local newspapers as well as online industry-specific websites such as Rigzone. In coding the job advertisements, I looked for a variety of different characteristics that articulated the ability to read and write, specific literacy artifacts, such as logs, technical manuals, and reports, and education requirements, such as certification or training. I also looked for requirements related to technical requirements, such as computer and digital literacy. There were no significant limitations surrounding the job advertisements as data source.

Reflecting on my data collection process, there was one area I underestimated, and that was audience. For example, in the worker interviews, I noticed the language they used to describe their work was very industry-driven. Processes and machinery were talked about in shorthand, even acronyms. I had to ask for clarification several times during each interview. Sometimes I did not want to interrupt the course of the conversation, so I took notes to look up certain terminology and acronyms after the interview or during transcription. I got the impression that the worker thought I knew what they were talking about, even though they were using industry jargon. I did not get the impression they were using this language to test me or challenge me as an outsider to the industry. I had a different but related experience with one labor market intermediary interview. In an interview with two managers, I used the word "rhetoric" in questions asked to describe their processes of determining the literacy background of applicants for certain positions. They were confused as to how I was defining rhetoric, and after several uses of the word, they finally asked me to explain what it meant in this context, or how I perceived its intent. 
The next three chapters work together to strategically tell a complex story of literacy sponsorship in an industry that is in a constant state of economic flux. Chapter 2 has two important functions. First, it lays out the history of the oil and gas industry in Texas and the literacy and learning expectations historically anticipated from the bluecollar upstream rig and service worker. The brief history of the industry leads up to 2013 where we see a shift in the industry in Texas with the boom of the Eagle Ford Shale and hydraulic fracturing. While the industry is booming on the outside, the industry is also quietly scrambling to stop the impending workforce hemorrhage called the "Great Crew Change," the retirement of nearly one-third of the workforce by 2022 . Second, the chapter introduces the rig and service workers - Manuel, Joseph, Ben, Sarah, and Abel. Interviewed at the height of the boom in 2013, these rig and service workers were caught up in all these shifting parts of the industry, including literacy and education expectations and requirements. Told by the workers themselves, these stories help us understand their roles in the larger oilfield systems and how rig and service communities of practice overlap in terms of learning and literacy. The chapter ends with a focus on the workers' questions and concerns about cultural shifts in the industry, including industry calls for academic education, more safety regulations (which means more paperwork), and a new generation of workers that have a different view of work ethic.

Chapter 3 focuses on questions and concerns brought up at the end of Chapter 2 concerning literacy and education shifts in the industry. In Chapter 2, workers questioned the reasoning behind the industry's call for more academically-educated workers in a traditionally blue collar part of the industry that has historically thrived on apprenticed, or situated learning. Some workers also questioned the need for significant literacy 
requirements, arguing that workers could function in rig and service positions with low levels of reading and writing ability. Following up on these concerns, this chapter investigates how the industry sponsors literacy and learning by looking at industry job advertisements for rig and service worker positions. Looking at 30 job ads, I pinpoint specific literacy practices and artifacts that rig and service workers are expected to know or learn as part of their position. However, a key finding in this chapter regarding labor education practices complicates literacy expectations even before a worker can start work. This complication is related to the application process itself. While all workers interviewed in Chapter 2 found their jobs via word of mouth and networking, the industry has moved toward online job ads, which I argue introduces potential workers to new literacy expectations and an added level of gatekeeping in the industry.

Chapter 4 lays out one strategy the oil and gas industry relies on to help fill, what I argue, is a significant gap in labor literacy, and that is the use of labor market intermediaries (LMIs). LMIs assist companies in finding workers, and workers in finding work. While some private, for-profit LMIs solely focus on job placement, non-profits like Texas Workforce Solutions (TWS) have expanded services for potential workers to help them navigate the job application process. In 2013, the oil and gas industry heavily utilized TWS to help find workers for its blue collar upstream positions. This chapter introduces TWS and its services and features interviews with TWS directors. These services for potential workers include understanding the job application genre, which includes assisting with resume language and writing. TWS services for employers include writing and revising job descriptions using industry specific language collected from the Occupational Information Network (O*NET), a website for job seekers and employers 
developed under the sponsorship of the U.S. Department of Labor/Employment and Training Administration(USDOL/ETA). Ultimately, my analysis finds that while TWS assists in providing labor literacy education and communication skills education to potential employees as part of their services, questions need to be raised regarding the blurring of lines between literacy and communication skills. Also, TWS, at least in 2013, did not focus on educating workers in learning digital technology outside of navigating online job ads.

Finally, in the concluding chapter, I summarize my findings, discuss its implication for literacy studies scholarship, and suggestions for further research. 


\section{CHAPTER TWO}

\section{COMMUNITIES OF PRACTICES AND LITERACY PERCEPTIONS IN THE OILFIELDS OF SOUTH TEXAS}

An oil rig floor is a mass of moving parts - pipes, chains, winches, all moving together in a type of mechanical symphony. The driller is the conductor, calling the shots to the roughnecks working the rig floor. He oversees the drill, manages the crew, and makes sure the rig is running smoothly. Floorhands are responsible for keeping the rig floor and tools clean and working. Upper-level rig workers include the derrickman who is responsible for climbing the derrick and guiding pipe into the wellbore, the hole being drilled.

In addition to the rig crew are those service crews. These crews move from rig to rig fulfilling varying needs. Service workers include CDL drivers hauling, gas, oil, waste and drilling mud to and from the rig sites. Welders build and repair parts for the rigs, and operators and technicians who build a variety of other parts, such as motors, tubing, pumpjacks, and pipe. Others, including electricians and wireline operators, are called upon to fix those parts if they break or are defective. This includes common problems such as dislodging and fishing broken pipes, drill bits, and tools out of the hole. Further on the periphery of the rig you have another service sector -- sales. Sales representatives from different companies travel from rig to rig selling parts and services. Their job is to 
sell valves for the pumps and rigs, pipeline and drill bits, drilling mud, fluids and motors for hydraulic fracturing, and mud and waste hauling services.

As rig and service crews move within and around each other's communities of practice, literacy, competency, and communication play significant roles in the fabric of rig culture. The term community of practice is rooted in concepts introduced by Lave and Wenger (1991) related to situated learning, the process of learning in the environment in which the skills and literacies will be learned, practiced, and, eventually, mastered. For a community of practice to work, those involved must share common goals and desires. A variety of literacies and competencies are foundational to these learning practices, and are very much tied to community culture. However, this culture is ever shifting. Part of these shifts is the unraveling and re-weaving of community's fabric, which does not always go smoothly.

The purpose of this chapter is to illustrate a shift in the South Texas oilfield in terms of literacy and competency expectations before and after the discovery of the Eagle Ford Shale in 2008. The voices of several oil rig and service workers who worked in the South Texas oilfield during this period tell stories of how shifts in technology and workforce can shape and reshape literacy, competency and culture in a boom and bust industry. In this chapter I argue that these shifts influence the value and perception of literacy and education by the blue-collar worker, as well as the industry at large. To do so, I have broken this chapter into three sections.

In Section I, I outline the recruitment experiences in South Texas oilfield rig and service workers from the 1990 s to the early 2000s. This section allows us to understand the historical nature of literacy sponsorship and expectations of competency before the 
discovery of the Eagle Ford Shale in 2008. Section II focuses on the learning practices of these oil and gas workers as entry-level -- or as Wenger calls them, "newcomers" - to the industry, including literacy's role in these practices. Section III discusses the rig and service workers' place in the industry after 2008, which is when the Eagle Ford Shale was discovered, creating a significant need for a new workforce and a shift in technology virtually overnight. This section is significant because it frames the worker as what Wenger terms "old-timers" in their communities or practices, highlighting the struggles with navigating shifts in industry culture, including changing literacy and learning requirements and a new generation of workers. Ultimately, I show how the concerns of the rig and service workers create a much-needed space for discussion on how industry acts as a workforce literacy sponsor during critical times of culture shift. The implications of this sponsorship, as evidenced through the worker interviews show distinctive signs of silencing more traditional learning practices in favor of more advanced tech literacies and related higher education degrees, risking the alienation of seasoned workers who connote this new valuing of literacy as a devaluing of the industry's historically prized hands-on capabilities. Thus, creating another implication -the thinning of the workforce in a booming industry.

\section{Section 1: Recruitment Experiences of South Texas Oilfield Workers (1990s-2000s)}

To get a sense of the rig and service workers' knowledge of the oil and gas industry prior to entering the workforce, including its literacy and competency requirements, I asked the workers to discuss how they were recruited. Recruitment is

5 Wenger's concept of communities of practice is a common thread throughout the chapters, but is secondary to the theoretical priority of literacy sponsorship. 
important in terms of sponsorship because it tells us how and by whom they were persuaded towards the industry as a career. Handley et al (2006) claim recruitment and marketing information plays a significant role in a worker's or potential worker's selfidentity. This "identity work" can change or maintain the worker's perception of self (pp. 644-45). Knowing their recruitment processes was important to uncovering what might be considered implied literacy practices related to the job search. In this case, none of the workers interviewed said they attended job fairs, or actively sought out marketing materials. Only one said they looked through job ads, but had no success. All said their jobs were secured through networking.

The workers' networking process yielded important findings regarding the literacy practices of the workers who entered the oil and gas industry in the mid 1990s to mid 2000s. Most workers who said they were recruited by networking were not required to complete a "formal" application. I define formal application as a written application, resume and cover letter submission. I stress the lack of a formal, written application to highlight the fact that these labor literacy practices, such as resumes, cover letters and written applications were not common practices in the blue-collar oilfield until the earlyto-mid 2000s. Manuel, 36 at the time of interview in 2013, is a driller for Pioneer Drilling. Back in the mid 1990s he tried for years to break into the oil and gas industry, but, he said, it just was not that easy. "I tried to get on with H\&P and Nabors, but I didn't have any experience," he said. What he did have was a GED, an electrician's license from Job Corps, and years of experience working on electrical lines. However, even with that experience and education, breaking into oil and gas was difficult. He looked through 
classified advertisements in the local newspapers. He went to bars in the oilfield towns and talked with workers. All said the same thing - no experience in oil and gas, no job.

Finally, a high school friend working in the oilfield helped Manuel get an interview as a floorhand on his rig. The interview was atypical, even by oilfield standards. Instead of a resume and a formal face-to- face interview, the company man, or rig boss, asked Manuel to go fishing with him. During the trip, the boat axle broke, and Manuel took the initiative to provide a solution. "He had a piece of pipe there, some wire, some Duct tape, and I said, just support it with a piece of pipe and duct tape until we can get it back and fix it," said Manuel. "Well, we ended up going out fishing with the way I had it and then bringing it back in. Well, he was impressed that I improvised real good." A couple of weeks later Manuel was offered the job.

While Manuel's experience entering the industry took a significant amount of labor, Joseph's experience was much more straightforward. This was mostly because Joseph was an oilfield legacy. Joseph, 38 at the time of interview in 2013, works in wireline, a service crew that moves from rig-to-rig fixing problems downhole. However, he started out roughnecking6, just like Manuel. However, his recruitment process was much easier than Manuel's as he had a direct link to the industry. In 1993, at 16, Joseph quit school and went to work with his uncle's rig crew. Most of the men in his family were in the oilfield, including his father, who'd worked in wireline for 37 years before retiring. This family legacy meant a certain amount of trust already existed due to

6 Term used to describe workers who do physical labor in the oilfield. According to ONET, roughnecking is described as being able to "assemble or repair oil field equipment using hand and power tools," and "performing physical activities that require considerable use of your arms and legs and moving your whole body, such as climbing, lifting, balancing, walking, stooping, and handling of materials." 
reputation. "When I started roughnecking, luckily, -- you don't always get into this, you don't always luck out like this - my uncle was the driller, my cousin was the derrickhand, my best friend was working floors with me," said Joseph. "So, I got teased out there like everyone else, but it wasn't as hard as it could have been." Once he started working with his family, people he trusted, and vice-versa, Joseph started improving at roughnecking. His crew pretty much stayed together all the time. Joseph said they didn't have any problem finding jobs because they had a ready-made crew7. "When we were looking for a job, we'd just tell them that we had our own crew, if you won't do that, we won't work for you," he said. "We felt comfortable working around each other, we knew how it worked." Joseph's legacy would eventually help him transition from rig work to service work in the wireline sector after years of roughnecking started taking a physical toll on his body.

Ben's recruitment story is a bit different than Joseph and Manuel's as he was referred by a professional colleague who had connections to the industry. Ben, 39 at the time of interview, is the co-owner of Exclusive Energy Services, a growing service company in Beatrice, TX, that supplies companies with fluids for hydraulic fracturing and motors for workover rigs. He grew up in the same small town outside of Corpus Christi as Manuel and Joseph, and graduated from high school in 1993. Back then, he originally wanted to join the police force, so he studied law enforcement at Bee County College, now Coastal Bend Community College. Even though he was doing well in school, Ben felt it was not the right path. "There was not a whole lot out there at the time

7 Instead of individuals applying for rig work, crews of men would contract out as a unit to drilling companies. 
in terms of jobs," he said. "The oilfield was one of the fields you could actually get into, and you could work your way up quick if you learned. You were making good money and climbing the ladder, which was one of the good things that caught my eye." He was working in Corpus Christi for a maintenance engineering company when an oilfield opportunity arose. "The lady I was working for said her brother worked offshore and happened to be looking for some [floor]hands," he said. Within that same week, Ben found himself in Houston taking a drug and alcohol test and physical exam. The following week he was hired on and headed off to the Louisiana gulf shore. "It all happened pretty quick," he said.

Sarah, like Ben, did not initially choose the oil and gas industry. A drilling mud salesperson, Sarah, 42 at the time of interview in 2013, works in sales for a vacuum truck and drilling mud company out of the same small town Ben, Manuel, and Joseph were born and raised. Sarah's work takes her wellsite to wellsite selling services and drilling mud fluids. Like Ben, she initially wanted a college degree. However, in the 1990s, after spending two years studying sociology and psychology at Texas A\&M University Kingsville, she left school to start selling insurance. By chance, one of her insurance clients happened to have connections to a well testing company, and talked Sarah into applying for a sales position. She made the transition from insurance to oil and gas equipment sales in 2008. "The job just kind of found me," she said. "The customers I had on the insurance side suggested it, so I said screw it -- I'll go. I don't know; it was just easy." The fact that she grew up in South Texas and was familiar with the oilfield also helped her cross over from insurance to oil and gas sales. "Knowing about the oil and gas industry was just the way I was raised," she said. "Dad was a welder, so I was around that 
environment a lot. I was around it just growing up in South Texas. Everyone you know works in the oilfield."

However, these referrals carried more weight for some more than others. Joseph's recruitment story illustrates how networking works as a type of gatekeeping function in the oilfield community. Newcomers can have different levels of what Bourdieu (1986) calls "cultural capital." Cultural capital is comprised of the attributes an individual possesses based on the constructs of power. In this case, Joseph's level of cultural capital correlates to his familial legacy and signifies a level of trustworthiness not necessarily associated with workers who are new to the industry and do not possess an established personal or professional connection to culture of the work. Trust is a type of currency in the oilfield. The difference between Manuel's and Joseph's respective experiences entering the oilfield is arguably defined by the level of trustworthiness. Where Manuel must earn, or achieve trust, Joseph's legacy status is able to easily leverage it. The decisiveness of the crew sticking together tells us that the level of trust was not one that was open to newcomers unless there was some type of established privilege that would allow entrance. As Joseph says, he was lucky.

Another part of recruitment worth mentioning was the interview process. Manuel's was of particular interest. In his case, the interview for his first rig job as floorhand demanded he prove his ability to think innovatively, skills he might not have been able to communicate in a formal interview. Improvisation was key in Manuel's hire, and this is a skill that can be difficult to articulate fully in a formal interview. Manuel's skill with improvisation was best presented in a way that allowed for the demonstration of skills learned through embodied learning. Much rig work is learned through embodied 
learning and modeling, and improvisation was a skill valued on the rig. Manuel could show the company man that he had the transferable skills, as well as the attitude and ability to think on his feet, which are all needed to work on a rig successfully, safely, and efficiently.

Looking at all four workers' recruitment experiences, they all have one characteristic in common: they were referred to the workforce by a friend or colleague. Referral and face-to-face hires were (and still are) typical in the upstream segment of the industry. Career networks specific to oil and gas, such as Rigzone, Driller.com, and Career Cast Energy Network claim networking is one of the best ways to find an entrylevel position in the oilfield. Jason Lavis, senior energy entrepreneur at Drillers.com, says that visiting rigs and contacting local recruiters in the areas where potential applicants see news reports for jobs is key to oilfield hiring. "The majority of positions are advertised and applied for electronically," he says. "But a bright-eyed go-getter approaching in person has a better chance of being noticed" (para. 18). Similarly, Brad Dunleavy, job market researcher at Career Cast Energy Network, says since entry level oilfield jobs don't require a special education, the companies filling these jobs advertise locally or not at all. "Locals can just walk in off the street and submit their resume, or a friend gets them a job, or a friend of a friend, etc.," he says. "The point is there is no need to advertise these jobs beyond the local market because there's never any shortage of people applying from the area" (para. 9). Dunleavy adds that these entry-level jobs are also filled through third-party firms, or labor market intermediaries, that are contracted by the oil companies. "You're never going to visit the Shell or Imperial Oil website and find an entry-level job to run a [vacuum] truck," he says. "The oil company has nothing do with 
hiring people for these positions" (para.11). The claims made by the oilfield recruitment analysts reflect the importance of networking and face-to-face contact heavily favored in oilfield hiring practices.

For the most part, the workers said that friends, family, and existing clients encouraged a move into oil and gas because these people felt the worker's respective personality and/or skill set were a good match. Some were also persuaded by the financial benefits of a career in oil and gas. I also asked if they had actively looked through job ads (created by the companies) or through visual rhetoric, like marketing pamphlets (also created to market the company) or job fairs, which are designed specifically as sponsorship mechanisms. None indicated that they attended a job fair. Only Manuel indicated that he looked at classified ads in the newspaper, but was unsuccessful. Networking between oilfield workers and companies supplied the basic for references, and the voices of trustworthy workers counted much more than a resume sent in through a service or in the office.

The recruitment experiences of Ben, Joseph, Manuel, and Sarah provide a snapshot into the worker's process of entering a specific work-oriented community. The common threads of networking and referral are important here because it shows trust is already there. Plus, this type of application process is valid more than a paper application, which tells us that character and cultural fit as vouched for by those already part of the community is valued over applications and resumes, which, while showcasing experience, do not do much in terms of showing character and work ethic. In addition, these rig and service communities will require the practice of a variety of knowledges, literacies, and competencies to navigate the shifting nature of the workers' places in the 
industry. These practices require a level of trust, problem solving, and innovation - or the ability to gain or hone such characteristics. Ultimately, it was evident that during the recruitment and interview process, skill sets were tested or showcased in difference ways, whether it be through informal assessment of skills, a client's referral, or a handshake.

In the next section I focus on the individual worker experiences of learning and literacy in their respective communities of practice. The concepts of legitimate peripheral participation (Lave and Wenger, 1991), and notions of the "newcomer" will be used as they pertain to knowledge-making and acceptance of and resistance to new ideas and concepts. What role will literacy have in their respective learning processes, and what does that tell us about the expectation of their respective communities of practice as members move from periphery to center? The next section explores the process each worker undertook moving from periphery to center and the role of literacy and learning throughout.

\section{Section II: Ways of Learning and Literacy Work in the South Texas Oilfield}

After being hired, Manuel, Ben, Sarah, and Joseph began training in their respective positions. This training was the workers' first step in becoming part of their respective communities of practice. They were what Wenger (2010) calls "newcomers" to their communities, participants on the periphery learning the language and tasks that are required to become full-fledged community members. Newcomers often make mistakes as they learn, and can be delegated more menial tasks as they build their competencies toward more central functions of the community. Wenger (2010) describes the newcomer as feeling like "a bumbling idiot among the sages" (p. 227). For Manuel, the frustrations of his newcomer status began the first day on the job. As a newcomer to 
the oilfield, Manuel was the "worm," the lowest rank of floorhand on the rig. His new workplace, a wellsite was just south of Falfurrias, a small town on the northern edge of the Rio Grande Valley. It was February, and as a South Texas native, Manuel was familiar with the cold, wet winters. However, he was not prepared for having to work outside in one. No one told Manuel what to wear; he had no slicker suit, no jacket, and to top it off he was working the nightshift. "I knew nothing," he said. "I had no idea what I was doing."

Manuel's first hitch, or shift, was filled with very specific tasks. As a floorhand, Manuel and his crew had to "trip" pipes. The nature of tripping pipe is very repetitive, and it takes multiple crew members working in concert to do it, and do it quickly. Because of the amount of pressure put on the pipe in the hole, the pipes can come out of the trip cracked, loose, or compromised in some other way, making them extremely dangerous. Manuel had only been on the rig site for two hours when a pipe twisted-off somewhere downhole:

The whole week was tripping pipe, in and out, in and out. I had no idea what I was doing. They told me to 'make the tongs tight,' and I had no idea what that was! That was to the verge where I was about to quit, and the guys were telling me that I was doing good, doing good, and if I could last this week, it will be the hardest week you will ever had in the oilfield. And to this day it was. If [the

8 Tripping pipe means taking the pipe "on a trip" out of the hole, then back in. Trips are necessary when pipe needs to be added on to the end of the string of pipe, or drill string, in order to drill deeper. These trips also occur when there is a problem downhole, like a "twisted off," or broken pipe, or a malfunctioning drill bit. 
driller] hadn't [twisted off] then it would have been a slow learning process. Because he twisted off it was a hell of a week.

Due to the unpredictable nature of the job, Manuel expected his first days to be stressful, and they met his expectations. "I had fear," he said. "Fear of getting hurt quickly. Because of not knowing what to do." This fear, combined with constant modeling and encouragement from his crewmates created a mental and physical rhythm that helped Manuel build confidence in his skills. Manuel's first days on the rig were crucial for learning, much of which was collaborative. "I hit it off with the guys and they looked out for me, making sure I was not putting my hands where I wasn't supposed to, stand where I wasn't supposed to," he said. "They showed me quick because...there is no learning the hard way... In a split second, something can kill you."

\section{Situated learning and “doing” knowledge}

As a newcomer, Manuel was limited in what it took to "do" knowledge because he did not know the rig language or related competencies. He said floorhands were not necessarily expected to read and understand technical manuals before applying knowledge to their job. Instead, their learning is mostly embodied. Embodied learning is communication and knowledge-building that are understood and negotiated between workers largely without spoken or written words. Workplace literacy practices, such as filing reports and filling out safety forms, were instead delegated to the motorman and driller, two positons higher up in the chain of command. Newcomers like Manuel were expected to learn the language and the competencies in tandem, which can lead to the type of frustrations Manuel described having on his first shift. 
Rig and service workers build competency in their work practices through repetition, which is especially important when they have limited workplace knowledge. Fortunately, repetition is part of the everyday rig and service work. Rig and service workers are constantly repeating physical practices, such moving tongs and chains, bringing up pipe or replacing drill bits, which like Manuel's experience are examples of embodied learning practices. Joseph says most of the challenges with rig work are solved while going through the motions constantly. "Each well is the same thing," he says. "Move the rig there, shut the rig up, drill the hole, while you are drilling the hole, you service the rig. Work the well, do whatever, and then move the rig to another spot." Joseph says that some people who come to work on the rig cannot get the practices down how many times they try. Thus, the inability to learn through repetition becomes a gatekeeping mechanism due to the dangerous nature of rig and service work. The crew relies on a newcomer's mastery of competencies quickly. "You have to get it," Joseph says. "Because you are talking about things that will kill you. Big heavy equipment all the time. If you don't, you are gone."

Part of this repetition Joseph talks about includes learning and utilizing tools that enact certain literacy practices. Workers continuously exercise certain behaviors such as reading and translating gauges and meters or working through formulas -- or "rig math" - to adjust downhole pressures. Joseph's service job in wireline demands working knowledge of the rig, as well as quick utilization of these streamlined mathematical concepts. While working wireline, Joseph says he must be able to identify the type of gauge, the metric it uses, interpret the reading it gives and then apply it to mathematical formulas. "I then use the data output to describe the condition of the mechanical system 
and its function within a specified tolerance," he said. Since Joseph left school at 16, he never made it to the higher calibers of math, such as algebra and geometry, but he says that is not a problem with rig math, especially since it is so repetitive. "With what I do now with wireline, you got to keep up with depths and figure out different weights of pipe and different formula's here and there, but if I got a calculator I could figure it out," he said. "My dad taught me everything, tricks to get around things. My dad, he didn't finish school either. He found out enough just to get by, and he made a living out of it."

A co-mingling of literacy and numeracy, the act of reading gauges and meters and rig math applications requires a variety of processes that consist of recognition, calculation, and translation. For Joseph, the functionality of these processes is what is important to survival in the industry, both culturally and financially. He is not concerned with the symbolic prestige of literacy, but instead he is more occupied with the importance of literacy and competency as it allows him to "get by." Lindquist and Seitz (2009) theorize that concerns of blue collar workers like Joseph about the value of literacy in the context of work are valuable jumping off points for considering layers of cultural capital in the workplace, specifically as it relates to literacy and money. They ask: "If you got real money is middle class literacy really necessary? Or in Bourdeuan terms, 'If you got real money, why bother with the symbolic kind?'” (p. 104). These questions are at the heart of many of the concerns communicated by the workers later in the chapter.

Like Joseph, Ben's experience with repetition is how he moved up in coiled tubing to an operator position. Between his first job on an offshore rig and his current position as a service company owner, Ben worked in several other positions, including as 
a CDL driver, and coiled tubing hand and operator. Coiled tubing, a cousin of wireline, allowed workers to fix downhole problems without stopping rig operation. At the beginning of his job in coiled tubing, Ben said supervisors will let you do a few things, but you are not doing a whole lot. Instead of doing you are watching, he said. "Get out of the way, the operator is going to operate," he said. "They'll call you over and you'll do some more stuff, then get out of the way again.” The learning process can take months, if not years, Ben said. Along the way, skills, like rig math are added into the routine. "Your supervisor may be throwing these equations out to you - hey, here is all the information we have on this well, I want to know -bottoms up time, rates, feet per second, just break it down for me," Ben said. "That is what you did." Ben said this was the way the supervisor was getting him ready to take over as operator. He was getting you ready for an operator position. Since this routine was daily and for weeks at a time, the supervisor could assess learning and add new tasks as Ben's experience grew. "Before you know it you are ready to take the driver's seat and operate," Ben said. "And he's not worried because he knows, he's been teaching you for the last 6-7 months." Ben's experience with apprenticed learning varies slightly from Manuel's experience in that Ben's position has more room for observation and feedback as he is continuously trading off with his supervisor. He could step to the periphery and observe the situation holistically. Manuel does not have that opportunity as much as he must learn by watching and doing at the same time. It is not clear if Manuel's supervisor or crew mates quizzed him like Ben's supervisor did him, but it seems rather unlikely considering the environments of coiled tubing and rig working are so different in terms of noise level and physicality. 
Repetition also allows workers to figure out what works best for their own learning needs. As Manuel learned more about rig work, he developed a variety of sensory-based strategies to help with solving downhole problems. Many of these strategies included paying close attention to certain sounds and vibrations. He said workers must become "literate in [their] environment," which he contends one can only learn to do while on the job. "Be one with the rig," he says. "If you hear something that is different, ticking, or something, never heard it before, you know something is wrong and have to go check it." Manuel's years of working on loud rigs have left him hearing impaired, so he relies on the vibrations of the pipes instead. "A lot of guys grab their hard hat and put it on the pumps and hear the 'swish, swish, swish' when the swab is going out," Manuel said. “I can't hear it, but I can feel it. I can tell. I guess that is where my body has adapted. Lose one sense and another takes over."

Manuel's sensory-based strategies are also examples of embodied learning practices accomplished through observation, mimicry and repetition, much like craft apprenticeship, such as carpentry and welding (Marchand, 2008, Herzfeld, 2004; Marchand, 2001; O'Connor, 2005; Portisch, 2007; Simpson, 2006). In their study of American blacksmiths, Keller and Keller (1999) note spoken word is designed for discussion and reflection of the work that is conducted, but is "not an instrument of the doing itself" (p. 27). These arguments echo Manuel's comments on his training. He says higher order reading and writing skills, such as those used to read technical manuals, were not valued as much as the ability to provide workers like him an education through more practical techniques related to the act of "doing" work. "There are guys who have been drillers for a long time and do not know how to write," Manuel said. "They are 
barely computer literate. But they are still in that position... these guys are good drillers, and I learned a lot from them."

When Manuel says the older drillers "do not know how to write," what he means is that they do not know how to write past an unspecified academic level. They know just enough to get by and to sign off on mandatory paperwork and fill out check-lists, a requirement for their job. In this argument, we hear echoes of Lindquist and Seitz (2009) and the questions surrounding the fiscal vs. symbolic value of literacy. Here, Lindquist draws from her Smokehouse Bar study, where she talked with working class patrons of a local bar about their thoughts and beliefs on literacy. She found that literacy's "cultural prestige" did not necessarily rest in the literacy practices of the workers. Instead, she found that "high knowledge is considered disloyalty" and "not displaying literacy knowledge publicly means it doesn't have the same uses and expectations of literacy as cultural capital" (p. 107). The patrons in Lindquist's study, like Manuel's driller, used literacy in discreet and implied ways for purposes of production rather than learning and knowledge creation. Lindquist refers to it as the use of "street smarts" rather than knowledge associated with creation or use of texts that create "cultural solidarity, and, ultimately, class identity" (p. 124). Basically, Manuel argues, being in a position of power, especially in a blue-collar industry, the cultural capital lies with the efficiency of how one does work efficiently and safely, and not necessarily why it should be done a certain way. The oilfield, as Manuel and Joseph, will argue, is not a democracy.

The non-reliance on reading and writing in the physical aspects of apprenticeship speaks to Manuel's claim that drillers can work and train newcomers with little written language skill. The value of reading and writing on the rig is based in record-keeping as 
opposed to instruction. However, this does not mean that literacy is unnecessary to knowledge-building in apprenticed learning. Language is regularly used to provide verbal direction and feedback, as well as for reflection and discussion. It also includes quizzing and testing, like Ben's experience with his supervisor in coiled tubing discussed earlier. Manuel's argument is that physical acts are highly valued rig learning because the action performed is visible and "doable" to the learner. In addition, visibility makes specific work-related movements easier to mimic and repeat rather than written or spoken directions, which require a process that demands not only translation of industry-specific vocabulary, but the translation of that language into movements. Any steps that are perceived as extraneous, that take away from efficient production, are stripped away from the learning process.

\section{Literacy-based learning and 'doing' knowledge}

While most situated learning in the oilfield occurs in the communities of practice where they are utilized, learning in the oilfield is not without certain complexities involving literacy's role. Specifically, these complexities entertain literacies considered to be outside the actual space and place of practice, but are brought into the field for reasons of advancement that situated learning alone cannot be of ultimate benefit. Here I pinpoint three examples where the oilfield workers move outside their community of practice to pull in learning that can help them advance in their field of work. First is Ben, who must complete a classroom-based and skills based course for his commercial driver's license (CDL). Second is Manuel, who is required to complete a certification course to move up to driller. Third is Sarah, who self-sponsors her own learning by building on her experiential learning in the oilfield by reading technical manuals and 
books about her industry. These examples represent the fine line between situated learning and academic education. Neither Manuel, Sarah, nor Ben considered their learning in any way academic even though each event contained academic literacies and learning. Instead, the workers saw their learning as situated in their community of practice since they used their new knowledge to move closer to the center of their respective communities.

The foundation for Ben's successful career in coiled tubing started with learning how to drive a big rig, or 18-wheeler, for Schlumberger, one of the largest service companies in the industry. Schooling in Ben's case was all driver safety training, and all general safety training. He spent one week in the classroom, and the second week driving 18-wheelers, in a private course the size of a small town. "The main thing was safety," said Ben. "Instead of throwing these young guys into 18-wheelers and saying 'drive down the road'-- because we were hauling, at the time equipment that was between 80 and 100,000 pounds - there was a lot we had to learn and practice. That's a lot of equipment, and they had to make sure we were capable of handling that equipment weight." In the classroom, Ben had to read about, discuss, and take tests on information about why drivers found themselves in certain situations more than how to physically do their job. For example, prior to driver training, Ben spent a week in the classroom reading, writing, and learning about the body, specifically how the body reacts to night and day. Understanding the psychology and biology behind why things happen allows drivers to feel confident in their knowledge of why they have to make certain choices when doing their job. "There can be times when you are wide awake at night and you start seeing that sun go down or that sun come up," he said. "Those are the two times of the day where 
you can be wide awake, and at that moment your body can change and you can start feeling drowsy." Ben says that most of the classroom-based learning? was about times when you might be tired, and why pulling over and getting a "15-minute cat nap" would help out a lot.

Ben's classroom-based learning was assessed through a rigorous testing process. He said there where were short tests every day, and at the end of the first week there was a written test you had to pass before you could get into the truck to start driving. These written tests included short essays that required the description of processes drivers would have to use to troubleshoot problems encountered on the road. Ben said some people did not pass these tests. And those who didn't pass the tests would in turn fail the class and be sent home. "Schlumberger did not sit there and say, 'oh we can change that answer.' They were pretty strict about it," he said. "And that is one of the main reasons that I went and started there because they would do everything -- send you to school, get your CDL, and pay for all this because they knew you would be an asset to the company."

The takeaway from Ben's experience as a newcomer to the truck-driving community is that industry-sponsored schooling is structured much differently than Manuel's or Joseph's apprenticed learning under their crewmates. First, Ben's training involves much more in terms of written literacy requirements. Manuel and Joseph's experience with literacy as newcomers was limited to language learning, which was learned in tandem with the hands-on learning process. Literacy in Ben's experience was split between classroom-based learning and simulated training. The role of note-taking was also part of the classroom-based learning, a literacy practice Lindquist and Seitz 
(2009) say reflects "workplace changes in literacy created by the knowledge economy and total quality management" (p. 134). In other words, the practice of note taking is an example of Freire's banking method, where information valued by those in power is provided and "deposited" into workers' knowledge. What we know from Ben is that his literacy practices as a newcomer encompass much more than just reading technical manuals and applying stated processes. It was less about how to put concepts into practice as it was an in-depth look at reasons why those concepts and practices exist. For example, understanding how the body works alerted Ben to the reason why he needed to take cat naps during long hauls. Learning about how parts of his truck move work together created a certain understanding towards why he needs to pump breaks on an 18wheeler. The hands-on training then provided the practice on how to do so.

Secondly, unlike that of Manuel and Joseph, Ben's learning as a newcomer involved formal assessment. Ben's training required reading and assessment before he was even allowed to get into the truck. When he did start driving, it was part of a simulation, a course, which encompassed an entire town. The next step, after further testing of skills, was acceptance into the community, which was noted through a "passing" of rigorous simulation challenge that put into practice his classroom-training with his driving. The regimentation of the learning process, both in the classroom and in simulation, communicated to Ben that Schlumberger valued its trainees as the company invested time and money in each trainee.

While we do not know much about Manuel and Joseph's assessment process on the rigs, what is known is that training and assessment was up to the crew itself and not a third party or industry-sponsored curriculum. Most likely, this variance is due to the 
domain of the communities, specifically the different relationships that rig and service communities have with the public. For example, Joseph and Manuel work specifically with rigs. They may be members of different communities - service and rig, respectively - but their domain is the rig. For Ben, it's different. His primary domain is the truck itself, as his learning revolves around operating and maintaining all its moving parts. However, there is an added layer of complexity in Ben's community in which Manuel and Joseph are not in immediate contact. This layer is the public. While he transports coil tubing between rigs and service yards, the area between encompasses mostly public road systems. This means that in addition to working within his own truck-driving community, he has to negotiate with other drivers, most of who have little understanding about how 18-wheelers work. Therefore, Ben must think for both himself and domestic drivers, and is led to believe that Schlumberger values such knowledge since it requires rigorous training and assessment.

While Ben's newcomer experience began with certification and assessment, Manuel found himself facing certification a few years in. It took Manuel four years to work his way up from floorhand to driller. However, before he could move into the position, he was required to attend a course in blow-out prevention (BOP) sponsored by University of Houston - Victoria. Certification courses like these are not uncommon for workers as they move through different positions on the rig. The 15 -hour course was 4 days long and crammed with technical knowledge drillers needed to understand about how to prevent a blow-out, which is when problems happen downhole that could lead to an explosion. "Before the class I knew what I was doing, but the course helped understand why," he said. "It taught us all the technical stuff." Manuel's reference to the 
purpose of the class as helping understand "why" is referring to the reasons for processes and procedures he has been doing and new ones he will be expected to do as a driller. The technical stuff is his way of describing the elements of the job that inform the worker about the reasons behind the practical elements, or competencies, that are expected as workers on the rig.

Making the decision to take the course was not easy for Manuel. Taking this course meant a type of classroom-based learning, including tests. Manuel was apprehensive. He had never seen the value in schooling, and he was adamant that it had nothing to teach him that he cannot learn on the rig. "I hate school. I hate to write" he said. "Don't mind reading, looking up facts, hate to write. Never liked it, and a lot of it is because I have dyslexia." Despite his views on school, he did find the required blow-out prevention course useful. The course included reading from a technical manual as well as work with a simulator, and concluded with drillers receiving their BOP surface supervisor card. After he completed the course, Manuel took his expanded knowledge back to his crew. But this type of knowledge sharing is not always the case. Not all drillers who take the course share their knowledge with the crew, and instead share only the basics of their knowledge. This reason, he says, is either due to the driller being disinterested in educating his crew, or related to job security. For Manuel, transferring his new knowledge was crucial for the crew in terms of understanding reasons behind rig procedures. Safety, in particular. "It's better for everyone if they understand why we do the things we do. It keeps them safe."

Manuel's experience in his certification course for driller brings up some interesting considerations surrounding texts and authority. Manuel has been very vocal 
about his distrust and lack of validation surrounding texts as sources of knowledge production. However, his reaction to reading technical manuals for purposes of this course is different. In this case, the manual is representative of authority, of rules and procedures he needs to follow to do the work in his new position as driller. Since his job requires training and keeping his crew safe, Manuel is relying on information (via the class) and the certification (a piece of paper signed by those in authority), to give him the power to do so. As Belfiore (2004) argues, "Paper is for telling government, customers, and international retailers that all has been processed accordingly to standards" (p.32). this situation tells us that certifications, classes, and other training once completed function as a hidden gatekeeper to knowledge sharing. Meaning, while Manuel knew the processes before his certification training, it was not until he learned the foundation of the processes and certified on paper that he felt he had the power to share his knowledge with his crew.

Sarah's experience with literacy-based learning is different than Manuel's and Ben's as it required much more self-sponsorship. At her first well-testing job in the McAllen, Sarah took it upon herself to ask questions to learn about the procedures so she was more informed. Learning about mud and flowback9, what it was, and how it worked on a rig was not exactly necessary to Sarah's sales position. However, learning about it made her more credible when talking to buyers. "At the beginning of flowback, I just asked," she said. "I asked [my employer] to take me through the vessel. I took the valves off myself. I drew pictures. Because I was illiterate." When Sarah calls herself

9 Flowback is liquid used in hydraulic fracturing that returns to the surface after being injected into shale. (Merriam-Webster) 
"illiterate," she means in terms of the language skills necessary to understand those flowback parts that she was hired to sell. Sarah sees herself as illiterate because she was unable to do her job as effectively as she wanted to without more hands-on education. By asking her employer to show her the physical apparatus and taking notes, she was actively apprenticing in her position.

After a while, Sarah found she was still not as "literate" in well-testing as she felt she needed to be. And, in such a male-dominated industry, Sarah said she knew she must know how her business work in the industry's various communities to be taken seriously. Therefore, she decided to self-sponsor her own education of the field. At her second well-testing site with a Houston-based company out of Corpus Christi, she began more in-depth research about the valves and other mechanisms that she was working with. Her manager at the time pushed her to continue learning, stating it could only benefit her career. "He was all about 'knowledge is power,"” she said. "He would have me read books, manuals, brochures, and then fly to Houston to test. He would buy and give us the college manuals." Working hands-on with the product afforded Sarah a much-needed foundation for reading and understanding information in the manuals. "For me, it was much easier to learn hands-on how the valves and everything work and then go back and look at the college manuals to see exactly what we were talking about," she said.

Sarah's situated learning experience in the field coupled with self-sponsored learning through the reading of manuals provided by her supervisor created a dynamic educational experience that she could apply at all stages of her sales job. From a critical literacy perspective, Sarah taught herself how to "decode" the text of the industry (Hull, 1993). Through this decoding process, she started understanding what parts a buyer 
needed from just a small bit of information. From there, she was being able to explain how parts of the rig and pipeline pressure worked, Sarah could learn the language of the rig and turn that into communication that the supply house could understand. However, Sarah soon would find herself in a challenging situation when faced with working with engineers, a group of workers who had substantially more cultural capital than she as a salesperson. She realizes that sometimes she knew more about how a rig worked than the engineers themselves. Sarah's experience is an example of what Handley et al (2006) term the participation versus practice paradigm. In terms of dynamics of power, constraints on newcomers like Sarah can be strongest when they practice "threatens to transform the knowledge" (p. 642). She found that she was essentially teaching these engineers, straight out of college with little to no rig experience, the anatomy of the rig. "We have come across engineers that have been trained, got degrees, and don't know what a closure is, doesn't know how it works," she said. "There are some that come in on summer programs and work pipeline and understand, but there are so many that don't. They depend a lot on people like us."

When Sarah says "people like us" she is talking about the non-degreed rig and service workers like Ben, Manuel, and Joseph, who learn through hands-on situations on the rig, or like her, a combination of reading and doing. Her experience and reading made her much more aware of her surroundings, a fact that she acknowledges daily. "I could go by a compressor station before and not know what it was, or what was going on there," she says. "Now I know what it is, what the jobs are, what relief valves are, and where they go. Before, I had no idea." She says that for the way she learns, her situated learning experience compounded with reading disciplinary literature was the only way that was 
right for her. This knowledge and research has also alerted her to impending changes in the field. Although at the time of interview she'd only been at her well-site testing job for less than a year, she already has her sights set on big production jobs as opposed to small rigging jobs due to the volatility of the oil and gas industry. If Sarah wants to move up into production, she acknowledged the power formal schooling will provide her career. Sarah says that if she went back to get a two-year degree in oil and gas technology or any aspect of the oil and gas industry, she would be an asset to any company. "I would be dangerous if I went back to school," she says. "I think so because I have worked in drilling, upstream and downstream production, so for as much as I know without school, to me, school would just put it over the top."

The key insights we take away from Sarah's experience is that she has a clear understanding of the value of both literacy and hands-on experience as part of her learning process. There's an interesting argument to be made about the distinction she makes between degree-learning and situated learning, even though she recognizes that formal education can be a useful adjunct to situated learning when it comes to career advancement. She has no problems asking questions, and recognizes and figures out how to surpass limitations in her knowledge by figuring out alternatives, such as drawing pictures of machinery parts, asking questions, and actively making connections between the parts and the descriptions in the technical manuals. What makes her attitude toward literacy's role in learning different from that of Manuel, Joseph, and even Ben? Since her job does not have an apprenticeship component like that of Manuel or Joseph, much more of her learning is self-sponsored. In addition, Sarah's role in the rig and service communities is based more in sales than in physical labor, so it stands to reason that her 
job revolves more around actively persuading people to purchase parts than it does fixing them. As Sarah mentioned earlier, she needed to work harder to be taken seriously in a male-dominated industry. Thus, rhetorically performing her knowledge of how certain parts of the rig work together, or why the chemical makeup of her company's mud is better than that of her competitors is forefront in conversations with potential buyers in the industry than physically demonstrating. The fact that if asked Sarah can physically demonstrate how parts work only bolsters her credibility. And, as she mentions, a degree would only put her over the top in an industry that has recently started communicating its desire for a more educated workforce, both technically and academically.

This purpose of this section was to draw out aspects of situated learning, both hands-on and literacy-based, in the rig and service communities of practice. What we know from these workers' experiences is that that situated learning is a complex process of knowledge-making, hands-on practice, and communication. First, apprenticeship, one aspect of situated learning, includes a combination of physical and mental abilities, as evidenced through Manuel "reading" the rig the way the drillers before modeled for him, Joseph solving problems with rig math, and Ben practicing and valuing the learning that occurs by nature of repetitive work. Literacy-based learning practices are also valued in the industry, but the reasons vary depending on the community's needs. Sarah's selfsponsorship with industry literature was not necessary for her job, but her boss pushed her to learn through reading and testing so she would be more competitive in the industry. Ben's experiences with classroom-based learning prior to hands-on learning allowed him to connect and incorporate scientific and psychological knowledge into the decisions he made as a driver. Finally, Manuel's reluctance to take a literacy-based certification course 
even though he knew it would help him move up in his job is evidence of cultural mistrust in classroom-based education. Regardless of literacy-based or hands-on based learning, these workers are examples of newcomers "doing" knowledge that they have created by taking different approaches to learning and literacy.

\section{Section III: Old-Timers and the Eagle Ford Shale}

Joseph, Ben, and Manuel often refer to the 1990s oilfields as working "back in those days." In 2013, the rig and service workers of the 1990s are no longer newcomers to the industry. They have reached what Wenger calls "old-timer" status, moving from the periphery of their communities of practice to the center. And, as old-timers, Joseph, Ben, and Manuel note significant changes in the modern oilfield from the days when crews traveled together and learned from one another. The first change is the shifting expectations in personnel hiring and training as the industry grapples with two major hiring needs: the entry-level rig hand and the academically educated engineer. A second change the old-timers face is the rapid advancement of technology. Laptops, tablets, and cell phones are increasingly commonplace alongside the tallybooks and hand-held calculators. Brandt (2001) chronicles a similar trend in the professional world, in particular how forms and expectations of various information technologies such as websites, PowerPoint, and email have forced many professionals in business to adapt to different genres of writing that rely on these technologies. This is no different for the oil and gas industry. These changes in learning and literacy culture pose significant challenges for the old-timer, as they learn to negotiate different work ethics that come with differing levels of power, competency, and education. This section focuses on the perceptions of the changing oilfield from the old-timer perspective as they pertain to 
resisting, questioning, and negotiating cultural shifts brought in by new workers and new learning and literacy expectations emphasized by the industry. The shifts are not just difficult for the old-timers. They require what Wenger calls a "realignment" to the needs of the industry.

The discovery of the Eagle Ford Shale in 2008 created an upswing in oil and gas work opportunities in the South Texas oil and gas industry for a variety of rig and service workers, primarily on the exploration side, which includes drilling and production. In 2012, the industry saw a skyrocketing demand for entry-level rig and service workers, such as righands, drillers, wireline, and CDL truck drivers. These jobs called for little or no academic education or industry-related experience, but touted the promise of on-thejob training, and hefty salaries. Thus, the field saw an influx of new workers into the oilfield who had the basic qualifications of physical ability, but knew little about the intricacies of rig work and the accompanying culture. Therefore, it was up to the oldtimers to teach them.

However, to the frustration of experienced old-timers, newcomers in the modern oilfield were, and still are, perceived as having little desire to become part of the existing culture. To be clear, older workers complaining about the work ethic of the younger generation of the workforce is not new. Nor is it unique to the oil and gas industry. But what is different is the scope of actual changes to the industry that are the result of technological shifts and a demand for a larger, more academically educated workforce. Joseph says because of this newcomer mentality, today's oilfield feels disjointed, like the workers are not really connected to the work they do. He says the oilfield is now full of people coming in to make money without really knowing what they are getting into: 
"You get people who -- crews don't even know each other -- from all parts of Texas, they come from Louisiana. They don't know each other," said Joseph. "You got a car salesman, a Subway worker, someone who was working at Walmart getting into the oilfield because they want to make some money. Back then [when I started] it was different." By different, Joseph means the environment, the culture of the rig and the work. What the newcomers does not realize, he says, is how backbreaking the work is: "You don't eat like normal jobs, you don’t shut down for lunch. I remember eating sandwiches with muddy dirty hands, I mean just grabbing a sandwich and eating it. When I started, get you a little drink when you could. It's not like that now."

What Joseph is describing is a shift in the social learning practices of rig and service work. Wenger (2000, 2010) defines social learning as bearing on social competence and personal experience, and that competence is historically and socially defined. Joseph's concern with the new generation of workers is that they do not understand the culture of the industry, nor do they want to. Instead, they are there for a paycheck. This attitude frustrates him because he sees a decline in the integrity of the culture and community of which he has been part for decades. Within rig communities, cultural guidelines such as apprenticed learning and legitimate peripheral participation are followed as part of the becoming a full-fledged member of the community of practice. However, it is not always so easy for the old-timer to accommodate shifts in the historical culture of competency building. While Wenger says that resistance is an anticipated reaction from the old-timer, the tensions created by new workforce expectations can force the old-timer to consider what they have already learned and practiced as now having limitations. In terms of literacy sponsorship, these shifts occur as movement toward more 
digitized use of texts like email and texting for communication and reporting. For drillers, the use of Excel spreadsheets is becoming an added layer of documentation between the reading of gauges and meters and creation of reports. The utilization of more forms and paperwork for safety reasons, while not necessarily requiring more reading and writing, is requiring more accountability for filling out paperwork for their job than doing the job they were hired to do. Lindquist and Seitz (2009) call this power dynamic a "paperwork is more important than production" situation (p.164) The act of filling out forms creates imbalances in power dynamics to mediate job risks (Belfiore 2004). For Joseph, Ben, and Manuel, having their learning processes and literacy backgrounds perceived as substandard in the modern oilfield is problematic. As Joseph says, it feels disrespectful and dismissive of traditional ways of their work and culture and alienates long-term experienced workers whose experience can be an invaluable teaching tool.

\section{Academic vs. hands-on experience}

The culture shift in the modern oilfield also creates tensions between the old-timer and newcomer as it relates to competencies learned in the classroom versus in the workplace. Old-timers argue that the industry's hiring practices give preference to whom they consider unqualified workers in both blue and white collar oilfield positions. To the old-timer, the term "unqualified" means that the employee does not have the hands-on experience and competency for the position. Instead, the industry is privileging academic learning and a college degree over hands-on experience. In other words, they have not done the appropriate work to move from the periphery to the center of the community of practice. 
This lack of peripheral work is a great point of contention when the newcomers are those in upper management positions, such as the company man. Manuel says for these positions of power, it seems that peripheral work in competency building is not necessary. Instead, a college degree in engineering or chemistry without any hands-on experience will do. He says he's seen workers fired because they will not go back to school even though they have a significant amount of hands-on experience. "There was an incidence in the company with a guy who worked his way up past driller, but he had no college degree," says Manuel. "He was good at what he did. They said early requirement, or you are fired. Experience had no weight." The attitude from upper management, which is outside the blue-collar oilfield community of practice, is one of "go to school or leave," says Manuel. This is frustrating, he says, because the "wrong things" are being taught in school. "There is no need for these classes in reading and writing, just experience," he said. "And in my experience, experience is what counts. Between floorhand and driller is where you get that." To add insult to injury, Manuel says, when the companies bring in engineers, tool pushers, and company men with college degrees and no hands-on experience, they expect him, the driller, to show them how the rig works. "You say, 'Wait a minute, that is not my job, you are not paying me for that," he says. "That is why you should have kept the guy who had experience. If you don't know anything about downhole pressure, or if you don't know anything about the pumps, that piece of paper you are so proud of is not going to help you out here."

Ben agrees with Manuel's perspective on the industry making a mistake by bringing in upper management with no hands-on experience. If the experience is lacking, then the academically educated workers need to be open to the viewpoints of others with 
more on the job training. Even though it may sound like there is a lot of tension between old timers and newcomers, Ben says it is "not as bad as you'd think." He says that in his experience if you stand your ground, have confidence in your knowledge, in your intelligence of your work and the complications related to doing the work incorrectly, then your intelligence will come across and the other will see your side. It really relies on communicating your knowledge and competency in a way that the other will understand and documenting all decisions and conversations. Ben talks about the time he disagreed with an Engineer and rig manager, the company man, about the best way to do a job safely and efficiently:

An engineer wanted me to do something, and I said I can't do it. Because that is my equipment that is in the ground, because I have the potential of losing the equipment in the ground, and I am not going to do that. The engineer says, 'But this is what I want you to do,' and I said no, can't do it. You know what, we keep logs, we will write it up in the paperwork, and if something comes up, we have it documented. I write down on the paperwork 'as per company man' we are going to do this, sign here please. The company man says, 'Well, hold on, let's talk about this.' And they start backing up.

Ben's reason for disagreeing with the engineer and company man was due to experience losing equipment when they tried the same technique, and it Ben's response illustrates the pride and respect he has for the job and his crew. "Because it is not only him on the line but me on the line because it came back to my company." Ben used paperwork and experience to argue for his way of doing things. Documentation, and paperwork in general, speak volumes in the oil and gas industry. Lindquist and Seitz (2009) call the 
documenting of others' mistakes, especially those in a position of power is done for protection, as well as creating a space for articulating power/social power tensions (p. 165). Using these rhetorical techniques, paperwork is used to document the worker's assuredness in their decisions, and the unsureness of the engineer or company man is a characteristic of the oilfield culture. The ability to leverage paperwork as a support mechanism for decisions making also illustrates Ben's ability to solve problems, a vital competency of any worker in the oil and gas industry. Paperwork is only one aspect of qualifying procedural concerns. Most often, he says, calls are made to upper management for clarification. "There is lot of calls that still get made in the field, but there are some situations where you would have to call the office to give them a little more help or to make sure 'this is what I want to do, the company man does not seem to want to, does the office have my back if this is what I do.' That is pretty much how it is. Not just your word against the company man.”

Ben wants to be clear that he is not "bringing down" schooled engineers and bosses, but he says there are certain situations where he's had discussions on location with an engineer who gave orders that were incorrect. "You step in there and have to say, 'You can't do this. This is the way you have to do it.' And the engineer comes back and says, 'No, this is what I want to do...,"' he said. Ben then had to explain that his crew have tried the engineer's technique before, and it did not work. Sometimes there are struggles between power and best practices, says Ben, but you should be firm in your stance for safety reasons. "If there is something that they are wanting you to do because they are new to the job, and they just started in the oilfield and came from an education, and a degree, sometimes you have to step in and tell them, 'I can't do that, and I am not 
going to do this." He says that in his experience if you stand your ground, have confidence in your knowledge, in your intelligence of your work and the complications related to doing the work incorrectly, then your intelligence will come across and the other will see your side. Success relies on communicating your intelligence and competency in a way that the other will understand, and that oftentimes requires strong will, patience, and the ability to provide documentation and examples to support your reasons.

What does the old-timer attitudes toward culture shifts tell us about literacy's role in the changing oilfield? First, with these shifts in culture comes the need to be able to communicate to people who are just coming into the community using language they will understand. Manuel argues that he should not have to train these people with degrees. Ben says he needs to argue with degreed engineers about the "right" way to do things. What is happening to the old timer is the need for realignment (Wenger 2010) by the old-timers in their communities. Joseph needs to realign his expectations or the newcomer due to shifts in the industry. Manuel needs to realign too, in terms of industry's needs for old-timers to teach newcomers the ropes. This is nothing new apprenticeship calls for old-timers to assist in learning newcomers the ropes. However, it is different when the newcomers are placed in in the center of the community by the industry without the hands-on competencies expected, but instead with academic knowledge. Thus, resistance toward these shifting expectations is expected. How the workers resist and realign with informed literacy practices is what is important. Ben recognizes and accepts his supervisor's lack of hands on experience. To defend himself 
and his knowledge, he uses the threat of documentation to challenge his new supervisor's demands.

\section{Technology and the changing oilfield}

Further complicating the reach of old-timer competencies in the modern oilfield is the industry's increasing reliance on digital technology. In the late 1990 s and early 2000 s the industry began adopting technology aimed at increasing efficiency and production. In 2014, technology such as cell phones, laptops, and email has been widely embraced by the industry, including rig and service crews, for its efficiency in communication and problem solving. Ben says technology in the 1990s is something he jokes about with his friends, especially memories of carrying around a pager, and when it went off, you had to use the house phone, or find a cell phone or pay phone to call in. "I remember when I started out, just a helper," he said. "That is what a lot of supervisors had to do, you know, they have to wait until the job was done and go and call from the payphone, tell them the job was done, and tell them if we needed something else. And now it's -- you need something? Just pick my cell phone up and call." Ben says that when texting became popular, oilfield workers wanted the company phone to include texting because the further out in the field you go the harder it was to get service. At first the companies weren't buying in to texting due to the overwhelming cost, but they soon came around, Ben says. "They figured out, you know, you can send a text, and it might not go through, but you might hit a spot where you hit a signal and it would send," he said. "So instead of finding a spot where you could find signal to call, texting was something that came into effect and actually helped out quite a bit on these wells when you are out there and could not get any communication." 
The challenges of computerized technology are not just delegated to cell phones. Ben says the dirt from the rural areas and rough roads would constantly cause malfunctions in the computer systems, shutting the whole job down. These shutdowns have happened quite a few times, Ben says, causing issues with efficiency. He says many companies have gone to computerized units now, but they still have backup systems that have the mechanical/electrical counter for safety's sake. "I still have a hydraulic gauge where I can sit there and look the counter," he says. "Where if something happens with the electronics we are not stuck in the hole with pressure. We can go ahead and come out of the hole because we can see what's going on we are not having to look at a computer to tell what's going on." As the industry begins to modify its standards to accommodate the pace of technology, a new rigidity in calculating mathematical concepts is also finding its way into rig culture. Joseph says he sees shifts in competency levels in wireline when it comes to how to "correctly" calculate rig math. "Even now, this wireline thing is getting more technical," he says. "I can go to a guy who does the same thing that I do and to figure out certain things --like how much a pipe weighs, buoyancy factor or things -- and [my colleague] he can come up with the way he does it, out of the book or whatever, which is how he was taught, and it is 10 pages long," said Joseph. "But my dad, he can show me how he does it, and it's like one page long. It's not the most technical way like [my colleague] did it, but it gets to real close to what he got, so you are getting by with it."

What is significant about Ben and Joseph's experience with tech shift is that while the industry is moving toward a more digital reliance for efficiency and safety reasons, there is still a significant reliance on analog technologies. Ben still carries his analog 
gauges and meters for back up. Joseph relies on rig math short cuts learned on the job because they are faster, even though they may not be 100 percent correct. The proven track record of the old-timer ways initiates a reluctance and resistance in the old timer to fully invest in newer fragile and potentially less efficient technologies in terms of their work. Thus, these feelings can create roadblocks for the old timer in terms of realigning to the new needs of their community.

As this section shows, rig and service workers are juggling a shift in the culture of the oilfield, a shift that the old-timers perceive as a devaluing of workplace experience in favor of newer generation of workers who have college degrees but are lacking in practical experience. The shift is further complicated by the increase in digital technology that favors a demographic of worker that has existing knowledge and competency in certain technological processes. Even though traditional literacy tools such as analog gauges and meters are still valued in emergency situations, such as tech failure, they are slowly becoming obsolete in favor of their newer and more efficient digital counterparts. When the newcomer and the old-timer come face to face in the workplace, there is a culture clash created by generational and educational differences. The only option seems to be realignment or leaving the industry. However, realignment can be complicated. Even if digital literacies are quickly becoming part of home literacy practices, this does not always mean that these skills are easily transferable to the workplace. In addition, even if a worker wants to increase their digital literacy skills, it is not always feasible with work and home responsibilities, as with Joseph.

\section{Conclusion}


As Manuel, Ben, Joseph, and Sarah have discussed, they feel their experience and culture is being jeopardized due to the cultural shifts in the industry related to education and workplace expectations. As newcomers to their communities of practice, the process of learning their roles was traditionally communal, with an underlying respect for the culture of an industry that was as exciting and fulfilling as it was dangerous and intolerant. But as the newcomers reached old-timer status, they found their shifts in status converging with a shift in the industry and forced to "realign" to the shifting learning and literacy expectations of the industry. The expectation from the industry that these oldtimers were to teach the newcomers the culture while simultaneously accepting cultural shifts in work ethic, respect, and workplace competencies caused frustration and anger among the old-timers whose experience seemed to be simultaneously valued and ignored by the industry.

The complexities of this situation require further study. What skills and literacies does the industry value in the newcomer? The old-timer? How is the industry expressing and supporting these claims? One way we do this is by looking specifically at how oil and gas companies communicate to potential workers the skills and abilities needed in the industry. In the next chapter, I investigate how these oil and gas companies sponsor literacy and learning in the upstream oilfield sector though a genre the industry now leans heavily on in terms of recruitment: the online job advertisement. An analysis of these job advertisements will shed light on what the industry values in literacy and learning, as well as the necessity of old-timers in the industry to perform the role of teacher, mentor, and life-long learner. 


\section{CHAPTER THREE}

\section{OIL AND GAS INDUSTRY AS LITERACY SPONSOR:}

JOB ADVERTISEMENTS ANALYSIS

In Chapter 2, oil and service workers discussed their perceptions of the industry, including the expectations for competency building and literacy use. There were several concerns brought up by the workers that related to literacy and competency expectations in their positions and changes to these expectations related to culture and technology shift in the industry. The source of these frustrations lies within the industry's shift in education requirements and literacy expectations of new workers. This shift has caused old-timers to find that their existing literate skills and competencies that have been passed down from generation to generation have now become "vulnerable" to what Brandt (2001) calls "unprecedented turbulence in their economic value" (p. 18). Basically, oldtimers like Ben, Joseph, and Manuel are now forced to conform to, or as Wenger (2010) says "realign" themselves toward the shift in industry standards (p. 34). However, in the case of this culture and technology shift, resistance is not an option as "large-scale economic forces" like the demand for oil and gas are what set the "trade routes" and "determine the worldly worth of that literacy" (Brandt, 2001, p. 18). How the oil and gas industry communicates this "worldly worth" of literacy and competency needs to potential workers is the focus of this chapter. 
In this chapter I investigate the literacies sponsored by the oil and gas industry through an analysis of a genre that most closely communicates the literacy and competency needs of the industry -- the job advertisement. Job advertisements act as a window into the industry, as they are usually prepared by the companies' human resources departments. They are also a type of response to material conditions, regulations, and policies created and distributed by the industry. As literacy researchers have argued consistently throughout the 1990s, literacy's relationship to economic change in communities and workplaces is complicated as well as substantial (Gee, Hull, and Lankshear, 1996; Gowen, 1992; Hull, 1997; Purcell-Gates, 1995). In the 2000s, this argument about literacy's complexities has not changed much. However, looking at job advertisements as a window into this change has yet to be attempted in literacy studies scholarship until now. The job advertisement genre is a rich source of examples that point to the culture shift in literacy and competency expectations. The findings suggest that while literacies such as reading and writing are valued in the industry, the use of reading and writing and understanding how these function in terms of finding jobs in the industry is complicated. Guiding questions for this chapter are:

- How do the job descriptions act as literacy sponsors?

- What do job ads tell us about literacy expectations, needs, and requirements in the oilfield?

- What do job ads tell us about mentorship/teaching roles of old-timers?

- What do the job ads tell us about the role of technology and digital literacy requirements? 
In order to answer these questions, I have broken this chapter into four sections. The first section provides background on the Eagle Ford Shale and the cultural and economic shifts driving the literacy and competency expectations listed in the job advertisements. Section II provides a brief overview of the methodology. Section III is a breakdown and analysis of four major areas of literacy requirements communicated in the job advertisements: communication abilities, including reading and writing; work-related literacy events and artifacts; academic and non-academic education, training, and mentoring; and digital literacies and technology. The final section is the conclusion and implication. The findings from this chapter are significant to the industry's reliance on labor market intermediaries for hiring and training purposes, which is the focus of Chapter 4.

In the next section I will provide a brief historical context for the culture shift in the oil and gas industry since the discovery of the Eagle Ford Shale in 2008. The history of the region and its dependence on the oil and gas industry is an essential foundation for understanding the workers' changing relationship to literacy and technology.

\section{Section I: The Eagle Ford Shale and the Great Crew Change}

In 2008, Petrohawk Energy was drilling for gas in South Texas's La Salle county between Laredo and San Antonio when they discovered what would be known as the Eagle Ford Shale play. The 50-mile wide play, or shale field, stretched 400 miles from Laredo on the Mexican border to Central Texas just northeast of Austin. Covering over 23 counties, the Eagle Ford was arguably the most significant oil and gas discovery in the United States since Prudhoe Bay, Alaska, in 1968 (Dukes, 2014). By 2011, the number of oil and natural gas wells had more than doubled since the discovery. In 2012, the Eagle 
Ford had an impact of over $\$ 60$ million on the South Texas economy, including the creation of more than 116,000 new jobs, most of which were due to a newer technique, hydraulic fracturing. In 2013, more than $\$ 30$ million had been spent on developing the Eagle Ford Shale play (Dukes, 2014).

Like most oil and gas booms, the discovery of the Eagle Ford Shale signaled the need for more engineers, geologists, as well as rig and service workers. However, this boom was different for two major reasons for this difference. First, with the new hydraulic fracturing market came the need for a new, more technologically advanced workforce as the industry demanded a significant knowledge of technology, engineering, safety, and communications. This meant hiring of more tech savvy individuals who knew how to navigate the new, advanced programming languages required by hydraulic fracturing engineers and related changes to oil production methods. It also meant hiring workers who knew how to navigate a variety of literacy tools and artifacts, such as technical manuals, digitized reporting systems, and professional communication via email.

The shifts in technology and literacy expectations were complicated by a second colossal challenge - the generational shift in the industry called The Great Crew Change. The Great Crew Change is the anticipated retirement of 50 percent of the oil and gas industry between 2012 and 2022. Most of these workers who are set to retire came into the industry during the boom in the 1970 s when the industry created 800,000 jobs. However, in 1982, the industry hit a massive downturn, resulting in the loss of 500,000 of these jobs and 25 years of industry stagnation (Roach, 2015). Those who came in in the 1970s and made it through the massive job cuts in 1982 are now set to retire. Due to the 
economic downturn and between 1982 and 2008 there is a major gap between the skill and education levels of retiring workers and the new workers coming in. The industry's sluggish 25 years not only killed hiring, but also turned potential petroleum engineers towards other industries, such as the internet technology sector. Industry experts argue that since there was such a huge gap between the last bust and current boom there are not enough educated workers to fill the industry jobs left empty by retirees. Experts also assert that older employees have "nobody in the mid-level (35-50 years old) to pass their knowledge to," and that younger employees are unfortunately, too still inexperienced for the responsibility" (Roach, 2015, para. 12). Repercussions of this gap are a decline in local production, and more global importation, the industry claims. For Texas, a state that's economy relies substantially on the oil and gas market, a collapse would be catastrophic.

\section{Culture and Tech Shift Impact on Current Oilfield Workers}

The technology shift coupled with the massive retirement of upper level employees have had, and will have, a significant effect on the blue-collar sector of the industry and its relationship to literacy. First, as companies begin to pull in more academically educated workers to fill managerial positions, there are concerns surrounding the value of book learning versus hands-on learning. As discussed in Chapter 2, the old-timer's concerns regarding the newcomer's lack of hands-on experience has created rifts in the team dynamics on the rigs, as well as concerns surrounding efficiency. Ben's argument with the new, academically educated company man about the best way to facilitate a potentially dangerous procedure related to coiled tubing is such an illustration. Joseph's experience with rig math is another example. As Joseph noted in Chapter 2, 
workers coming into wireline from universities with no-hands on experience tend to gravitate toward mathematical models learned in books, which, he said, take longer and are more complex. He argues his rig math, which was passed on from his father, took less time, and, while it might not be perfect, was close. For Ben and Joseph, these examples of how different technologies, whether they be old-school techniques or academiclearning models, can mediate literacy practices. The worth placed on the technology by the industry correlates to its value in learning and work processes. How this value is communicated is why an analysis of job advertisements, which act as windows to the industry's knowledge, skills, and abilities requirements, is valuable to the study of workplace literacy.

The culture and tech shifts have also put a significant amount of weight on the value of mentorship. As companies hire right out of university with little hands-on experience as they scramble to hire managers and engineers to replace retiring workers. Oilfield services giant, Schlumberger says the answer to the Great Crew Change would be partly answered by technology but also by "creative corporate practices that attract and retain talented new workers and optimize the potential of the workers already part of the company" (Black, 2008, para. 10). By "optimization" Schlumberger means mediation through mentorship.

While mentoring programs are now on the rise white-collar parts of the industry, such as engineering and geophysics, buy-in from workers in these areas has been slow. A 2006 survey by the Society of Petroleum Engineers' Young Professionals group found that mentoring was a "common practice" among only 37 percent of survey respondents at the largest companies profiled (more than 3,000 employees). These larger companies 
include rig and service companies like Schlumberger and Baker-Hughes. The survey also found that mentoring was not practiced at all by 46 percent of mid-sized companies and 44 percent of small companies (Saunders, 2011, para. 13-15). Granted, the survey was conducted in 2006, two years before the Eagle Ford Shale boom. However, it does show the significant need for mentorship in the industry before the boom, and the pervasiveness of such a need as the horizon of the Great Crew Change moves closer.

In order to get these new engineers and managers up to speed, the industry is trying to persuade old-timers to stay on longer or part-time in order to help mediate the generational shift. Workers on the brink of retirement are being asked to start mentoring new workers early. Chevron's Horizons initiative, a formal 5-year training program for recent graduates, is one such program. The program is led by professional trainers who provide technical courses and hands-on experiences to newly hired graduate (Saunders, 2011, para. 13). Another example is ConocoPhillips' Legends program, which brings back senior project managers from retirement to train younger hires (Saunders, 2011, para. 15). Both programs aim to take advantage of old-timer expertise by prompting them to share information and train new workers in competency requirements so they are up to speed with the foundations of their new positon before moving in and moving forward.

The mentorship problem is not isolated to white collar engineers and upper level managers. In fact, the issues is more complex at the blue-collar level of the industry. As the industry tries to get ahead of the Great Crew Change, companies are hiring and training graduates for positions that do not yet exist. Thus, these graduates are put into leadership positions on rigs to gain management experience to move into higher-level white collar jobs once they become available. As new engineers and company men are 
hired to work on rigs with drilling and service crews, the lack of hands-on experience coupled with little mentorship creates tensions for the existing crew members. New engineers and company men are tasked to work with or manage rig crews, which complicates the generational challenges with tensions related to class difference. As Manuel notes in Chapter 2, he and his crew are expected to mentor and train these new bosses, even though it is not part of their job description. For a blue-collar worker like Manuel who has been in a position for several years, has the skillset to work in a managerial position, but cannot be elevated due to lack of an academic degree, being asked to train a less-experienced superior is frustrating. Investigating mentorship requirements as they are communicated through job advertisements will provide another context for how the industry is mediating learning and literacy practices of its old-timers and newcomers.

The Great Crew Change coupled with shifts in oilfield culture and technology have created a complex issue for the industry. On one hand, the industry is forced to replace a vast number of retirees with years of hands-on experience with a new generation of workers with little-to-no hands on experience. On the other hand, the boom and bust culture of the industry has made it difficult for the industry to find workers with a substantial amount of hands-on experience and a significant knowledge of the new technology needed to succeed in today's oil and gas industry. Thus, the industry is forced to hire engineers and upper level managers and company men with a working knowledge of technology, but little hands-on experience. These knowledge gaps, coupled with class and culture differences create the tensions the workers describe in Chapter 2, and are the impetus for the analyses performed in this chapter. 
In the following sections I analyze these shifts in literacy expectations as they are reported in job advertisements for blue-collar rig and service positions. The purpose is to consider how the industry is communicating literacy and competency expectations, mentorship needs, and related learning requirements to potential workers.

\section{Section II: Job Advertisements as Evidence of Literacy Sponsorship: Methodology}

Job advertisements are a genre that mediates communication between oilfield and the public. By public I mean those outside the communities practice that make up the industry. These include potential employees. Job advertisements are also ways, as Brandt (2001) says, to see what literacies and competencies are being sponsored and in what ways they are being sponsored. It is this demand that drives how and what type of education is valued and what is demanded of others.

Job advertisements for oil and gas companies are, for the most part, created by two entities: The human resources department, or, if they are smaller companies, then they might be written by the managers or owners themselves. The content of the advertisements, which is driven by Human Resources policies, is required to communicate certain factors about the position. This may include job title, salary, and work hours, as well as knowledge, skills, and abilities. Job advertisements are oftentimes posted on company websites, social media, or distributed via local media, such as newspapers and television networks. Companies also have the option to post these jobs to industry recruitment websites such as like Rigzone.com and Fuelfix.com. In order to post job advertisements, the company must be a member of the website, just as job seekers must be members to list their resumes. Once a company submits a job description, a Rigzone account representative will review it and recommend any changes that need to 
be made. Once the position is listed, all job seekers whose skills and abilities match that of the new position will be sent an email alerting them of a potential match and suggesting they apply. Rigzone members can apply with "one click," meaning all they should do is hit the apply button and their resume will be sent to the employer in application for the job.

The overall goal of job advertisements is to attract and persuade the most qualified workers to apply for the jobs being posted. Companies want people who fit the qualifications on the job descriptions and can provide high return on investment (Copeland, 1997; Goetsch, 2008; Zhu, 2008). Ads for oil and gas workers are no different. The audience for oil and gas job advertisements are job seekers in all parts of the oil and gas industry, from blue collar upstream workers to white collar geologists and engineers. Therefore, those reading the job descriptions must be able to interpret what the companies needs are and know if they are a match for it. If we look at oil and gas job ads through the lens of literacy sponsorship, they are tools the oil and gas companies use to referee literacy expectations between companies and the public. Meaning, they need to provide a clear indication to the reader what the company is looking for in terms of soft and hard skills, as well as education, albeit hands on, academic, or a combination thereof. If this communication does not occur, then misconceptions and animosity are created, resulting in the silencing of potentially strong candidates for positions.

While there is no substantive research on job advertisements as literacy sponsors specifically, job advertisements content analysis has been in used in information technology studies to determine qualification shifts (Goetsch, 2008; Zhu, 2008), and evaluation criteria for librarians (Choi \& Rasmussen, 2009; Hoffman 2017; Kim et al., 
2013; Reeves \& Hahn, 2010; Wise et al., 2011) and serials catalogers (Copeland, 1997).

Other rhetorical analyses framed academic job advertisements as a type of marketing tool aimed at community college faculty hopefuls (Winter, 2009), while others analyzed ads for gendered language (Gaucher, Friesen, \& Kay, 2011). In the oilfield specifically, research has been conducted on the impact of oil giant Shell advertising methodologies as it shifted from a local to global approach (Verity, 2005). However, the Shell analysis focused on strategic planning concepts for marketing consumer projects, not jobs.

In researching workplace literacy expectations in the upstream sector of the oil and gas industry, I decided to focus on job advertisements as the genre communicates literacy needs in a variety of positions. I looked at 55 job ads in a variety of rig and service positions open in Fall 2013. I chose this time frame as it was the height of the oil boom in South Texas, which created a wealth of upstream and midstream positions.

These job ads were chosen from a variety of online and print sources. Most online ads came from Rigzone.com, Indeed.com, or local oil and gas news and jobs site EagleFordShaleJobs.com. I chose these websites because they had the most job ads for oil and gas upstream jobs in the Eagle Ford Shale region, and were repeatedly labeled as the foremost sites for jobs by people in the industry with whom I interviewed. Print job advertisements came from the Corpus Christi Caller-Times and the Beeville Picayune, both of which serve people of the counties within and adjacent to the Eagle Ford Shale. All ads listed the name of the employer.

The ads were chosen as they represented a variety of positions in rig and service work. They included drilling rig crew members, such as drillers, motorhands, derrickmen, and floorhands. Service crew positions included pump technicians, well-test technicians, 
workover rig crew members and crew leaders, safety attendants, equipment operators, machinists, rig mechanics and electricians. Other service jobs that required indirect work with the rig included CDL drivers and parts and service sales representatives. All jobs are from rig and service companies within the Eagle Ford Shale region, and all jobs are considered part of the upstream, blue-collar segment of the industry.

When coding the job ads, I asked several questions to determine how literacy was defined, valued, and articulated. For example, was literacy categorized as a requirement, or a preference? Was literacy considered a competency? Was it listed at all? For purposes of this research, mentions of "certifications and training" were counted as literacy events when they were required prior to employment. These were also considered literacy events as opposed to strictly competency-building. This was determined since, 1.) certifications and training usually require the acquisition of language in addition to new skills, and 2.) require reading and writing on forms as an acknowledgment of completion and/or assessment. On-the-job training, if listed in the job advertisement as such, is categorized separately. For sake of clarity, most job advertisements are cited in the text using signal phrasing as opposed to formal American Psychological Association (APA) parenthetical conventions. They are, however, cited formally on the References page.

\section{Section III: Job Advertisement Results and Analysis}

There were four (4) distinct areas of literacy expectations throughout the job ads: Communication abilities, including reading and writing; work-related literacy events and artifacts; academic and non-academic education, training, and mentoring; and digital literacies and technology. In the following sections I describe the results, explain how 
they are examples of the industry sponsoring literacy, and highlight connections between literacy expectations and the culture shift in the industry.

\section{Communication, Reading, and Writing}

Job ads described reading and writing in terms of viability, usefulness, and interpretation. Several ads articulated the need for successful applicants to have general reading and writing abilities that were deemed "effective," and show a level of understanding and interpreting the content of their jobs to their colleagues. Two requirements stood out in terms of literacy - the need for communication skills, both oral and written, and the ability to read and write English. Most rig and service position requirements generalized communication abilities as "written and oral" communication skills. These written and oral skills were required to be "effective," (Sidewinder's Drilling Rig Mechanic), “good” (CETCO’s Well Test Specialist; Leam Drilling’s MWD Field Engineer), and "proficient" (Weatherford's Thru Tubing Sales Representative). It is unclear how these companies define each of communication benchmark as there is no rubric or scale included as part of the advertisements.

Several rig and service positions specifically stated the need for potential employees to understand English. All positions listed by Nabors, an international service company specializing in wireline and coil tubing, required applicants to have a working knowledge of the English language, both orally and written. Nabors' job descriptions for Field Service Technician, Workover Rig Crew Member and Crew Chief, as well as Vacuum Truck Driver were all required to have the "ability to read, write, and speak English to the extent that they are able to understand verbal and written instructions as well as give verbal and written instructions in English." Lewis Energy Services also 
stated one of its requirements for Driller was the "ability to read, write, and speak English” (para. 3).

To further articulate communication standards, some ads described how the company expected these literacy skills to be used, and sometimes at what level. For example, the Pump Technician job description for National Oilwell Varco Distribution Services said that in addition to "oral and written" skills, applicants must possess "knowledge of downhole and work over terms" (para. 3). This means that applicants, in addition to being able to read and write English, must possess a working knowledge of basic industry language. Therefore, not only does this weed out those who are not proficient in English, it can potentially negate applicants who are not familiar with oil and gas discourse.

Sometimes, ads generalized literacy expectations. In five different ads, the communication skills required are unclear in terms of being oral or written. However, it can be assumed that "communication" refers to a combination of literacy practices depending on the needs of the position. For examples, the Regional Account Manager is required to plan programming and obtain new clients and prepare proposals. This position is part of the sales service industry; thus, the requirements will be much different than a driller, derrickhand, or floorhand, whose work is mostly physical and hands on. The regional account manager is required to communicate with a variety of people throughout the industry, and much of the communication requires specific types of sales and marketing rhetoric and writing. Therefore, when the ad calls for "exceptional communication and organization skills," it is implied that the literacy practices needed 
require literacy, both written and oral considering the type of work the manager needs to do.

Expectations are different in more hands-on positions, such as Patterson's Motorhand and Lewis Energy’s Derrickman. Both require applicants who can communicate in ways that were "clear and effective" in terms of working within a team environment (Motorhand, para. 3; Derrickhand, para. 2). Considering both these positions require communicating with crews from a variety of distances and in very loud environments, "clear and effective" can be interpreted as physical signaling, such as hand and arm signals, in addition to spoken and written instruction. Total Safety's Safety Attendants need "clear communication abilities" as they are required to inform the safety attendant taking over the next shift of any "abnormalities" or concerns that need followup (para. 3). Communication in this case can be written or oral as informing during shift change usually requires both ways. Safety attendants can leave notes, write reports, or place a phone call to their relief depending on the circumstances or the procedures predicated by the company (para. 4).

Sponsorship evolves even further in some instances, to include the actions that are required utilizing certain literacies in accordance with specific competencies. For example, the job requirements of an Assistant Driller for Atwood Oceanics include being able to effectively "review all available well planning documentation available on the rig," as well as "perform all available well planning documentation available on the rig" (para. 2-3). Meaning, the assistant driller must be able to read and understanding planning documentation and be able to articulate it to his crew for them to perform all necessary tasks and responsibilities. The term "documentation" can also be interpreted as meaning 
technical manuals. However, only one job ad specifically states the need for workers to be able to read technical manuals. Total Safety's job ad for Safety Attendants listed the "ability to read and interpret documents such as safety rules, operating and maintenance instructions, \& procedure manuals" as a required skill for the position (para. 3). To be clear, other job ads listed the ability to follow instructions as a job requirement; however, none communicated the need to be able to read manuals pertaining to safety or any other form of instruction or procedure.

Overall, what can be discerned from communication, reading, and writing requirements articulated in the job ads is that they are linked to giving and following instructions. These results tell us that certain levels of English, whether it be spoken or written, is needed to perform positions in the industry in the Eagle Ford Shale region of Texas. Even though the region is largely Latino and Hispanic with vary degrees of Spanish language ability. This expectation is not necessarily just for service industry positions, but rig positions as well, including drillers. As the culture of the industry shifts to include more articulated standards of literacy, workers are going to be expected to be able to communicate in both written and spoken English for purposes of clearer more effective communication orally as well as written. More examples of written communications standards, such as form literacy are discussed in the next section.

\section{Work-Related Forms and Texts}

Also, prevalent in the job advertisements was the presence of work-related forms and texts. For a variety of reasons in both rig and service areas of the industry, workers are expected to log data, create reports, and fill out and submit work tickets. Technical 
manuals as part of this section because the focus is entirely on text creation as opposed to reading for information and learning and problem-solving.

\section{Log Books and Record Accuracy}

Log books, or tally books, are used by workers to write down notes, pressures, weights, time in-time-out, and different sorts of activities. Truck Drivers use record logs (See Appendix 1) to document pre- and post-trip weights and measures for reasons of safety and inventory. Field Service Technicians must be able to maintain personal truck logs for the same reasons. Measurement While Driving (MWD) Field Engineers and drillers need to be able to monitor as well as read and interpret well logs to made reparations. Motorhands use $\operatorname{logs}$ to record maintenance and repair activities to the rig. Log books are a combination of numeracy, graphing, and text, depending on what kind of $\log$ is being used and the purpose.

The ability to keep and maintain accurate records in the log books is a significant part of rig and service jobs. Drillers for Lewis Energy must be able to maintain inventory records of drilling mud and its components, as well as mud used (para. 3). Assistant Drillers for Atwood Oceanic must be able to assist the driller with this process, which includes "keeping accurate records of downhole dimensions and tool identification numbers" as well as "accurate records of fluid displacement when tubulars are run in/pulled out of the hole" (para. 3-4). Service crews, such as drilling rig mechanics and equipment operators, must be able to maintain wellsite records and logs required by their respective companies. Shop Hands, such as those working for Superior Energy Services must be able to "provide records for all equipment repairs" (para. 2). Work Orders and Tickets 
Rig and service workers depend on logs to know if maintenance or materials are needed. If said need arises, work orders or tickets need to be created and submitted. Work orders and tickets are forms that indicate some type of maintenance or repair to be done or that has been done on or for a drilling rig. In oil and gas, work orders and tickets assume a level of literacy that includes the ability to document and describe work needed or that has been completed. Nabors' Vacuum Truck Drivers are required to "maintain accurate work tickets based on the company's requirements and the work performed for the customer" (para. 2). Schedulers for Talisman Energy need to be able to "generate work requests/work orders for required follow ups of completed work orders" (para. 3). And Nabors' Field Service Technicians need to be able to "complete and electronically submit field tickets on-site" (para. 1). This tells us that in addition to comprehension, the worker needs to articulate in writing, albeit formally, informally, via form, email, or text work that has been completed or needs to be completed. Depending on the company, this may include the need to articulate reasons why. Reasoning skills are not articulated as part of the job requirements; however, they may be assumed as part of the "ability to communicate" part that nearly every job ad includes.

Two job advertisements referred specifically to form literacy. Wireline Equipment Operators for Lewis Energy Services are required to be able to "complete proper jobrelated paperwork and other records" (para. 2). Talisman Energy's Planner/Scheduler is required to "create standardized task lists for some repetitive equipment maintenance activities." (para. 2 ).

\section{$\underline{\text { Reports }}$}


Reports are generated after work or maintenance is completed. Several rig and service crew positions require some variation of writing and synthesizing information as part of the reporting process. The ability to write, prepare, and complete reports is a mainstay in many rig and service positions, which assumes a certain level of basic reading and writing skills, as well as an understanding of the genre or reports required by the industry. For example, applicants for Sidewinder Drilling's Drilling Rig Mechanic position must be able to "write reports on major equipment failure, modifications, equipment performance and maintenance history," as well as, "complete and hand over reports, logs, records and notes according to approved procedures and instructions" (para. 2-3 ). Lewis Energy Service's Derrickman "prepares mud reports, informs driller and mud engineer of unexplained changes in pumps as directed" (para. 2 ). Applicants for Sidewinder's Floorhand position are required to "report incidents, equipment failures, system failures, and abnormalities as per company procedures" (para. 2). It is unclear as to what "company procedures" means in terms of the format of reporting (verbal vs. written.) One position, that of maintenance Planner/Scheduler for Talisman Energy, listed several aspects of reporting as main job requirements, from obtaining information, to "completing and verifying reports for the Foreman" (par. 4 ). In addition, the position required a specific audience of rig foreman, who use the reports to make decisions at business meetings and show drilling trends.

Reporting also required the ability to ensure the reports for accuracy. Applicants for Lewis Energy Services' Driller position needed to prove they could "ensure accurate documentation of shift operations and compliance with environmental regulations" (para. 3 ), and Talisman Energy's Planner/Scheduler must be able to "maintain the integrity of 
all reporting sheets" (para. 2 ) In addition, the Assistant Driller for Atwood Oceanics need to be able to "assist the driller to confirm reporting on drill fluid conditions by assigned personnel" and "assist the driller to confirm reporting on drill fluid conditions by assigned personnel” (para. 3).

Certain job ads for higher level positions required the need to review the reports for errors in addition to completing and monitoring the data and report writing. Well Test Specialist for CETCO Oilfield Services requires applicants to have the "skills and abilities to be able to record and report accurate well test data," but also the ability to plan, coordinate, report on, and conduct the collection of samples" (para. 2 ). Similar requirements were found within job ads for Workover Rig Crew Chief and DOT Crew Chief positions, which call for applicants to "complete the Field Service Reports, document services performed, equipment used, billable consumables and compensable crew time" (para. 2; para 2, respectively). Orion Group's drilling supervisor position requires similar literacy skills, such as the ability to "monitor, document, and report all rig operations affecting the well" (para. 2).

What can be discerned from these job ads regarding specific workplace texts is that workers, both on the rig and service sides, need to be able to interpret and translate readings from different tools and machinery to create texts such as logs, work orders, and reports. This interpretation and translation requires a certain level of numeracy skills, as well as familiarity with the discourse. It is unclear from the job ads themselves if these literacy skills and related competencies are expected to be mastered before employment or during on-the-job training. The next section does shed some light on the training question. 


\section{Academic and Non-Academic Education and Training}

While many positions seem to require a certain level of training and certification prior to be hiring, there were several positions that listed on-the-job training as a requirement. This type of training varied in scope from operation-based to safety.

Overall, 13 job descriptions listed on-the-job training as a priority. Depending on the job, the worker had to have the willingness to be trained or the ability to mentor others. While one might expect workers in upper-level positions to be the ones doing the training, that was not the case in several job ads. From floorhands to crew chiefs, workers in all areas were expected to train and/or mentor others. Upper-level positions such as CETCO Oilfield Services Well Testing Specialist are expected to "obtain and present resources" on processes and safety (para. 2 ). Patterson's Motorhand is expected to provide instructions, train, and oversee floorhands during drilling (para. 2 ). Similar expectations were found for Sidewinder's Floorhand and Drilling Rig Mechanic, who are both expected to train and mentor new hands in their respective areas as they are assigned to the rig. Other positions are expected to participate in various training activities as part of their position, most of which are related to safety. Safety training program participation is mandatory for Sidewinder's Drilling Rig Mechanic. New Crew Workers and Crew Chiefs for Nabors are expected to participate in company-wide training on all rig operations and safety procedures, as are Mechanics for Key Energy and Vacuum Truck CDL Drivers for Nabors. Others, like Dayliter's Field Service Technician, is not only required to participate in but also prepare safety-related job meetings and trainings before each new task or project. For others, like Fastorq's Shop Hand, most that is required is the "ability to be trained quickly" (para. 1). 
There were a few other training-based requirements that took a different rhetorical approach. Lewis Energy took a type of modeling approach in their requirements for Equipment Operator II, who needs to be able to "promote safety and awareness" to the rest of the crew (para. 1). Instead of training, Leam Drilling Systems' MWD Field Engineer is required to participate in "performance improvement initiatives" as required by the company (para. 1). Performance Improvement Initiatives are programs are aimed at creating more efficient work and improving the bottom line of the company (EGYM Limited, 2013).

\section{Certifications and Higher Education}

While on-the-job training was predominant, there were quite a few positons that required certifications or higher education. Four positions required specific certifications. Nabors' Vacuum Truck Driver required a brake certifications, while Key Energy "highly preferred" their Mechanic II to have certifications from trade or technical school in maintenance or repair (para. 2). Orion Group's Drilling Supervisor required a technical/vocational certification, and a series of technical "courses" such as "advanced drilling industry technical courses," an audit course (para. 3). Atwood Oceanic required its Assistant Driller to have "valid well control and drilling technology certifications and other safety and training courses," which the ad said were required by the company and regulatory standards (para 3).

Another four positions listed a cross-hatch of certifications and higher education under a general requirement for employment. Lewis Energy Services' Rig Maintenance Electrician I requires a minimum one year certification from college, technical or vocational school, but it is unclear as to what the degree is required to be in. Lewis 
Energy Service's Frac Electronics Technical I requires an Associate's Degree in a related field, or a technical certification is required. Sidewinder Drilling requires and applicant to have "training and appropriate certifications" to be considered for the position of Drilling Rig Mechanic (para 2.).

Two ads cited a preference for a college degree (CETCO Oilfield Services' Well Test Specialist) or "some college" (Leam Drilling Systems' MWD Field Engineer). However, two positions also communicated that the hiring company would consider experience over formal education. Sidewinder's Drilling Rig Mechanic position description states that, "training and appropriate certifications along with a demonstrated ability in oral and written communications may be substituted for formal education" (para. ). Atwood Oceanics will consider a "work experience and demonstrated ability of oral and written communications may be subbed in lieu of formal education" when considering applicants for the Assistant Driller position (para. 2).

What do we know about literacy sponsorship from these requirements? The requirements surrounding education and training tell us that potential rig and service workers must have the soft skills to learn quickly. Certifications in certain areas are common in the industry as they do show that workers have the capacity to learn certain methods, processes and related discourse (Black, 2008). Considering the dangerous nature of many rig and service positions, these certifications can provide potential employers with a sense that workers do maintain a certain amount of maturity and work ethic, which are valued soft skills articulated in the Society of Petroleum Engineers, the industry's professional organization, as high importance in the industry. 
Also interesting was that some positions articulated that hands-on experience would be considered in lieu of formal education. In cases like that of Rig Mechanic and Assistant Driller, certifications and demonstrated experience when used together could substitute for "formal" education. While these are the only two mentions of training and education substitution in 50 analyzed job ads, it does show a shift in the cultural and educational expectations of two positions that have not historically required academic degrees (citation needed here). As several workers mentioned in Chapter 2, these shifts are becoming more and more evident as the industry discussion continues to involve higher education as a requirement for positions that have not historically required degrees.

\section{Digital Literacy and Technology}

As discussed in Chapter 2, the use of digital technology in the oil and gas industry has brought about quite a few shifts in how workers communicate with one another, create and send reports, and articulate needs and problems. Familiarity with digital technology and associated devices has also started becoming part of position descriptions. For example, computer and software literacy were requirements or preferences of nine (9) positions across various rig and service positions, but in varying levels of competency. Software competency in Microsoft Office was listed as an "essential skill" for Weatherford's Thru Tubing Sales Representative position, as well as Talisman Energy’s Planner/Scheduler. Sidewinder’s Drilling Rig Mechanic requires “strong computer skills” (para. 3), while Leam Drilling Systems required its MWD Field Engineer position to have a "technical aptitude" and "proven competency in computer software" (para. 2). There were similar requirements for Customer Service 
Representative at National Oilwell Varco Distribution Services, which needed to "provide technical support" for the company and its clients (para. 3).

Other positions only required fundamental knowledge of computers. For example, Lewis Energy Services Electronics Technician I in Frac only needs "basic software knowledge" in tandem with computer hardware maintenance (para 2). Atwood Oceanic's Assistant Driller needs "basic computer skills" (para 2), as does CETCO’s Well Test Specialist. However, to be hired as a Field Service Technician, one must have "basic computer skills," but also be "proficient in using Apple products (i.e., iPhone and/or iPad)" (para. 2).

For a limited amount of information on technology needs, there is quite a bit we can discern regarding literacy sponsorship and the culture shift in the industry. First, several ads used language that communicated a background with technology. Words like "essential," "strong background," and "aptitude" infer significant use of technology on some scale as part of the job. On the other hand, positions also used the word "basic" to describe knowledge of certain software and tools. Considering the subjectivity of some of the language here, it can be unclear to the potential employee what is considered. For example, the Field Service Technician requires "basic computer skills," but must also be "proficient" in Apple products. This binary (proficient/basic) communicates different levels of knowledge between computers and Apple products, which can complicate or confuse potential applicants who consider computers and Apple products tools that do the same type of work.

\section{Conclusions and Implications}


Results of the job advertisement analysis was, for the most part, unsurprising in terms of literacy's connection to hard and soft skills expectations. Similar to what Scribner (1987) found in her study of dairy employees, the oilfield is "saturated" with literacy expectations at the implied level (p. 3). Meaning that even though some jobs may not list specific literacy expectations, the expectation that a worker can read, write, and communicate is considered common knowledge. First, literacy and competency requirements were communicated using industry specific language to describe the processes and tools needed for the position. In some cases, acronyms were used, which tells us there is a specific audience in mind for this position, and that there may be no room for alternative interpretation. Second, specific soft skills were integral for strong employee applicants. Soft skills include in the job ads were communication skills and the ability to take direction, learn, and speak and write English. Most of the soft skills are related to being able to take direction, speak clearly, and provide information to others regarding needs, orders, and repairs. Third, mentorship also factored into the requirements for about one-third of the jobs analyzed. As noted above, mentorship and training characteristics were important in lower level rig positions just as much as upperlevel rig positions, such as driller and well testing specialists to lower-level positions like floorhands.

Overall, the job advertisements communicated a significant need for literacy in oil and gas rig and service positions. Job ads tell us that literacy has specific roles mid-higher level jobs that require reporting, communication with other sectors, every day literacy practices. Job advertisements sponsor literacy by listing out what the industry/company wants. They say they list need specific literacies, such as computer and digital tech and 
procedural and policy-based language. This includes reading and writing in log books, collecting data, and writing and sending reports. Sometimes the job ads say what literacy and competencies the worker is expected to learn on the job. Sometimes it is what they are expected to already should have to do their job. Sometimes it is what level of literacy is expected. This could be high school, college, certifications, a 4-year. By preferred, it tells you what the industry is really looking for. Sometimes it might also say they will consider a certain amount of experience in lieu or education. Or vice versa.

Even as these job advertisements may, on the surface, seem to clearly articulate the literacy and competencies needed in these oilfield positions, there are hidden implications to these expectations. As I was working through and sorting the job advertisements, I thought back to Chapter 2 and Manuel's voice in my head telling me the story of his mentor driller who taught him a lot even though he was "illiterate." This driller, along with most the rig and service workers I interviewed for this project, did not use job advertisements as guides for jobs. They didn't need to. As discussed in Chapter 2, they all were connected to their jobs via networking, no formal application required. Thus, Manuel's mentor, like many other blue-collar rig and service workers who got their job through networking may have never had to fill out a formal application for their position; they never sent in a resume, or had to write a cover letter.

If this absence of job market literacy was the case, there is room to argue that that these workers did/do not have much experience with or understand how to navigate an online application process that required a specific process of writing and rhetoric. Resumes may not have language matches. Applications may be incomplete. Workers might not know how to effectively craft a resume as it is not a literacy practice or genre 
with which they are familiar. In the end, highly qualified workers might not even apply at all. While the results of the job ads analysis above provide much to consider in terms of literacy and competency expectations, the fact is that the act of formally applying for a job is an implied literacy practice that is not commonly considered. While job ads are mediators between companies and the public, is it more accurate to say that they are gatekeeping potential employees more than they are a matchmaking genre? In the next chapter, I unpack the role of the labor market intermediary as literacy sponsor in the oil and gas industry, which will address this question. 


\section{CHAPTER FOUR}

\section{LABOR MARKET INTERMEDIARIES AS LITERACY SPONSORS IN THE SOUTH TEXAS OILFIELD}

In Chapter 3, we learned that oil and gas workers are not sure how to apply to jobs online or they do not trust online applications and the technology involved. The industry's cultural-historical preference to face-to-face communication and networking also adds to these challenges negotiating online applications. Articulating work experiences and related literacy levels can compound these challenges with workforce and job application genres such as resumes, covers letters, and written references, as well as cultural and literacy-related challenges in negotiating online job advertisements. The use of labor market intermediaries, or LMIs, are one way the industry is working through these challenges.

The overall goal of an LMI is to match worker skill sets with employer needs. How they do this varies. Bonet, Cappelli, \& Hamori (2013) describes LMIs as "entities that stand between the individual worker and the organization that needs work done" (p. 1). For example, LMIs have the power to look at a job seeker's application and decide if they meet the requirements of an employer. The expectation is that the application, whether it be a form or a resume and cover letter will provide a concise summary of the person's qualifications as they relate to the job for which they are applying. However, if 
the submitted application does not display an adequate qualification match, the applicant will not go further in the hiring process. Bonet et al's (2013) description of an LMI is one of boundaries or walls, and defines LMIs function as gatekeepers just as much as matchmakers, if not more so. However, LMIs can fluctuate in terms of the strictness of their gatekeeping. Autor (2009) says the function of the LMI is to "mediate between individual workers and the organizations that need work done, shaping how workers are matched to organizations, how tasks are performed, and how conflicts are resolved" (p.9). Autor's description implies a matchmaking ideology that benefits the worker as well as the employer by providing assistance to both sides in shaping how they communicate their skills, abilities and needs, respectively. In other words, both employers and applicants are educated in terms of their rhetoric and advised in terms of revisions needed. Much like community college vocational programs and job training program, LMIs focus on the local level to assist their home communities. Pennell (2007) argues that LMIs "reflect, foster, and respond to actual and perceived shifts" in America's employment process, and have been doing so for decades. Educating and assisting local communities about these shifts and help prepare them to navigate these shifts is a significant part of LMI work, just as much as community college education and job center work. The acts of mediating and shaping implies the LMI have the abilities not only match and gate-keep, but also build bridges. This bridge-building as it is seen through the lens of literacy sponsorship is the main focal points of this chapter.

In this chapter I explore the types of LMIs that work with the oil and gas industry and potential workers in South Texas. The above descriptions paint the LMI's function as matchmaker between worker and employer. However, as Bonet et al (2013) and Autor 
(2009) point out, since their purpose is to set up boundaries and function as mediators, the LMI can be perceived as a gatekeeper for the industry. With Pennell (2007), we see the dual role of matchmaker and gatekeeper playing out at the local level. Thus, it is arguable that this dual role can influence their perception by the worker, who, as we have seen in Chapters 2 and 3, values trust within their communities of practice. The chapter is guided by the following research questions:

- How do LMIs goes about "brokering" workers they find suitable for the oil and gas industry? How is literacy implicitly and explicitly involved in the "brokering" process.

- How do LMIs mediate and/or mentor applicant literacy learning and utilization?

- What literacies and competencies are more valuable to the oil and gas companies? The LMIs? What drives that value?

- LMIs consider themselves "matchmakers" between the employers and the worker. How can they also be considered another form of gatekeeping?

In the following sections, I introduce labor market intermediaries in South Texas, explain how they work with employers as well as job applicants, and how the roles they play in strategizing job placement is illustrative of the value of certain literacies and competencies sponsored by the oil and gas industry. Throughout these sections, matchmaking and gatekeeping will also play an influential role in how LMIs ultimately sponsor literacy and competency.

\section{Two Types of Labor Market Intermediaries}

In South Texas, prominent LMIs placing workers in the oilfield rig and service positions include for-profits LK Jordan, Reliable Staffing, and the non-profit Texas 
Workforce Solutions. Most of this chapter will focus on Texas Workforce Solutions, as it is in the complex position of being a state agency operating as a labor market intermediary for public and private sector businesses. However, it is important to acknowledge and briefly overview for-profit labor market intermediaries as they provide much needed context for Texas Workforce Solutions' complex role in brokering literacy and competencies in the oil and gas industry.

Two of the main for-profit labor market intermediaries in South Texas are L.K Jordan and Reliable Staffing. A corporate labor market intermediary, LK Jordan performs a human resources function for their business clients, and focus mostly on executive-level hires. They also employ a self-proclaimed "aggressive" approach to recruiting qualified job seekers, and uses "creative sourcing strategies" to successfully place their recruits ("Welcome to LK Jordan," lkjordan.com). Reliable Staffing takes a more mechanical approach to recruiting by inviting employers to facilitate a type of purchase or rental of employees. Based in Texas and New York, this family-owned business claims to be "dedicated to matching employee to client, not just filling a position," and claims their care in this area correlates to a lower attrition for the staffing company ("Introduction to Services," LK Jordan). Contrary to LK Jordan's active and targeted recruitment strategies, Reliable Staffing requires the employer to facilitate the matchmaking process. For example, at the bottom of the Reliable Staffing homepage a yellow button that says, "Order Reliable Employees" is featured promptly in the center of the page, serving as the focal point. (See Appendices 2 and 3 for examples of this button). Employers then fill out the form, which asks them to describe the type of employee they want for a certain position. The term "order" is indicative of a buying and selling, a "brokering" so to speak 
of the employee, their literacies and competencies, by the staffing agency and the client company looking for workers.

There are two points regarding literacy that are important to point out about forprofit LMIs. First is literacy's role in the commodification of labor. The terminology of "ordering" used by the for-profit LMI to describe the action of hiring workers creates a perception of worker as commodity, a tool bought and sold for specific purpose. This viewpoint reinforces Brandt's argument that literacy sponsors respond to specific economic factors (Brandt, 2001; Brandt, 1995). In this case, the oil and gas companies are responding to the need for oil and gas production in new areas, which is the reason for the vast number of positions opening in South Texas almost overnight. Thus, to accommodate the mass hiring need, companies rely on a third-party hiring system, the LMI, both for-profit and non-profit, to fill a variety of positions quickly and effectively. The same argument lends itself to the disposability of these positions. Supply and demand drives what types of positions are valued at certain points in the production cycle. Thus, the workers, and their literacies and competencies are valued more or less at different times of the economic cycle of the industry. As Brandt (2005) suggests literacy may be considered a form of capital, and opportunities to create, utilize, and manage literacy can be "configured ... in rationales of production and profit-making" (p. 194). When workers are no longer needed due to economic factors that call for the slowdown of exploration or production sectors in the industry they are let go.

The second point about literacy is how it relates to the for-profit LMI's role of matchmaker versus gatekeeper. While these for-profit LMIs may describe themselves as matchmakers, they arguably function more as gatekeepers. Unlike a matchmaker, there is 
no actual mediation, explicit or implicit, occurring at the very first level of communication, the application. For example, if a match does not occur between job description and application automatically, the for-profit LMI simply keeps moving on until they find one. For example, if a company wants to hire a driller, then they need to use the job advertisement to communicate the job expectations needed for the position. Certain language and acronyms like "TWIC 10, ," $\mathrm{BOP}_{11}$," and "CDL12" are used to communicate industry-specific knowledge and certifications that are needed to qualify. There is limited discussion, questions, or clarifications of the job advertisement provided by the for-profit LMI to the applicant or employing company during the application process. Instead, there is an expectation that the employer, a.) knows how to effectively and correctly explain their needs in the job advertisements they write and submit to the labor market intermediary, and, b.) that job applicants know how to effectively and correctly fill out and/or create job application materials, such as forms, resumes, job letters, etc. Both the job advertisement and the job application are images, literacy artifacts, of the company's expectations and the applicant's knowledge, skills, and abilities required to meet those expectations. Essentially, there is an implied literacy expectation by the for-profit LMI and the companies that all applicants have the basic skill set to fill out an application in a way that explicitly communicates their skill set.

However, these implied literacy expectations of the applicant are problematic for two reasons. First, the assumption that applicants understand and are literate in labor genres such as applications, resumes, and job letters. Literacy is normalized here in terms

10 Transportation Worker Identification Credential

11 Blow-out Prevention

12 Commercial Driver's License 
of implied understanding of labor genres. In other words, the act of reading and writing as part of the application process is expected by the employer. This act of normalization renders the practice of literacy as invisible, or unconsidered by the employer as a possible roadblock for potential applicants who have varying levels of reading and writing abilities and access to sponsors. Since for-profit LMIs are tasked with matching workers with employers by coordinating job applications with job advertisements, the way an applicant navigates language, as well as reading and writing, is not necessarily considered. This situation of expectation versus reality also extends to genre familiarity. As the workers in Chapter 2 discussed, networking was the most utilized way of securing jobs. None of the workers filled out a formal application or created a resume. Situations like this, coupled with limited reading and writing ability further complicates the idea that all potential applicants can navigate text-heavy workforce genres like resumes and cover letters. Unfortunately, this can end in applicants who fit advertised positions in some areas may be overlooked as their inability to communicate their work experience is not taken into consideration by the for-profit LMI or the company hiring employees. These for-profit institutions simply broker workers, buying and selling the ones that work on paper and tossing aside the ones who don't.

While it might seem that the workers are the ones lacking in these skill sets, it is not always the case. This leads to the second problem with implied literacy - the employer's inability to communicate needs and expectations. Overall, the same issues surrounding the normalization of literacy can befall the employers. Since for-profit LMIs disseminate job advertisements as opposed to creating them, if the advertisements submitted are too vague, or use non-industry language or jargon, problems that directly 
involve literacy can affect how applicant applications are created or received. Like applicants, there is an assumption on the part of the for-profit LMI that the employer, whose cultural and economic capital extends to the ability to communicate needs effectively with the public. Again, we see issues of expectations versus reality arising in terms of literacy expectations. However, these challenges with language effectiveness on the part of the employer, especially if misleading, vague, or incorrect, can have greater implications for applicants and for the industry.

These missing areas of labor literacy and education described above are where non-profit labor market intermediaries find their niche. One such non-profit LMI is Texas Workforce Solutions. This non-profit LMI plays a significant educational role for potential oil and gas workers by not only matching candidates and employers, but also consulting with potential candidates to help make their application materials stronger in terms of articulating their literacies and competencies. In the next section, I will outline how this multi-branched, state-run organization works with employers and applicants alike to fill in the gaps surrounding job market literacy practices and genres.

\section{Texas Workforce Solutions of the Coastal Bend}

The Texas Workforce Solutions of the Coastal Bend (TWS)13 job recruitment center is tucked way inside a 3-story abandoned shopping mall in the center of Corpus Christi. The center covers a 12-county area in the Eagle Ford Shale, including Corpus

13 Texas Workforce Solutions is the recruitment and job search branch of the state agency the Texas Workforce Commission, or TWC. The TWC is the governing body of Texas Workforce Solutions (TWS), which is a statewide network of 28 workforce development boards, their contracted service providers, as well as community partners, that provide workforce development services and help skilled workers find jobs ("About Texas Workforce," TWS.org) 
Christi, Beatrice, and the hometowns of all the oilfield rig and service workers featured throughout the earlier chapters. It is one of the only businesses left in this once popular shopping destination for Corpus Christi residents and the surrounding counties. The center takes up about three stores worth of real estate, and it is the only reason, besides the dollar movie theatre, that people come to the mall anymore.

In 2013, the TWS Coastal Bend center is bustling. The center is ringed with computer-filled cubicles used by job seekers to browse the agency's job database, Work in Texas, for job listings. On this day in September most the cubicles are full. More job seekers are sitting on couches in the entryway filling out paperwork attached to clipboards. Depending on the seeker's needs, the paperwork could be for a variety of reasons. On this day, it's mostly intake forms asking for basic information to help a recruiter get acquainted with their particular needs. This is the norm for anyone new to Workforce, according to Stephanie Timms, regional associate director for TWS Coastal Bend. "We work with a very diverse group of individuals," she said. "We may have skilled professionals that come through our doors or come through Work In Texas, or we may have people who didn't complete even high school. They did not get through eighth grade, or something. We have to work to identify what fits best with them."

Today, Stephanie is running reports on oil and gas job advertisements current in the Work in Texas database. For TWS, best fit means matching the skill sets of job applicants to the needs of employers. Given the current industry boom in the Eagle Ford Shale region of Texas, oil and gas industry employers are looking for a multitude of competencies. Looking over the last 30 days of job postings across all job boards, not just Work in Texas, she notices the numbers for oil and gas are up 600 percent from 
September 2012. "It looks like first-line supervisors or production operators and workers 14 is the highest if we want to just talk about the number of postings that are available ... supervisor and operator level is what's most needed," Stephanie said. These manager positions include but are not limited to industrial engineers, and petroleum engineers. Operator level positions, which are semi-managerial include industrial and repair workers service industry, and industrial machinery mechanics. It's hard to discern which is most in need, though. "It gets kinda hairy to rank things since things change constantly," she said.

This constant shift in the oil and gas industry that Stephanie describes underlines the importance of TWS's mission to bridge the gap between employer and worker expectations. The way TWS Coastal Bend works in terms of employer relations is much like a middle man (Pennell), a type of third-party human resources department that contracts out to a variety of businesses and industries. John Gonzalez, director of Business Services for Texas Workforce Solutions Coastal Bend, works very closely with Stephanie and TWS Coastal Bend in terms of business relations and recruitment. Today, he's in and out of the office, running between meetings with employers and his recruitment staff. He stops in to talk with Stephanie for a bit about the current job ad numbers and subsequent applications coming in through WorkInTexas, the statewide job database TWS maintains for employers and job seekers. His focus today is on the increased number of employers in the database. "We have employer counts that are coming in on an annual basis that are increasing by 100 s of a percent," says John. "So,

14 Production operators and workers are anything from floorhand to driller, and may include service workers, such as those in wireline and CDL truck drivers. These workers work on the production, or upstream side of the industry. 
we recognize that there is a higher usage by employers that perhaps were not using it before." This information on the number of new employers using the database tells John that TWS Coastal Bend's recent approaches to marketing the full range of services that Texas Workforce Solutions as opposed to just the human resources aspect has had some effect. "Over the last 5-6 years under. . . we have seen a very practical approach to marketing the full scale of services that Workforce Solutions offers," he said. "Prior, it might have been a little bit more of this 'ask the unemployment office,' or 'that's a state office. We want more people to refer to us as the 'employment' office."

Re-inventing the identity of the Coastal Bend office is a multifaceted process that requires extensive communication with both employers and workers. Both employers and applicants must communicate their needs clearly and accurately, and, as John and Stephanie understand, this does not always happen. Therefore, their work is not only as matchmaker and/or gatekeeper, but sponsor of education and literacy, especially in terms of navigating labor market genres and soft skills development. It is also important to note that sponsorship is happening for the employer as well as the applicant, as we will see later in the chapter.

The following sections outline TWS Coastal Bend's process for assisting both employers and applicants in these areas. To frame the work the LMI does to match community workers to local oil and gas jobs, I begin with addressing the challenges of hiring for oil and gas industry jobs in South Texas.

\section{South Texas Oil and Gas Industry Hiring Challenges}

The main challenge to finding qualified workers for oil and gas industry jobs is the quantity and quality of skilled workers. According to John and Stephanie, there are 
several reasons why this problem exists in South Texas. The most significant is that employers are requiring workers who have are multi-dimensional in terms of skill and work ethic. Meaning, applicants must be able to present that they have the technical skills required for the job, as well as the work ethic to navigate the physical and intellectual demands of the positions. John says the reason for this is that employers are becoming pickier in who they hire. "We have gotten to the point in this economy here in South Texas and because of Eagle Ford Shale mostly," he says. Many of these are major outside foreign investors, and they have really raised the bar in terms of expectations."

One of these expectations is passing drug and background checks 15. Passing a drug test and background check will also negate applicants, even those who have a solid background in the industry. Stephanie ties passing drug and background checks to work ethic, which she defines as a soft skill. And, she says, it is one that is in high demand in the oil gas industry. "It is not a given that people have a work ethic. You cannot just assume it is there," she says. "So you have to seek that out. Just like you cannot take for granted that just because someone says they are drug free you can do a test and they are, because, they are not." John agrees with Stephanie, adding that TWS Coastal Bend must educate and communicate these requirements to applicants constantly as they are deal breakers. Literacy, in this case, are forms and tests that are used to rate and rank applicants by their choices and mistakes just as much as their accomplishments. In other words, employers, as well as the LMI, use literacy artifacts like drug tests as gatekeeping

15 Oilfield companies randomly drug test every month. Depending on the job, background checks can negate an applicant from employment due to anything from speeding tickets to DUI, DWI and domestic violence. CDL positions are notoriously difficult to fill in Texas due to the number of tickets you can get before your license and CDL are suspended (personal interview, John Gonzalez). 
mechanisms that control economic risk. "Employers are choosier today. And rightfully so," he says. "Regulations have gone up. Insurance requirements have gone up. You have to regulate risk as much as possible." John implies that there is a correlation between not passing background and drug tests and work ethic that makes employers feel applicants are not worth the risk not only because of insurance reasons, but because of return on investment. "Cost of turnover is huge, so they are not going to just burn and turn, because it costs them money," John says. "So, there are forces at play that you cannot just feed the animal with anybody and everybody. There has to be a little bit of strategy at play behind that now."

This strategy John alludes to is hiring outside the local. Hiring outside the local means going outside the Coastal Bend, and going outside of Texas 16, to find qualified workers. John says going outside the local community is not TWS Coastal Bend's preferred strategy, but it is where the state government is putting their energy in terms of finding skilled individuals to fit the needs of the shifts in the oil and gas industry. With a boom in place, investments that fit the need of the employer are prioritized. However, as an LMI that maintains their focus on the local communities, TWS Coastal Bend keeps their own marketing efforts as local as possible. "We want to take care of what we have first," John says.

16 In 2013, Texas Governor Rick Perry launched a campaign outside of Texas to bring more workers into the state to work in oil and gas. It was a nationwide campaign, and as a state office, TWC was forced to comply, even though it was really outside the mission and structure of the regional offices, like Workforce Coastal Bend. As the job ads were open to all, not just Texans, on WorkInTexas, out of state applicants were allowed, grew, and created a variety of challenges. 
The next section discusses how TWS Coastal Bend creates matchmaking opportunities between the employers and the local community.

\section{The LMI and the Employer}

John and Stephanie note three main areas of assistance TWS Coastal Bend provide for employers. The first is writing and revising job advertisements. The second is teaching employers how to use WorkInTexas, the TWS-run database of open jobs, for human resources purposes. Third is effectively marketing jobs to the local community in ways that showcase shifts in the industry socially as well as professionally. These three areas of assistance have one significant common thread, which is the navigation of literacy, language, and expectations of an industry that is undergoing cultural and economic shift.

\section{Assisting in Writing and Revising Job Advertisements}

Writing and revising job advertisements for employers is a standard offering from TWS Coastal Bend. As John mentioned earlier, the increase in the number of employers, both local and out-of-state, taking advantage of the oil and gas boom in South Texas has created challenges with filling positions. Some of these challenges stem from employers using regional slang terminology on job sites which is then used in job advertisements. The cultural difference in terminologies can be confusing for applicants and employers, alike, and may unnecessarily and unintentionally gate-keep. To complicate matters, these employers, may also be making the cultural transition from hiring via networking and word-of-mouth to the industry-standard, which is online, written job descriptions. This cultural transition from networking to online applications is not lost on local employers, either. Therefore, to alleviate these issues, John says TWS Coastal Bend recruiters need 
to mediate between the employer's needs and the language standardized by the industry in the region. "It's kind of black and white: we don't seek to alter what the employers want," he said. "We will make suggestions on what key words seem to be a better fit." To do this, John says that TWS Coastal Bend wants to understand the terminology from the employer's perspective for purposes of clarity. "One employer may use one description, and in the same industry another may use a different description, and they are going after the same candidate," he said. "And we will kind of help line that up a little bit based on what's in ONET."

The Occupational Information Network, or ONET, is a continuously updated database of job descriptions, including responsibilities (“About Us," ONET.org). An influential literacy sponsor, ONET is supported by the US Department of Labor/ Employment and Training Administration as a baseline for industry language. Employers and intermediaries like TWS Coastal Bend use ONET to create job ads, including language that describes the skills and competencies that are needed to perform the work required for the position. The occupation descriptions contain standard occupational titles that may not match the title the employer gives each job. They may also include terminology that is not regionally specific. For example, in American oilfield regions, the average 14-days on/14 days off shift of most rig workers is called a "hitch." However, in Canada, it is referred to as a "tour." Minor details like this can throw off applicants if used incorrectly in a region. Therefore, John's team relies on ONET as a benchmark. "At the end of the day, WorkInTexas is just looking at it from words," says John. "So, it is our role to help facilitate that employer's ability to get the best outcome in terms of best matches. So, you have the computer doing the first screening and the human element 
kicks in with our team doing the real application of whether it makes sense or not." ONET's influence makes it a solid example of a literacy sponsor as it influences local, regional, and national language use across a variety of contexts and economies, with the oilfield being just one of many examples.

\section{WorkInTexas as Human Resources}

When employers contact TWS Coastal Bend for assistance in finding workers they do so because of what John calls the "human element" factor. Meaning, says John, they know they will have face time with recruiters regarding their needs. "For example, an employer will say 'I would like to place an order' or place a job posting," he says. "We take that information and either load it up [in Work in Texas] ourselves or help the employer load it up." Granted, not all employers may have used WorkInTexas. They might not have had the time to try it or even know about it, John says. For this reason, TWS Coastal Bend will sometimes nudge employers to use the system if they seem like they'd be a good fit for the local community. "One of our [recruiters] may also go out and proactively seeks a relationship with an employer who grants us the opportunity to work with them," he says. However, the increasing number of employers coming into the system on an annual basis tells John that this relationship between employers and the system is working. "We have employer counts that are coming in on an annual basis that are increasing by 100 s of a percent."

While the influx of new employers is a symbol of growth, it also creates challenges for TWS as these new employers lack the knowledge of the TWS system and WorkInTexas. "We recognize that there is a higher usage by employers that perhaps were not using it before," he says. Some typical challenges that John sees these employers 
having with WorkInTexas are related to a lack of knowledge with the genre of online job advertisement. This includes negotiating the online forms used to create these job advertisements, as well as navigating the online WorkInTexas system to post the jobs. Posting the jobs requires setting up an account online in addition to uploading job advertisements and understanding where to find applications submitted in response to the advertisements. As these employers might be used to working with people face-to-face first rather than relying on a digitized system, TWS is tasked with educating the employer on the genre conventions of a system that lacks, what John refers to as the "human element." Meaning, for an employer who is used to networking as the main form of potential employee engagement, the culture and technological shift requires education on how to navigate these new literacies. These challenges are also compounded by regional terminologies as well as cultural shifts within communities and the industry. Thus, TWS is required to put more time and energy into employer training and communication that it has in the past.

Even though educating the employers on these new literacies and genres is time consuming, this is the type of work TWS Coastal Bend needs to do for employers to be very comfortable in utilizing the database. This ease of access is the key to filling positions, John says. "Perhaps for some of these business owners that are not your Halliburtons and not your Baker Hughes, but are smaller, they can actually use this as an HR application recruitment tool on their own," he says. Ultimately, the goal is the persuade employers to use WorkInTexas in a human resources capacity. "We are always working to help empower the employer to use WorkInTexas so that they can do it at 24/7 at their leisure vs. our limited scope of operations," says John. 
Empowerment in this situation is arguably literacy education. Once the employers become knowledgeable about the processes surrounding the conventions of writing the job advertisements as well as navigating the new technologies related to the online WorkInTexas system, they can then educate their own staff on how to use the system. "If we can help empower them by using WorkInTexas, then it will have a larger multiplier effect because hopefully they can train their HR department," John says. Outside of filling positions, this sustainable, localized process of workplace literacy education is TWS's major goal for the employer.

\section{Marketing Job Availability to the Local Community}

Marketing jobs to the local community consists of pointed outreach through various local entities, such as local community programs, organizations, local media outlets, and government offices, such as Housing Authority. This outreach consists of calling and emailing these local organizations to communicate what TWS can do in the local community. Most of the time this communication includes general information about TWS services, but it may also involve inviting the organization to partner on a project.

How this invitation is crafted depends on the type of partnership TWS sees as potentially valuable to the local community. Partnership projects include job fairs or information sessions hosted at the organization. For example, TWS partners with local Corpus Christi television station KIII Channel 3 as a sponsor of their "Hot Jobs" portion of the local news every Tuesday evening. This 30 -second segment is used to promote jobs that pay $\$ 12$ or more an hour throughout the 12 counties. This segment is uses as a way to highlight oilfield jobs as they usually pay well above the minimum. Stephanie 
says the utilization of local media, like KIII is relatively simple way to strengthen TWS's presence. "We want to make some of those jobs prominent. We want to make those jobs more visible," she said. "And of course, we want to drive people back to WorkInTexas, but we want to get those jobs out there." Overall, John adds, TWS focuses on the argument that there is a local connection to responsibility and accountability. "We are essentially trying to use the marketing and communications plan that is important to really creating credibility and really creating a value added from the employer's perspective because this is an employer driven program."

While local entities are the leading way of marketing jobs to the community, the use of social media is in its preliminary stages. As of 2013, TWS is just beginning their use of social media as a marketing tool. John says they are currently utilizing Facebook and LinkedIn, he anticipates that their usage will grow quickly. "Especially now that all these platforms are talking to one another," he says, "It is very easy to share information across the board. So, I anticipate this as being a very viable avenue for us." This mentality is important as the growth of social media as a marketing platform is important to keep employers interested and invested in TWS Coastal Bend and WorkInTexas. To keep them interested means keeping the local applicant pool interested. This means communicating with and creating buy-in for the local applicant pool needs is key.

To market to younger generations who are considering oil and gas careers, Stephanie says, utilizing social media campaigns is the underlying factor in TWS Coastal Bend's new marketing strategies. "Right now, we are just getting our little toes wet," said Stephanie. "One of the things we are doing with the Eagle Ford Shale Consortium and the grant funding that we received from Texas Workforce Commission specifically for Eagle 
Ford Shale is we've taken on a project to increase that visibility through social media." This project includes working with local colleges and university to attract interns who will grow the TWS Coastal Bend presence on social media over the course of the next year. If TWS Coastal Bend can show employers their new marketing strategies are working, Stephanie says, they are more likely to invest in TWS Coastal Bend and WorkInTexas. They are hopeful these strategies will pay off. "How that is all going to roll out, we are still waiting to see," says Stephanie. "But one of the outcomes we hope to get from it is a stronger presence [in the local community]."

The point of this section is that LMIs assist the employer with job ad creation and revision, function as human resources, and create marketing and outreach campaigns to attract potential workers to the advertised positions. In terms of literacy, what most interesting about these three areas is that they are all examples how LMIs craft literacy artifacts for the benefit of the employer. Crafting, in this sense, is a significant form of literacy sponsorship in that how and what is written is created, shaped, cut, and built upon explicitly and implicitly by TWS for the benefit of the employer. For example, TWS Coastal Bend can either write or revise job advertisement for the employer. However, if they find the job ad does not articulate needs to industry standards, such as official job titles, certification titles, then they use ONET to revise, or craft, new language that supports industry requirements. They are not, as John argues, changing the message the employer is trying to get across. As discussed previously, employers -- and old-timers alike-- display challenges to creating job ads that articulate industry standard language as well as accessible language for workers. Thus, it is arguable that the labor market intermediary is there to interpret and revise for the sake of both parties. However, in the 
end, the words that are used need to reflect what the industry says is "correct." What is discussed in a later section of this chapter is how the LMI helps the worker revise their application to fit the industry standard of this "correctness" through various forms of literacy education and mediation.

In addition to job ad revision, another valuable takeaway is how TWS Coastal Bend chooses to market jobs to establish connections locally. Utilizing emerging literacies such as social media as a sponsorship tool shows that the LMI, and by extension, the oil and gas industry, has a growing awareness of how new generations of workers - and potential applicants - communicate and share information. At the same time, TWS also utilizes older more established literacy tools, such as television (Hot Jobs segments), and local organizations (Housing Authority) to distribute information in a way that reaches those who are not connected through social media or who might not be aware of the TWS Coastal Bend presence on it. From old-timers to potential newcomers, TWS Coastal Bend is trying to reach as many potential applicants as they can for the employer. However, at the pace that social media changes and the finicky nature of its many audiences, TWS Coastal Bend will has to keep up. Hiring college-level interns from local educational institution Texas A\&M University - Corpus Christi who have knowledge of social media shifts and emerging platforms is one way they are trying to meet this challenge.

In the above sections I have laid out how TWS functions as a sponsor of literacy for the employers in the Coastal Bend area. However, while TWS is no doubt an authority in labor literacy genres, they, too, need training and support to achieve such cultural capital. One example of continued professional development need is with 
terminology. John says this is especially needed in the satellite offices that work with staffing that uses highly technical language, like the oilfield. John related a situation with the TWS office in Beatrice that works quite a bit with retail. With the boom in the oilfield, which has a significant economic presence in the same county as Beatrice, the office has seen a significant increase in workers looking for oilfield positions. Therefore, it is up to John and Stephanie's branch to train the Beatrice office staff to be the best resources for the community, starting with language education. "Our office really needs to work with [the Beatrice office] to really get that lingo down," said John. "So, these are the customers we are seeing. You are not talking to the employer. That match has to occur. They have to share information between themselves so that language is carried over." Once that language of the industry is learned, then the staff can ask more informed questions about worker and employer needs, said John. "I am sure that in the rural areas because they are so small that they have the ability to communicate with one another," he said. "Like, look, tell me what the employer needs, tell me what you go out there. And that is the people component about what our centers do."

\section{The LMI and the Worker}

While TWS may have internal and external challenges with helping employers and staff finding the best terminology for creating industry specific job materials, prospective workers face similar hurdles as they work to negotiate unfamiliar genres and language during the application process. The matchmaking process between employer and potential employee requires the TWS to read applications, ask questions, compare applications to job ads, and be knowledgeable in a variety of technical languages so they can navigate different vocabularies. This section breaks down how TWS assists 
applicants through the application process, conversations with applicants, and educational resources provided for assistance with workplace and labor literacy tools and practices.

\section{Understanding the Application Process}

The most significant way TWS assist applicants is with understanding the application process. Sometimes applicants do not understand form literacy, such as job applications or the process involved with accessing, filling out, and submitting it. Therefore, part of what TWS offers job hunters is assistance with these labor literacy genre. Workforce specialists are available to sit down face-to-face and work through the application process with the potential worker. One of the leading reasons this assistance is required is the applicant's lack of technical literacy. "At our office in Beatrice, this is apparently an issue," said Stephanie regarding technical literacy. "There are some guys, floorhands, that are not very tech savvy, so we have staff there to assist them." This Stephanie says that TWS has the "unique ability" in that they are not just a website and a matching system, but that we have staff to back it up. "One on one to get them where they need to be with their matches," said Stephanie. "They will get them referred to the jobs where they need to be."

Helping applicants understand the application also requires recruiters to know when to offer extra assistance. Recruiter must be able to recognize situations where they should suggest TWS- sponsored programming or continued education options to applicants that will help make them more qualified for certain positions. However, if a recruiter is just looking at a paper application, those needs might be unclear for a variety of reasons. Therefore, John says, the recruiter rarely takes it at face value. "The profile is created by the job seeker," he says. "So, if they do not necessarily know how to fill it out 
completely, then that's going to be a challenge." At that point, the recruiter calls the applicant in for a face-to-face conversation.

\section{Conversations with the Applicant}

At TWS, if an application is submitted and no initial match is made, the recruiter will then go through the applicant's list of activities and experiences one-on-one with the applicant. John says the reason for this is to extract from the knowledge, skills, and abilities what is applicable in terms of employer need. "Because the computer does the matching in the first step, and there is no match . . . this is where the human element comes in and says, okay, let's talk. Help me understand your background.” This conversation allows the applicant to then add some keywords that might not have been used in their submitted application. John says the use of industry specific terminology is central in matching workers to jobs, and it is up to the recruiter to "shorten the gap" between employer and applicant in terms of industry-specific language. "It's at that point where you start identifying where the nuggets of gold are from them," said John.

At the same time TWS is assisting the applicant, they are also considering the employer's perspective. "It's our responsibility as well to not fluff it up so much so that when [the employer] gets that individual that there really isn't any substance there," John says. “The applicant, he might have been, 'yeah, I had that experience,' but we need to be able to, as we are talking through those conversations, extract enough information that will lead us to determine if it is a qualified referral or not." For example, an applicant applying for a gas truck driving position may have a TWIC card and CDL, both of which is a requirement for many oilfield rig and services positions, including shipping oil and gas. However, the bigger question is if they also have two years of driving experience 
with that commercial driver's license (CDL). This experience is fundamental because two years' experience is minimum to get on with certain employers' insurance. These are examples of some key questions that would be asked by that the employer, and the applicant will have a heads up. This directive approach to questioning allows the recruiter to clarify vague areas of the application, as well as pushing the applicant to unpack their skillset a little more. This skillset includes literacy practices, such as certifications and credentialing, which is key for securing TWIC and CDL licenses. However, even with licensing, an additional roadblock is encountered if a worker does not have the correct amount of experience. Why the applicant decided to provide the amount and kind of information they did is not the point. What is more important here is if they could understand the kind of information that was needed and how to communicate that information for a specific audience. The role of TWS is to make sure they reach that audience.

Ultimately, John says, the combination of conversation with screening questions supplied by the employer provides a filter TWS can use in the matchmaking process. "When you put that element to it, that conversation, and start really screening as to what [the employers] require, that gives us another filter, if you will." What filters out might fit what the employer needs, or it might point towards the necessity of more training and development. If the latter is the case, TWS has a variety of options ready to suggest to the applicant.

\section{Career Readiness Resources and Educational Opportunities}

After going over an application and having a conversation with an applicant, TWS recruiters may conclude that more education is needed to fulfill certain job 
requirements. Most of the time, Stephanie says, these requirements are related to soft skills needed for the position. "Employers may not even care about their education, they just want you to be able to speak to people right. There are certain things you can't do," she said. "The things that we assume are taught in the home, there are some people who just never learn that. And so the staff that meets with them, they help others see, say, you know what need a little more intensive service rather than just doing the job search on the computer." Stephanie is talking about careers in a broad sense here, not just oilfield positions. To bridge this soft skills gap, TWS partnered with local community college Del Mar College to create a "career ready" training program related to soft skill development. "Maybe we need to get you some assistance, or get you into the classes, whatever you need to make you successful," she said. "There are natural handoffs from the people up here to the program, the people in the back who are behind the cubicles who have caseloads, and all that. And we use those specialized programs to help a universal group of people and customers."

The curriculum for these specialized career readiness programs is developed inhouse and is credentialed by Del Mar College. The four-day classis offered weekly. Stephanie says about 1,400 people have graduated from this soft skills course with a "Career Ready" certification from Del Mar College. John says this type of certification gets the worker started with a transcript of their learning and skills sets and is oftentimes the beginning of a relationship with academic learning. "If they never had exposure to higher education, this may be the impetus for them to say, you know what, I got a certificate from there," he said. "Maybe I can go get a traditional/additional education." 
Another resource offered through TWS is programming for youth, adult, and dislocated workers. The boom and bust culture of the oilfield oftentimes results in layoffs, and this type or programming helps workers with job skills and literacies needed to find jobs in the interim or switch fields altogether. "With the Workforce Investment Act17, we have an adult, dislocated worker, and youth program and we use the funding from there, part of that funding, to assist with training," says Stephanie. Eligibility for the adult and youth program is based on low income status. "Through the assessment phase we see where they are at," said Stephanie. "And if a CDL is something they want to go forward with, we can put them into a training program at Del Mar College or one of our other training providers, to get that CDL." The dislocated workers program is not based on income, but on whether the worker has recently gone through a layoff. Dislocated workers can receive that same training benefit as those in the adult program, with added socio-economic incentives, said Stephanie. "On top of the training benefit, we also help them with any of the support services they might need," she said. "If they need childcare, if they need transportation expenses, work clothes... we can assist them with those once they get hired."

17 The Workforce Innovation and Opportunity Act (WIOA), which is what Stephanie is referring to, is designed to help Texas job seekers secure the employment, education, training and support services necessary to succeed in the labor market and to match employers with the skilled workers they need to compete in the global economy. It is related to the Workforce Investment Act of 1998, which was not renewed in the early 2000s. The WIOA is legislation overhauling and reauthorizing the provisions of the Workforce Investment Act. Congress passed WIOA by a wide bipartisan majority and the president signed it into law in 2014. 
Overall, the diversity of the South Texas region requires TWS recruiters be knowledgeable and effective in how they communicate with a range of people at varying levels of literacy and competency. "We may have skilled professionals that come through our doors or come through WorkInTexas, or we may have people who didn't complete even high school," says Stephanie. "They did not get through 8th grade or something." said Stephanie. "We have to work to identify what fits best with them. "

\section{Conclusion}

The purpose of this chapter was to showcase a unique literacy sponsor utilized by the oil and gas industry to fill a complex variety of positions in South Texas. Key takeaways related to literacy sponsorship include how a non-profit labor market intermediary, such as Texas Workforce Solutions, utilizes a multi-step educational, literacy-based process to match workers to jobs. The steps in the matchmaking process differ depending if TWS is working with an employer or applicant.

As mentioned by Stephanie and John, there is pressure by the community and the industry to make sure the employer is supported is deeply rooted in workforce literacy activities, especially those related to labor education. The reason behind this is multidimensional. The employer is the key to a worker's financial success, which directly benefits the economic success of the local community and region. Therefore, the first step is assisting is assessing whether the employer needs assistance with the invention, review, revision, or dissemination, or a combination thereof. Once that has been established, TWS can plan assistance procedures accordingly. In the case of oilfield jobs, the process has included educating the employers on industry-specific terminology, as needed. It also includes assistance for employers unfamiliar with technical literacy, such as the 
navigation of online job advertisement databases like WorkInTexas. This literacy and genre education make TWS a significant literacy sponsor of technical, organizational, and digital literacies and competencies. The second step of the process is marketing. While TWS works with employers to create clear, concise job advertisements, they also play the role of mediator between the employer and the public. Recruiters create relationships with organizations and media in the local areas to reach potential applicants. How they create these relationships is dependent upon how they communicate the benefits of a relationship between the organization and TWS for the main purpose of supporting the local community and the employer.

Turning to the applicant, TWS's process is imbedded in accurate communication of knowledge, skills, and abilities. Steps in this process are like those taken with the employer. Recruiters work with potential applicants at all stages of the writing process, from understanding the job advertisement, to creating an application or resume. The invention process also includes language use and transparency. Recruiters ask prescreening questions to make sure an applicant is articulating their experiences concisely to the audience while also using language that shows they have knowledge of the industry. As applicants might not be tech savvy, TWS will also assist with navigating the WorkInTexas system, teaching them how to upload their application and check its status. In addition to written and technical literacies, TWS also assists applicants with soft skills, such as how to talk to employers and co-workers. As Stephanie discusses, she sees quite a few applicants from South Texas who have challenges with these workplace literacy practices. Partnerships with local community organizations and educational institutions, 
including Del Mar College, have been created to support the educational and economic futures of its residents.

The literacy events created and supported by TWS are key elements in the brokering of literacy in South Texas. On one hand, they shuffle texts and language back and forth with the employer, providing feedback and ideas on how to best reach applicants. On the other hand, they do the same, but with potential employees, making sure they communicate their knowledge, skills, and abilities to the employers in language that engages with industry standards. Both processes of language movements are illustrations of moving language and literacy along trade routes until a match is found, a niche filled. 


\section{CHAPTER FIVE}

\section{CONCLUSIONS AND FUTURE RESEARCH}

The purpose of this dissertation was to investigate a variety of literacy sponsors that implicitly and explicitly effect the nature of oilfield work in the Eagle Ford Shale region of South Texas. First, I wanted to understand the perceptions of literacy and its uses in the upstream sector of the oilfield. How did the rig and service workers' experiences in school and at work shape their thoughts about reading and writing? What did they think about the state of literacy in the industry? What is the industry communicating to them about valued literacy practices, and why does that matter to the workers? Second, I wanted to delve into the workers' perceptions of literacy. What was at the root of their concerns about literacy's role in the industry's culture and technology shifts happening in 2013? To do this, I relied on the analysis of a significant sponsor of literacy in the oilfield - the job advertisement. Considering the workers' concerns, I was curious to know what these advertisements communicated to the potential worker about literacy expectations, artifacts, and requirements in the oilfield. Finally, I need to understand how the industry supported potential workers who might have skills needed for the industry but were unfamiliar with job advertisements and job applications. One way the industry responds to this problem is through the use of another literacy sponsor -the labor market intermediary, or LMI. How do they function as a literacy sponsor with 
the employer, as well as the potential applicant? How do these LMIs mediate and/or mentor applicant and employer literacy learning and practice?

As Manuel, Ben, Joseph, and Sarah illustrated in Chapter 2, they felt their experiences and culture were being transformed and challenged due to the technological and ideological shifts in the industry related to education and workplace expectations. When the workers were newcomers to their communities of practice, they were introduced to and became accustomed to apprenticeship and mentorship as the foundation of their learning. However, as the newcomers reached old-timer status, they found their culture of work and learning converging with a shift in the industry and forced to "realign" (Wenger) to the changing learning and literacy expectations of the industry. This process of realignment is where the tensions between hands-on learning and academic learning erupts, and is where this study finds its place in literacy studies research.

As old-timers found themselves teaching newcomers the ways of the rig, questions, as well as frustrations, arose as to whose job it was to mentor whom. The situation was further complicated by the fact that some of the newcomers were in positions of power above the old-timer. These tensions directly affect the perception of how literacy is used by both the newcomer and the old-timer. Is it a tool for work, or a weapon for power? The values and perceptions of literacy were the motivations for the analysis of job advertisements in Chapter 3. As literacy sponsors themselves, the advertisements provided information on industry specific language used to describe the processes and tools needed for the position. They also alerted the worker to mentorship and professionalization requirements, as well as soft skill need and technical 
competencies. On the surface, these job advertisements looked like practical roadmaps to the literacy and competency needs of the industry. However, considering the varying literacy abilities of potential workers, the advertisements functioned as gatekeepers to the industry just as much as they did matchmakers between jobs and workers.

While the job advertisements communicated a significant need for literacy in oil and gas rig and service positions, the fact is that the act of formally applying for a job is an implied literacy practice that is not commonly considered. The enormity of this realization was the impetus for Chapter 4's study of labor market intermediaries as literacy sponsor for both the employer who writes the job advertisements and the applicant who needs help responding to them. Key takeaways in this chapter related to literacy sponsorship include how a non-profit labor market intermediary, such as Texas Workforce Solutions (TWS), utilizes a multi-step educational, literacy-based process to match workers to jobs. The steps in the matchmaking process differ depending if TWS is working with an employer or applicant. The literacy events created and supported by TWS are key elements in the brokering, or buying and selling, of literacy in South Texas.

\section{Conclusions and Discussion}

The worker interviews, job advertisement analysis, and labor market intermediary case study revealed a complex relationship among literacy, the workers, and the industry. This relationship featured two commonalities surrounding perceptions of literacy: visibility and economic values.

One example of visibility and economic value is how the workers view technical manuals. In Chapter 2, Manuel says he never used tech manuals. His driller/mentor never used manuals, and was, as Manuel claims, “illiterate.” However, once it was time for 
Manuel to move into a driller position, he had to read technical manuals as part of the certification process. Taking this certification course was not considered superfluous as it had cultural and economic value for Manuel. It was a classroom full of roughnecks who wanted to move into driller positions. They spoke the same language, and valued the same practices and literacies. To Manuel, these particular classroom-based technical literacy practices was not considered something academic. It was not like Manuel claimed literacy was in high school and college, which was "teaching them the wrong thing." In that certification course literacy was viewed as invaluable.

Another example of the relationship between visibility and value is how and when the workers choose to "see" literacy in their work. For example, while the results of this analysis uncovered a substantial "saturation" (Scribner) of literacy requirements on the rig, the workers did not actually recognize these practices as examples of such. Instead, as Manuel argues in Chapter 2, reading and writing is not "necessary" to do a job well. However, as pointed out continually throughout the interviews in Chapter 2 and the job descriptions in Chapter 3, literacy is always there. It is in the form of manuals, logs, reports, and e-mail. It is the act of transcription and translation from reading meters and gauges and translating the information into words and texts for reports and logs. The worker does not consider these practices as literacy, as the term literacy brings to mind an academic version of reading and writing. Since these literacies are intertwined and/or mediated by numeracy, technology, and other tools that are used to transform or interact with texts, they can render literacy's relationship to the act or practice as invisible.

These literacy expectations that were implied or invisible, include workplace literacy practices such as reading and answering the job advertisement itself. The cultural 
and technological shifts in the upstream sector of the industry included investments in online application systems, requiring the navigation and negotiation of job market genres, such as online applications, resumes, and cover letters, which was literacy work oldtimers were not accustomed to. As I mentioned earlier, the job advertisements, which were meant to match workers to jobs, were actually acting as gatekeepers, potentially causing the sector to hemorrhage talent. Thus, the industry had to do something to bridge the gap between old-timers and the new tech and literacy requirements in the industry.

In order make these literacy practices and artifacts more visible for all upstream workers, the oil and gas industry utilizes the services of another literacy sponsor -- labor market intermediaries (LMIs) - to assist with understanding the purpose of these labor genres. LMIs consider themselves "matchmakers" between the employers and the worker, and for the most part this terminology is accurate. The LMI helped the job applicant uncover - or make visible - their skillsets by assisting them with the applications and resumes. They provided them with education opportunities for soft skills development, which includes various amounts of reading and writing as part of the curriculum. For the employers, the LMI assisted in crafting and revising job descriptions for the employer. In some cases, this process included assisting the employer with understanding "correct" versions of industry specific language. Overall, the responsibility of the LMI was to help make visible certain literacy processes that were historically or culturally invisible until now. The reasons for this invisibly vary among reasons from lack of experience to lack of necessity. However, culture and technology shift in the industry increased the value of these literacies, thus requiring their use even though a large segment of their industry might never have been exposed to them previously. 


\section{Reflections}

As I mentioned in Chapter 1, the aim of this dissertation is to fill gaps in literacy studies scholarship surrounding pre-employment literacy expectations in vocational job sectors. Much of the existing literacy studies scholarship situated in vocational workplaces focuses on the activities surrounding knowledge use and practice, especially as it relates to language difference, class, education, and culture shifts (Gee, Hull, Rose, Barton and Hamilton, New London Group, Brandt, Graff, Darrah). However, what peaked my interest was the processes by which workers find their way into a position in which these challenges and complications arise, hence the focus on recruitment practices. I do think I accomplished this goal as exemplified through the variety of primary sources used to show the multi-faceted way literacy sponsorship works in the oilfield to recruit and train workers in their positions.

What makes this dissertation successful is my personal relationship to the community studied, which afforded me ease of access to interviewees. Trust is a unifying factor throughout this project, including the methodology. Without the trust of the people I interviewed, I do not think the stories and opinions would have been as rich, considering this demographic's profound distrust of academia. My relationship with the community also made it easier to personally conduct the research required. In September 2013, I traveled to South Texas to conduct worker and LMI interviews, search for job advertisements, and conduct archival searches at three different universities oil and gas program curricula (the latter which was cut from the project due to time and space). I stayed with friends and family during that time, which made the trip economically feasible. 
Even though the overall project was successful, there were complications that arose during various points of the research process. First, there were issues of trust regarding the project. As I mentioned in the methods section of Chapter 1, some oilfield workers did not feel comfortable participating in the project due to a significant distrust of academia, even the ones with whom I had a personal friendship. Regardless of our relationship, they connected academia with conversations surrounding the evil nature of the oil and gas industry. Prior to every worker interview, apart from Sarah's, I was asked questions surrounding my "actual" writing intentions. I had to clarify several times that my research interests were not connected to environmental studies or climate change arguments. A version of trust also manifested in the Texas Workforce Solutions interview process. As discussed in the Chapter 1, there was a situation prior to the interview where John commented on the value of the research to TWS as much as mine. The inference here was that the work conducted in and after the interview should benefit their economic and social interests as much as it would benefit my education. In this case, I referred to the consent forms for clarification on the purpose of the study, as well as sections on compensation and risk.

My second complication concerned the worker interview questions. I created different lists of questions for the different types of interviewees depending on their position in the industry and their academic background. For examples, I had questions for rig and service workers with some higher education, with 4-year or 2-year degrees, with GEDs, and with no high school degree. The original intent of the questions was to gather information that I could link back to literacy and degree attainment, which was one of my original research questions. However, after the interviews had been conducted and I was 
coding for variations in literacy use, I realized that the questions had entrenched our discussions in perceptions of education and class issues more than literacy use specifically. Therefore, I did not get as much specific information about literacy practices, tools, events, as I originally wanted and anticipated.

Finally, if I had to recreate this study knowing what I know now, I would change two factors involving the interviews. First, as I mentioned, I would create more literacycentered questions. Second, I would have sent my interviews to a transcription service instead of doing them myself. While there are valid methodological arguments for the researcher to conduct the transcription work themselves, it took me months to get them completed due to my limited time outside of my full-time job. Working with a transcription service to complete this part of the process would have provided me time to read over the interview transcript as I listened to the interview, allowing me to focus more on the content than the act of transcribing. Plus, I would be able to correct any transcription mistakes during this time.

\section{Implications and Further Research}

As discussed throughout this dissertation, the workers see their culture being swallowed up by the pressure of schooling. They are bombarded with the industry's argument for a more degreed workforce. With this continual rhetoric in their industry that upward mobility is only afforded with a degree, the worker throw up their hands in frustration asking why school, and, even more importantly, how? Since academia is a reason for much of the discussion surrounding hierarchies, culture, and literacy expectations on the rig, the natural next step in this research is to consider how oil and gas programs at institutions of higher education function as literacy sponsors. Process 
technology and oil and gas technology programs at Laredo Community College, Coastal Bend Community College, and Del Mar College are rich sites for assessment. Research will begin with how oil and gas curriculum — primarily as it is described in course catalogs and syllabi - functions as a sponsor of literacy.

Another potential focus area is institutional marketing rhetoric. Since students make their decisions to apply for programs based, first, on marketing materials and, second, on the course descriptions, an analysis of brochure language, visual, placement in departments, in communities and online would extend arguments make in Chapter 4 regarding the visibility of literacy in certain domains. These materials will provide a particularly thought-provoking glimpse into the skills and literacies sponsored by the institutions, and, in-part, by the oil and gas industry. Guiding questions for this research include:

1. How do the curriculum and marketing materials from the community college programs draw in students to their oil and gas programs? Does this rhetoric target the current workforce, or is it more so aimed at potential students coming out of high school?

2. How are these programs funded, and what does this tell us about the privileged literacies and skills in the oil and gas industry, as well as the dual-sponsorship (industry and schools?) that creates the privilege?

3. What literacies and skills are sponsored in the curriculum descriptions, and how do they inform the blurring of the lines between academic and vocational skills? 
4. How do curricular and recruitment materials work for and against one another in terms of communicating literacies and skills necessary for working in the oil and gas industry?

The implications of this dissertation research to literacy studies have much to do with timing. Considering that there has not been critical literacy research conducted specifically in vocational workplaces since the early-mid 2000s with scholars like Gee, Hull, and Lankshear's The New Work Order and Mike Rose's The Mind at Work, now is a good time to rethink its value to the overall conversations surrounding sponsorship in this area. As discussions in higher education shift toward the value of community colleges and vocational education, more current research into trades-related literacy values and expectations is necessary. Lastly, an in-depth analysis of the funding, recruitment/marketing practices, and oil and gas program curriculum rooted in South Texas community college systems will extend the research in this dissertation by providing a clearer picture of the oil and gas skills, literacies, and outcomes in which the institutional partners are investing. 


\section{REFERENCES}

Atwood Oceanics. (2013, July 17). Assistant driller. Retrieved from https://www.rigzone.com/oil/jobs/postings/134072_Assistant_Driller_Achiever/

Autor, D.H. (2009). Studies of labor market intermediation: Introduction. In D. Autor (Ed.), Studies of labor market intermediation (pp. 1-26). Chicago, IL: University of Chicago Press.

Baclawski, P. (2017, August 7). The shale revolution and the great crew change. Retrieved October 13, 2019, from Rigzone.com website: https://www.rigzone.com/news/oil_gas/a/151302/the_shale_revolution_and_the_g reat_crew_change/.

Barton, D., \& Hamilton, M. (1998). Local literacies: Reading and writing in one community. London: Routledge.

Barton, D., Hamilton, M., \& Ivanič, R. (2000). Situated literacies: Reading and writing in context. London: Routledge.

Barton, P. E., \& Kirsch, I. S. (1990). Workplace competencies: The need to improve literacy and employment readiness. Washington, D.C.: Information Services, Office of Educational Research and Improvement, U.S. Dept. of Education.

Basu, K., Maddox, B., \& Robinson-Pant, A. (2009). Interdisciplinary approaches to literacy and development. London: Routledge. 
Bauman, Z. (2007). Consuming life. Cambridge: Polity Press.

Beder, H. (1999). The Outcomes and Impacts of Adult Literacy Education in the United States. [Report]. National Center for the Study of Adult Learning and Literacy.

Belfiore, M. E. (2004). Literacies, Compliance and Certification. In M. E. Belfiore \& InSites Research Group (Eds.), Reading work: Literacies in the new workplace (pp. 15-32). Mahwah, N.J: L. Erlbaum Associates.

Billett, S. (January 01, 2006). Constituting the workplace curriculum. Journal of Curriculum Studies, 38, 1, 31-48.

Billett, S. (November 01, 2002). Toward a Workplace Pedagogy: Guidance, Participation, and Engagement. Adult Education Quarterly, 53, 1, 27-43.

Black, G. (2008, September 9). Priming the pipeline: Upstream sector grooms next leaders. Retrieved October 13, 2019, from 3coast website: http://www.3coast.com/priming-the-pipeline-upstream-sector-grooms-nextgeneration-leaders/.

Boman, K. (March, 2015) Progress, Challenges Seen in Implementing Digital Oilfield Technology. Retrieved February 7, 2017, from http://www.rigzone.com/news/oil_gas/a/137566/progress_challenges_seen_in_im plementing_digital_oilfield_technology.

Bonet, R., Cappelli, P., \& Hamori, M. (2013). Labor market intermediaries and the new paradigm for human resources. The Academy of Management Annals, 7(1), 341392. https://doi.org/10.1080/19416520.2013.77421. 
Bourdieu, P. (1986). The forms of capital. In J. Richardson (ed.), Handbook of theory and research for the sociology of education (pp. 241-258). New York: Greenwood Press.

Bourdieu, P., \& Thompson, J. B. (1991). Language and symbolic power. Cambridge, Mass: Harvard University Press.

Brandt, D. (2001). Literacy in American lives. Cambridge: Cambridge University Press.

Brandt, D. (May 01, 1998). Sponsors of Literacy. College Composition and Communication, 49, 2, 165-85.

Brown, J. S., \& Duguid, P. (1991). Organizational learning and communities- of-practice: Toward a unified view of working, learning, and innovation. Organization Science, 2(1), 40-57.

Carnevale, A. P., \& Desrochers, D. M. (December 07, 2002). The Missing Middle: Aligning Education and the Knowledge Economy. Journal for Vocational Special Needs Education, 25, 1, 3-23.

Carpenter, C. (2018, October). New hires: Bridging the gap between academics and needs in the oil field. Retrieved October 13, 2019, from https://pubs.spe.org/en/jpt/jpt-article-detail/?art=4732.

Castellano, M. (1997), “It's Not Your Skills, It's the Test”: Gatekeepers for Women in Skilled Trades. In G. A. Hull (Ed). Changing work, changing workers: Critical perspectives on language, literacy, and skills. (189-213). Albany, NY: State University of New York Press.

CETCO Oilfield Specialist. (2013, August 5). Well Test Specialist. Retrieved from https://www.rigzone.com/oil/jobs/postings/376087_Well_Test_Specialist/. 
Cope, B. \& M. Kalantzis (Eds.), Multiliteracies: Literacy learning and the design for social futures. (pp. 43-68) London: Routledge.

Copeland, A. W. (1997). The demand for serials catalogers: An analysis of job advertisements, 1980-1995. The Serials Librarian, 32(1-2), 27-37. https://doi.org/10.1300/J123v32n01_03.

Darrah, C. (1997). Complicating the Concept of Skill Requirements: Scenes from a Workplace. In G. A. Hull (Ed). Changing work, changing workers: Critical perspectives on language, literacy, and skills. (249-272). Albany, NY: State University of New York Press.

Darrah, C. (1997). Complicating the Concept of Skill Requirements: Scenes from a Workplace. In G. A. Hull (Ed). Changing work, changing workers: Critical perspectives on language, literacy, and skills. (249-272). Albany, NY: State University of New York Press.

Dayliter Rentals, LLC. (2013, June 27). Field Service Technician. Retrieved from http://eaglefordshale.com/jobs/careers/field-service-technician/.

Defoe, T. (2004). Literacies at Work in a Culture of Documentation. In M. E. Belfiore \& In-Sites Research Group (Eds.), Reading Work: Literacies in the New Workplace (pp. 151-194). Mahwah, N.J: L. Erlbaum Associates.

Dewey, J. (1938). Experience and education. New York: Macmillan.

Duffy, J. (2007). Writing from these roots: Literacy in a Hmong-American community. Honolulu: University of Hawaii Press. 
Dukes, R. (2014, January). Eagle Ford Deal Value Leads the U.S. in 2013. Retrieved from: https://eaglefordshale.com/efs-news/news/eagle-ford-deal-value-leads-theu-s-in-2013?rq=2013.

Dunleavy, B. (2016, August 18). How to get your foot in the door with an entry-level oil industry job. Retrieved: https://energy.careercast.com/article/how-get-your-footdoor-entry-level-oil-industry-job.

Equipment Operator II. (2013, August 14). Retrieved from: https://uscareerslewisenergy.icims.com/jobs/7808/co-op-mechanic-i/job.

EYGM ltd. (2013). Performance improvement Positioning Canadian oil and gas companies for success from the inside out (pp. 1-24) [Consultant]. Canada.

Ferdman, B. M., Weber, R.-M., \& Ramirez, A. G. (1994). Literacy across languages and cultures. Albany: State University of New York Press.

Flower, L. (2008). Community Literacy and the Rhetoric of Public Engagement. Carbondale: Southern Illinois UP.

Freire, P. (1970). Pedagogy of the oppressed. New York: Herder and Herder.

Gaucher, D., Friesen, J., \& Kay, A. C. (2011). Evidence that gendered wording in job advertisements exists and sustains gender inequality. Journal of Personality and Social Psychology, 101(1), 109-128. https://doi.org/10.1037/a0022530.

Gee, J. P. (2004). Situated language and learning: A critique of traditional schooling. New York: Routledge.

Gee, J. P., Hull, G. A., \& Lankshear, C. (1996). The new work order: Behind the language of the new capitalism. Boulder, Colo: Westview Press. 
Gee, J.P. (1990). Social Linguistics and Literacies: Ideology in Discourses. London: Falmer.

Gerber, R., \& Lankshear, C. (2000). Training for a smart workforce. London: Routledge. Goetsch, L. A. (2008). Reinventing our work: New and emerging roles for academic librarians. Journal of Library Administration, 48(2), 157-172. doi:10.1080/01930820802231351.

Gowen, S.G. (1992). The Politics of Workplace Literacy: A Case Study. New York: Teachers College Press.

Grabill, J. T. (2001). Community literacy programs and the politics of change. Albany: State University of New York Press.

Graff, H. J. (1979). The literacy myth: Literacy and social structure in the nineteenthcentury city. New York: Academic Press.

Graff, H. J. (1987). The legacies of literacy: Continuities and contradictions in western culture and society. Bloomington: Indiana University Press.

Graff, H. J. (1995). Reflections on the History of Literacy: Overview, Critique, and Proposals. In Graff, H. (Ed). The Labyrinths of Literacy: Reflections on Literacy Past and Present. (pp. 3-31). Pittsburgh, Pa; U of Pittsburgh Press.

Grubb, W. N. (1996). Learning to work: The case for reintegrating job training and education. New York: Russell Sage Foundation.

Grubb, W.N. (1997). Dick and Jane at Work: The New Vocationalism and Occupational Literacy Programs. In G. A. Hull (Ed). Changing work, changing workers: Critical perspectives on language, literacy, and skills. (159-188). Albany, NY: State University of New York Press. 
Halbritter, B., \& Lindquist, J. (2012). Time, lives, and videotape: Operationalizing discovery in scenes of literacy sponsorship. 75(2), 171-198.

Handley, K., Sturdy, A., Fincham, R., \& Clark, T. (2006). Within and beyond communities of practice: Making sense of learning through participation, identity and practice*. Journal of Management Studies, 43(3), 641-653. https://doi.org/10.1111/j.1467-6486.2006.00605.x.

Hart-Landsberg, S., \& Reder, S. (1997) Teamwork and Literacy: Teaching and Learning at Hardy Industries. In G. A. Hull (Ed). Changing work, changing workers: Critical perspectives on language, literacy, and skills. (316-334). Albany, NY: State University of New York Press.

Hawisher, G. (2004). Becoming Literate in the Information Age: Cultural Ecologies and the Literacies of Technology. College Composition and Communication 55,4, 12 24.

Hawisher, G. \& Selfe, C. (1999). Global Literacies and the World Wide Web. New York: Routledge.

Hawisher, G. \& Selfe. (2005). Reflections on Computers and Composition Studies at the Century's End. In I. Snyder, M. Joyce (Eds). Page to Screen: Taking Literacy into the Electronic Era. (p. 3-19). London: Routledge.

Heath, S. B. (1983). Ways with words: Language, life, and work in communities and classrooms. Cambridge [Cambridgeshire]: Cambridge University Press.

Herzberg, B. (1994). Community Service and Critical Teaching. College Composition and Communication 45, 307-19. 
Herzfeld, M. (2004) The Body Impolitic: Artisans and Artifice in the Global Hierarchy of Value (Chicago, University of Chicago Press).

Hoadley, C. (2012). What is a community of practice and how can we support it? In D. H. Jonassen \& S. M. Land (Eds.), Theoretical foundations of learning environments (Second ed., pp. 287-300). New York: Routledge.

Hull, G. A. (1997). Hearing Other Voices: A Critical Assessment of Popular Views on Literacy and Work. In G. A. Hull (Ed). Changing work, changing workers: Critical perspectives on language, literacy, and skills. (3-42). Albany, NY: State University of New York Press.

Ivanic, R. (2009). Improving Learning in College: Rethinking Literacies across the Curriculum. London, New York; Routledge.

Jalbert, K., Willow, A., Casagrande, D., \& Paladino, S. (2017). ExtrACTION: Impacts, engagements, and alternative futures. Retrieved from http://public.eblib.com/choice/publicfullrecord.aspx?p=4865750.

Jones, V. (2017, August). What will happen to experienced oil, gas workers? Retrieved October 13, 2019, from https://www.rigzone.com/news/oil_gas/a/151424/ what_will_happen_to_experienced_oil_gas_workers/.

Jury, M. (1997) Widening the Narrowed Paths of Applied Communication: Thinking a Curriculum Big Enough for Students. In G. A. Hull (Ed). Changing work, changing workers: Critical perspectives on language, literacy, and skills. (214248). Albany, NY: State University of New York Press.

Kalman, J. \& Losey, K. (1997). Pedagogical Innovation in a Workplace Literacy Program: Theory and Practice. In G. A. Hull (Ed). Changing work, changing 
workers: Critical perspectives on language, literacy, and skills. (84-116). Albany, NY: State University of New York Press.

Keller, C.M., and Dixon Keller, J. (1999) Imagery in cultural tradition and innovation, Mind, Culture, and Activity: An International Journal, 6 (1), 3-32.

Key Energy. (2013, July). Mechanic II. Retrieved from: https://www.rigzone.com/oil/jobs/postings/401180_Mechanic_II/.

Kilisek, R. (2014, September 9). Data avalanche and the 'great crew change' in the oil and gas industry. Retrieved October 13, 2019, from Breaking Energy website: https://breakingenergy.com/2014/09/09/data-avalanche-and-the-great-crewchange-in-the-oil-and-gas-industry/.

Knobel, M., \& Lankshear, C. (2007). A new literacies sampler. New York: P. Lang. Kozol, J. (1985). Illiterate America. New York: Penguin.

Kress, G. (2000). Multimodality. In B. Cope \& M. Kalantzis (Eds.), Multiliteracies: Literacy learning and the design for social futures. (pp. 182-202) London: Routledge.

Lam, W.S.E. (2000). L2 Literacy and the Design of the Self: A Case Study of a Teenager Writing on the Internet. TESOL Quarterly 34,3, 457-82.

Lankshear, C., \& Knobel, M. (2003). New literacies: Changing knowledge and classroom learning. Buckingham [England: Open University Press.

Lave, J. (1991). Situating learning in communities of practice. In L. Resnick, J. Levine, and S. Teasley (Eds.), Perspectives on socially shared cognition (pages 63-82). Washington, DC: APA. 
Lave, J., \& Wenger, E. (1991). Situated learning: Legitimate peripheral participation. Cambridge [England: Cambridge University Press.

Lavis, J. (2018, April 12). Finding an entry-level oil field job. Retrieved October 7, 2019, from Drillers website: https://drillers.com/finding-an-entry-level-oil-field-job/.

Leam Drilling Systems, LLC. (2013, July 22). MWD Field Engineer. Retrieved from https://www.rigzone.com/oil/jobs/postings/2352312/MWD_Field_Engineer.asp.

Lenters, K. (2008). Programming Family Literacy: Tensions and Directions. Community Literacy Journal. 2,2, 3-22.

Leung, C. (2005). Convivial Communication: Recontextualizing Communicative Competence. International Journal of Applied Linguistics 15,2, 120-44.

Lewis Energy, LLC. (2013a, August 3). Electrician I. Retrieved from https://usacareerslewisenergy.icims.com/jobs/3265/electrician-i/job.

Lewis Energy, LLC. (2013b, August 14). Electronics Technician I. Retrieved from https://uscareers-lewisenergy.icims.com/jobs/3493/electronics-technician-i/job.

Lewis Energy, LLC. (2013c, August 14). Equipment Operator II. Retrieved from https://usacareers-lewisenergy.icims.com/jobs/equipment-operator-ii/job.

Lewis Energy, LLC. (2013a, August 14). Driller. Retrieved from https://uscareerslewisenergy.icims.com/jobs/3433/driller/job/.

Lewis Energy, LLC. (2013b, August 15). Derrickman. Retrieved from https://uscareerslewisenergy.icims.com/jobs/3144/derrickman/job/.

Lindquist, J., \& Seitz, D. (2009). The elements of literacy. New York: Longman. 
Luke, C. (2000) Cyber-Schooling and Technological Change. In B. Cope \& M. Kalantzis (Eds.), Multiliteracies: Literacy learning and the design for social futures. (pp. 69-91) London: Routledge.

Lund, L., \& McGuire, E. P. (1990). Literacy in the work force. New York, NY: Conference Board report.

Marchand, T. H. J. (September 01, 2008). Muscles, morals and mind: craft apprenticeship and the formation of person. British Journal of Educational Studies, 56, 3, 245 271.

Martin-Jones, M., \& Jones, K. (2000). Multilingual literacies: Reading and writing different worlds. Philadelphia: Jon Benjamins.

Matthews, C. M. (2018, July 10). Oil's new technology spells end of boom for roughnecks. Wall Street Journal. Retrieved from https://www.wsj.com/articles/oils-new-technology-spells-end-of-boom-forroughnecks-1531233085.

Merrifield, J. (1997). If Job Training is the Answer, what is the question? Research with Displaced Women Textile Workers. In G. A. Hull (Ed). Changing work, changing workers: Critical perspectives on language, literacy, and skills. (273-294).

Albany, NY: State University of New York Press.

Minyard, M. (2003). How to fix oil industry "brain drain": Change the industry, not the image. Oil and Gas Journal, 101(40), 20-22.

Mitchell, C., \& Weiler, K. (1991). Rewriting literacy: Culture and the discourse of the other. New York: Bergin \& Garvey. 
Moll, L. and Gonzalez, N. (1994). Lessons from Research with Language-Minority Children. Journal of Reading Behavior, 26, 439-456.

Nabors. (2013, August 3). Truck Driver Vacuum CDL A Only. Retrieved from https://www.rigzone.com/oil/jobs/postings/Truck_Driver_Vaccuum.asp

Nabors. (2014a, August 21). Crew Chief_-Experienced Workover Rig. Retrieved from https://www.rigzone.com/oil/jobs/postings/crew_chief_experienced.asp

Nabors. (2014b, August 28). Crew Worker-Experienced Workover Rig. Retrieved from https://www.rigzone.com/oil/jobs/postings/crew_worker_experienced.asp

Nabors. (2014c, September 1). DOT Crew Chief_Experienced Workover Rig-Victoria, TX. Retrieved from: https://www.rigzone.com/oil/jobs/postings/ crew_worker_experienced.asp.

National Oilwell Varco. (2013, July 23). Pump Technician. Retrieved from https://www.rigzone.com/oil/jobs/postings/401529/Pump_Technician.asp.

Niyazov, S. (2019, July 5). How the replacement of blue-collar jobs by AI will impact the economy. Retrieved October 13, 2019, from IoT For All website: https://www.iotforall.com/how-ai-replacing-blue-collar-jobs-impact-economy/ O’Connor, E. (2005) Embodied knowledge: the experience of meaning and the struggle towards proficiency in glassblowing, Ethnography 6 (2), 183-204.

Ogbu, J. (1988). Literacy and Schooling in Subordinate Cultures: The Case of Black Americans. In E. Kintgen, B. Kroll, M. Rose (Eds). Perspectives on Literacy. (pp 227-42). Carbondale: Southern Illinois UP.

Ohmann, R. (1985). Literacy, Technology, and Monopoly Capitalism. College English 47, 675-89. 
Orion Group. (2014, August 29). Drilling Supervisor. Retrieved from www.rigzone.com/jobs/postings/899272709/Drilling_supervisor.asp.

Orr, J. E. (1990). Sharing knowledge, celebrating identity: Community memory in a service culture. In D. Middleton \& D. Edwards (Eds.), Collective remembering (pp. 169-189). Newbury Park, CA: Sage Publications. University Press).

Pahl, K., \& Rowsell, J. (2010). Artifactual literacies: Every object tells a story. New York: Teachers College Press.

Pastor, M., Leete, L., Dresser, L., Benner, C., Bernhardt, A., Brownstein, B., \& Zimmermann, S. (2003, May). Economic opportunity in a volatile economy: Understanding the role of labor market intermediaries in two regions. Final research report to the Ford, Rockefeller, and Russell Sage foundations, New York, NY.

Patterson Drilling Company, LLC. (2013, June 30). Motorhand. Retrieved from www.rigzone.com/oil/jobs/postings/32454/Motorhand.asp.

Peck, W., Flower, L, and Higgins, L (1994). Community Literacy. College Composition and Communication 46, 2, 199-222.

Pennell, M. (February 01, 2007). "If Knowledge Is Power, You're about to Become Very Powerful": Literacy and Labor Market Intermediaries in Postindustrial America. College Composition and Communication, 58, 3, 345-384.

Pennell, M. (January 01, 2011). The Flattening of Literacy: Community Colleges and Skills Training. Community College Journal of Research and Practice, 35, 4, 312-329. 
Portisch, A. (2007) Kazakh Syrmaq-Production in Western Mongolia: Learning and Skill in a Domestic Craft Tradition (School of Oriental and African Studies, University of London. Unpublished $\mathrm{PhD}$ thesis).

RCW Energy Services, LLC. (2013, August 6). Regional account manager. Retrieved from: https://www.rigzone.com/oil/jobs/postings/403881/ Regional_Account_Manager/.

Roustabouts, oil and gas. (n.d.). Retrieved February 6, 2019, from https://www.onetonline.org/link/summary/47-5071.00

Sandlin, J. \& St. Clair, R. (2005). Volunteers in Adult Literacy Education. Review of Adult. In J. Comings, B. Garner, and C. Smith (Eds). Learning and Literacy (pp. 125-154). Mahwah, NJ: Lawrence Erlbaum.

Sandlin, J. A. (January 01, 2004). "It's All Up to You" How Welfare-to-Work Educational Programs Construct Workforce Success. Adult Education Quarterly, 54, 89-104.

Saunders, B. (2011, October 20). The Great Crew Change: "Honey, How Are We Going to Train All These Kids?" Retrieved https://www.rigzone.com/news/oil_gas/a/111627/the_great_crew_change_honey_ how_are_we_going_to_train_all_these_kids/.

Saunders, B. (2012a, March 14). Are we developing and retaining rig workers "well" enough? Retrieved October 13, 2019, from https://www.rigzone.com/news/oil_gas/a/115958/are_we_developing_and_retaini ng_rig_workers_well_enough/. 
Saunders, B. (2012b, April 18). The great crew change: Is too much textbook-only training risking safety? Retrieved October 13, 2019, from https://www.rigzone.com/news/oil_gas/a/116834/the_great_crew_change_is_too_ much_textbookonly_training_risking_safety/.

Schaffner, H. A., Van, H. C. E., \& John J. Heldrich Center for Workforce Development. (2003). A nation at work: The Heldrich guide to the American workforce. New Brunswick, NJ: Rutgers University Press.

Schultz, K. (1997). Discourse on Workplace Education: A Challenge to the New Orthodoxy. In G. A. Hull (Ed). Changing work, changing workers: Critical perspectives on language, literacy, and skills. (43-83). Albany, NY: State University of New York Press.

Schultz, K. (1997). Discourse on Workplace Education: A Challenge to the New Orthodoxy. In G. A. Hull (Ed). Changing work, changing workers: Critical perspectives on language, literacy, and skills. (43-83). Albany, NY: State University of New York Press.

Scribner, S. (1987). Literacy in the workplace. Information Update: A Quarterly Newsletter of the Literacy Assistance Center, 4(1), 3-5.

Selber, S. (2004). Multiliteracies for a Digital Age. Carbondale, IL: Southern Illinois UP.

Selfe, C., \& Hawisher, G., (2004). Literate Lives in the Information Age: Narratives of Literacy from the Unites States. Mahwah, NJ: Erlbaum. 
Sennett, R. (2008) The Craftsman (London, Allen Lane). SIMPSON, E. (2006)

Apprenticeship in Western India, Journal of the Royal Anthropological Institute, $12,151-171$.

Sidewinder Drilling. (2013, July). Floorhand. Retrieved from www.rigzone.com/jobs/postings/403258/floorhand.asp

Sidewinder Drilling. (2014, August 7). Drilling Rig Mechanic. Retrieved from https://www.rigzone.com/oil/jobs/postings/426523/Drilling_Rig_Mechanic.asp

Sowacki, B. (2016, July 11). “The Great Crew Change:” Lost generation of workers leaves few options for next oil boom. Retrieved from: https://www.dallasnews.com/business/2016/07/11/the-great-crew-change-lostgeneration-of-workers-leaves-few-options-for-next-oil-boom/

Street, B. V. (1984). Literacy in theory and practice. Cambridgeshire: Cambridge University.

Superior Energy Services. (2013, August). Shop Hand. Retrieved from http:///www.rigzone.com/jobs/postings/400708/Shop_Hand.asp.

Talisman Energy. (2013, August). Planner/scheduler . Retrieved from https://www.rigzone.com/oil/jobs/postings/401958_PlannerScheduler/.

Tomlinson, C. (2018, October 1). Energy companies are forgetting the lesson of great crew change. Retrieved: https://www.houstonchronicle.com/business/columnists/tomlinson/article/Energycompanies-are-forgetting-the-lesson-of-13271735.php.

Torlina, J. (2011). Working class: Challenging myths about blue-collar labor. Boulder, Colo: Lynne Rienner Publishers. 
Total Safety. (2013, July 9). Safety Attendants . Beeville Times Picayune, p. C3.

Verity, J. (2005). Interpreting the successful transformation of Shell's advertising activity 1997-2002. Management Decision, 43(1), 72-85.

Vygotsky, L. S., \& Cole, M. (1978). Mind in society: The development of higher psychological processes. Cambridge: Harvard University Press.

Weatherford. (2013, August 7). Sales Representative, Thru Tubing. Retrieved from http://www.rigzone.com/jobs/posting/401389/Sales_Representative.asp.

Wenger, E. (2010) Communities of practice and social learning systems: the career of a concept. In Blackmore, C. (Editor) Social Learning Systems and communities of practice. Springer Verlag and the Open University.

Yanyue, Y. (2014). Turning Friends into Research Participants: Rationale, Possibilities and Challenges. CORERJ: Cambridge Open-Review Educational Research eJournal, 1(1), 80-104.

Yuan, Y. (2014). Turning Friends into Research Participants: Rationale, Possibilities and Challenges. CORERJ: Cambridge Open-Review Educational Research eJournal, 1(1), 88-104. 


\section{APPENDIX 1}

\section{EXAMPLE LOG BOOK}

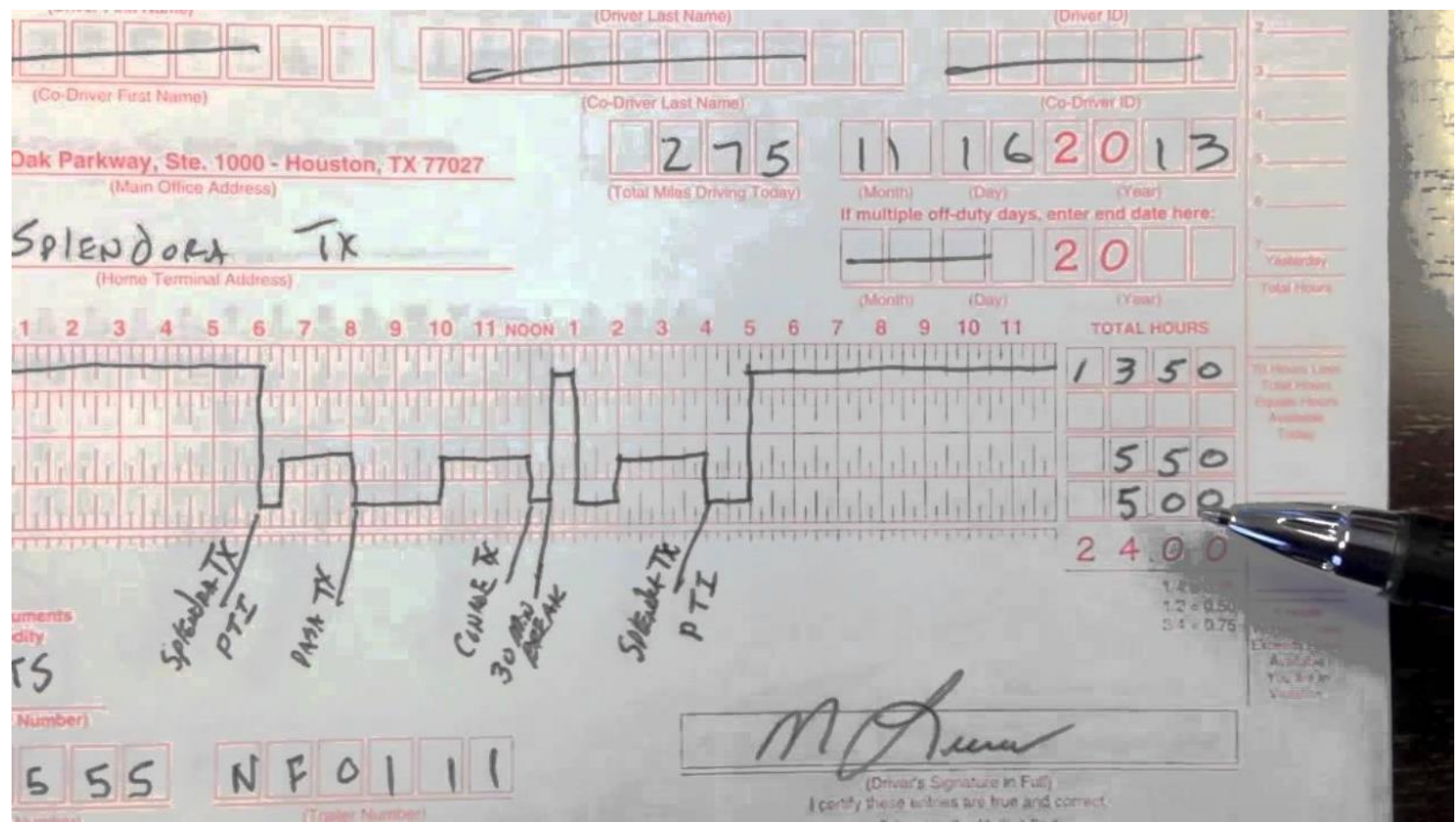




\section{APPENDIX 2}

\section{RELIABLE STAFFING WEB PAGE}

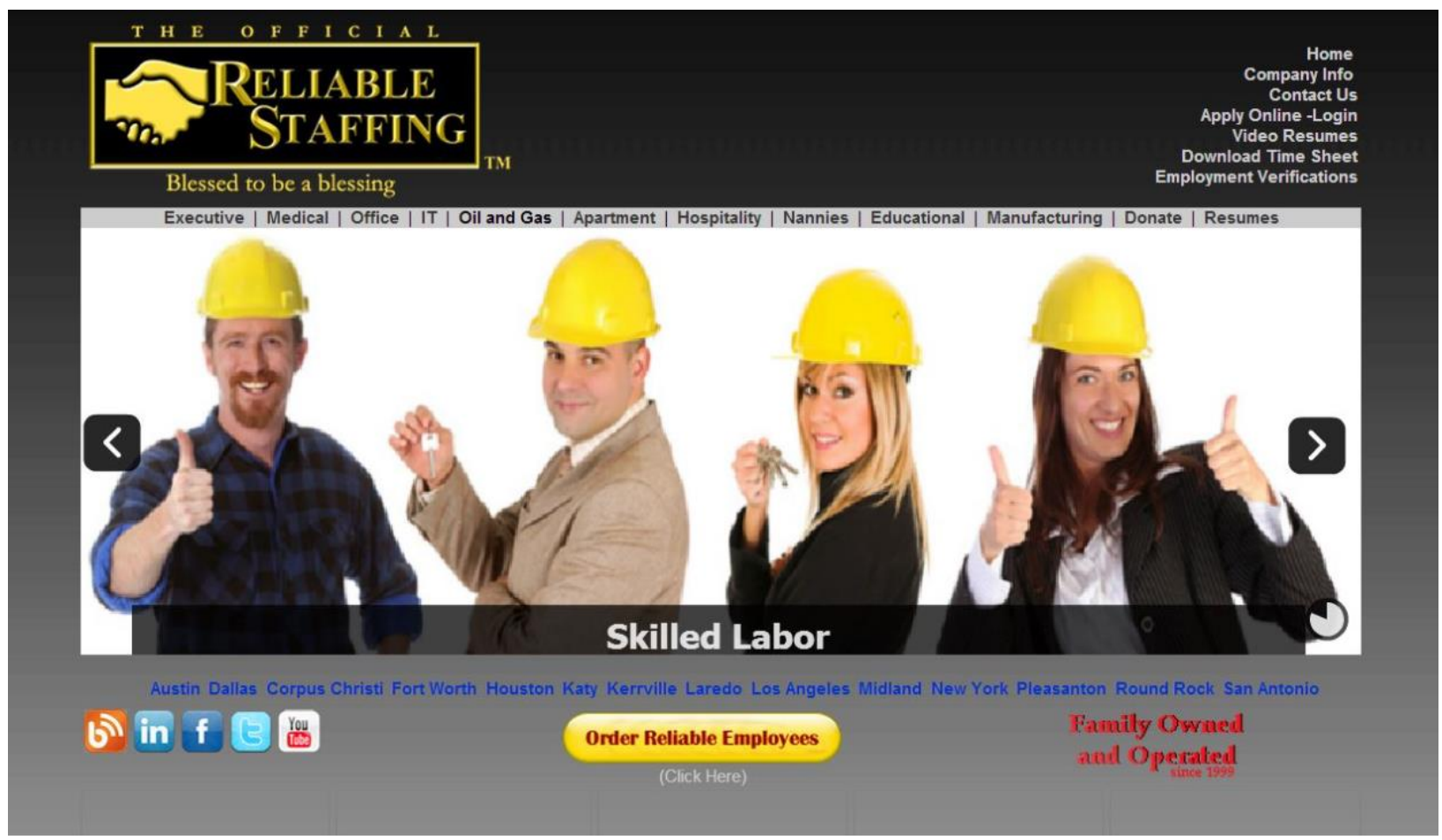




\section{APPENDIX 3}

\section{RELIABLE STAFFING WEB PAGE 2}

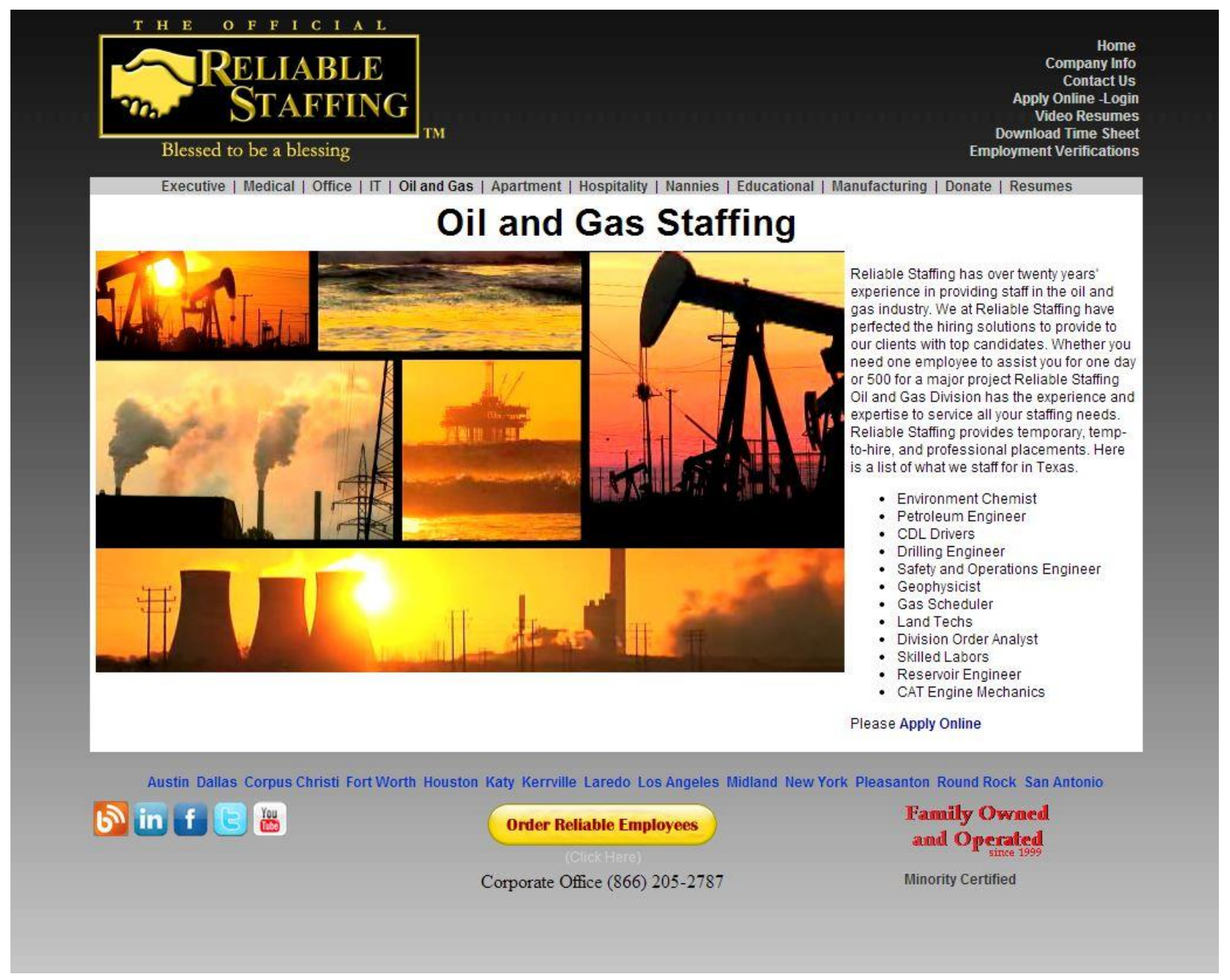




\section{APPENDIX 4}

\section{PARTICIPANT INTERVIEW QUESTIONS}

\section{GROUP 1 - Students currently enrolled in oil and gas programs will be asked the following questions:}

1. Please tell me about your background, including where you grew up, where you went to school.

2. What type of position are you looking for in the oil and gas industry? To the best of your knowledge, what skills do you need to acquire that position?

3. Can you tell me a little about how you chose the oil and gas industry as a profession? What do you find intriguing about it? Does your family work in the oil and gas industry?

4. When considering this industry, did you visit with any industry recruiters at job fairs? If so, can you talk about that experience and the effect it had on your decision to enter the industry and the program? If you did not attend a job fair, why not?

5. Talk a little bit about why you decided on this program specifically. How did you find out about it? What makes you think you are a good fit?

6. When considering programs how often did you look for or run across advertisements for the program in the newspaper, social media, or on television? Basically, how did this program "recruit" you, do you think?

7. Did you get to talk to a program recruiter or any professors when you were making a decision to enroll in a program? If so, how did that experience affect your decisions making?

8. How do you plan on financing your education? How much impact did funding play in your decision to enroll in the program?

9. What kinds of skills do you think you bring to this program, and in turn, to the industry? By skills, I mean characteristics like the ability to learn, reading and writing, problem solving. It could also be hands-on types of skills like mechanics, carpentry, computer technology, etc.

10. When you were deciding on a program, how much of a role did your previous academic education, say high school or any other college, or lack thereof, play into it?

11. What challenges, if any, do you think will prevent you from finishing this program?

12. What expectations do you have for the program? Meaning, when you think about the reasons you decided on this program specifically, how do you see it helping you meet your career goals?

13. After you complete the program, what expectations do you have about getting a job in the oil and gas field? Do you think having this education/certification make you a better candidate than those who do not? Why or Why not? 
14. Participants will be asked to look at a series of job advertisements (see attachment) and answer the following questions related to their content:

a. Consider these ads. Which would you consider applying for and why?

b. What do you find most desirable about those jobs and why?

c. Considering the skill qualifications desired by the employer, how is your current educational program assisting you in meeting these qualifications?

d. Also, of the skills and requirements desired by the employer, which do you think come natural to you? Meaning, which do you think you possessed before enrolling in an education program?

e. You did not choose to apply for some of the jobs. Why? If you feel you did not meet (or will not meet even after finishing your program) the qualifications for the job, which qualifications are you/will you be missing?

f. Do you feel you have certain skills you could bring to this job that are not being asked for? In other words, what skills do you think may be missing from these job ads that from your experience are necessary for a productive and meaningful work environment?

\section{GROUP 2 - Potential Students considering a program will be asked the following questions:}

1. Please tell me about your background, including where you grew up, where you went to school.

2. What type of position will you eventually be looking for in the oil and gas industry? To the best of your knowledge, what skills do you need to acquire that position?

3. Can you tell me a little about why you are considering the oil and gas industry as a profession? What do you find intriguing about it? Does your family work in the oil and gas industry?

4. When considering this industry, did you visit with any industry recruiters at job fairs? If so, can you talk about that experience and the effect it had on your decision to consider specific education programs? If you did not attend a job fair, why not?

5. When considering programs how often did you look for or run across advertisements for the program in the newspaper, social media, or on television? Basically, how did this program "recruit" you, do you think?

6. Did you get to talk to a program recruiter or any professors when you were making a decision to enroll in a program? If so, how did that experience affect your decisions making?

7. Talk a little bit about the programs you are considering. How did you find out about them? What makes you think you are a good fit for these programs? Taking into consideration your personal life, as well as professional aspirations, why do you think you are a better fit for some more than others?

8. What kinds of skills do you think you will bring to a program, and in turn, to the industry? By skills, I mean characteristics like the ability to learn, reading and writing, problem solving. It could also be hands-on types of skills like mechanics, carpentry, computer technology, etc. 
9. As you decide on a program, how much of a role did your previous academic education, say high school or any other college, or lack thereof, play into it?

10. What do you think will prevent you from entering a program?

11. How do you plan on financing your education? How much impact will funding play in your decision to enroll in a program?

12. What expectations do you have for a program? Meaning, how do you see education helping you meet your career goals?

13. If you complete a program, what expectations do you have about getting a job in the oil and gas field? Do you think having an education/certification make you a better candidate than those who do not? Why or Why not?

14. Participants will be asked to look at a series of job advertisements (see attachment) and answer the following questions related to their content:

a. Consider these ads. Which of these seems most desirable to you? Why?

b. Which of these jobs seem attainable with the skills you have right now without a degree? If applicable, what is it about your desire for education is stopping you from applying for jobs like these?

\section{GROUP 3 - Former Students/Workers who have completed a program will answer the following questions:}

1. Please tell me about your background, including where you grew up, where you went to school (high school and post-secondary).

2. What type of position are you looking for/currently hold in the oil and gas industry? To the best of your knowledge, what skills do you need to acquire that position?

3. Can you tell me a little about how you chose the oil and gas industry as a profession? What do you find intriguing about it? Does your family work in the oil and gas industry?

4. When considering this industry, did you visit with any industry recruiters at job fairs? If so, can you talk about that experience and the effect it had on your decision to enter the industry and the program? If you did not attend a job fair, why not?

5. Talk a little bit about why you decided on this program specifically. How did you find out about it? What makes you think you are a good fit?

6. When considering programs how often did you look for or run across advertisements for the program in the newspaper, social media, or on television? Basically, how did this program "recruit" you, do you think?

7. Did you get to talk to a program recruiter or any professors when you were making a decision to enroll in a program? If so, how did that experience affect your decisions making?

8. How did you finance your education? How much impact did funding have on your decision to enroll in the program?

9. What kinds of skills do you think you brought to this program, and in turn, will bring/do bring to the industry? By "skills" I mean characteristics like the ability to learn, reading and writing, problem solving. It could also be hands-on types of skills like mechanics, carpentry, computer technology, etc. 
10. When you were deciding on a program, how much of a role did your previous academic education, say high school or any other college, or lack thereof, play into it?

11. Did you have any challenges finishing this program? If so, what were they? If not, what motivated you to complete the program?

12. Going in, what expectations did you have for the program? Meaning, when you think about the reasons you decided on this program specifically, how has it helped you reach (or begin reaching) your career goals?

13. When you completed the program, what expectations did you have about getting a job in the oil and gas field? Do you think having this education/certification made/makes you a better candidate than those who do not? Why or Why not?

14. Now that you are part of the industry, do you think the education offered by the program adequately prepared you to enter the oil and gas workforce? Please explain.

15. Participants will be asked to look at a series of job advertisements (see attachment) and answer the following questions related to their content:

a. Consider these ads. Which would you consider applying for and why?

b. What do you find most desirable about those jobs and why?

c. Considering the skill qualifications desired by the employer, how did your post-secondary education assist you in meeting these qualifications?

d. Also, of the skills and requirements desired by the employer, which do you think come natural to you? Meaning, which do you think you possessed before enrolling in an education program? Which do you think your education program enhanced? Or hindered?

e. You did not choose to apply for some of the jobs. Why? If you feel you did not meet the qualifications for the job, which qualifications do you feel you are missing?

f. Do you feel you have certain skills you could bring to this job that are not being asked for? In other words, what skills do you think may be missing from these job ads that from your experience are necessary for a productive and meaningful work environment?

\section{GROUP 4 - Workers who decided to forgo higher education and move straight into the oil and gas workforce will answer the following questions:}

1. Please tell me about your background, including where you grew up, where you went to school (high school and post-secondary).

2. What type of position are you looking for in the oil and gas industry? To the best of your knowledge, what skills do you need to acquire that position?

3. Can you tell me a little about how you chose the oil and gas industry as a profession? What made you think you were a good fit? Does your family work in the oil and gas industry?

4. How did you go about your job search? Did you look for job advertisements? If so, where, and what were you looking for specifically, such as job requirements and benefits? 
5. When looking for a job, how often did you turn to social media such as Facebook, or Eagle Ford job boards for assistance? What are your thoughts on the benefits of social media in looking for a job?

6. When considering this industry, did you visit with any industry recruiters at job fairs? If so, can you talk about that experience and the effect it had on your decision to enter the industry? If you did not attend a job fair, why not?

7. How did you make the decision to go straight into the industry as opposed to going to a community college for a certification or associate's degree?

8. Was the promise of on the job training a motivation for entering this industry/current position in the industry? Can you tell me a little about the training?

9. What kinds of skills do you think you bring/do bring to the industry? By "skills" I mean characteristics like the ability to learn, reading and writing, problem solving. It could also be hands-on types of skills like mechanics, carpentry, computer technology, etc.

10. When you were deciding on this industry, how much of a role did your previous academic education, say high school or any other college, or lack thereof, play into it?

11. Going in, what expectations did you have for working in the oil and gas industry? Meaning, when you think about the reasons you decided on this field specifically, how has it helped you reach (or begin reaching) your career goals?

12. Now that you are part of the industry, is there pressure to get certified in certain areas (like CDL, safety) that would require you to go back for higher education? Is there pressure from the industry to do this? If so, does your employer offer to pay for certification training? If they did, would that be an incentive to go back to school?

13. Participants will be asked to look at a series of job advertisements (see attachment) and answer the following questions related to their content:

a. Consider these ads. Which would you consider applying for and why?

b. What do you find most desirable about those jobs and why?

c. Of the skills and requirements desired by these employers, which do you think come natural to you? Meaning, which do you think you have because you learned them by watching others, through practice, play, games? Skills you developed other than through classroom education.

d. You did not choose to apply for some of the jobs. Why? If you feel you did not meet (or will not meet even after finishing your program) the qualifications for the job, which qualifications are you/will you be missing?

e. What is your perception of higher education when it comes to jobs in the oil and gas industry? Considering your job/career, and those around you who work in the same job and have the same background as you, would you ever consider going back to school? Why or why not?

f. Do you feel you have certain skills you could bring to one or more of these jobs that are not being asked for? In other words, what skills do you think may be missing from these job ads that from your experience are necessary for a productive and meaningful work environment? 


\section{GROUP 5 - Recruiters for Community College/University will be asked the following questions:}

1. Please tell me about how you became a recruiter for XXX college/university, and what specific programs you are currently recruiting for related to the oil and gas industry.

2. What skills are you looking for in potential new students for these programs? How do you communicate this skill set to potential students?

3. When talking to potential students about these programs, what questions or concerns do they usually have regarding how their current skills can be utilized in the program, and, therefore, within the industry?

4. When potential students approach you at a job fair or in the office for information on oil and gas industry jobs, what seems to be their reason or motivation behind their interest?

5. What demographics do you see enrolling in these programs, and if they are changing, how so?

6. Some potential students are unsure if these programs are a good fit for them. Some may be wavering on going to school or going straight into the oil and gas industry. What do you say to potential students who are in this position?

7. What incentives or benefits do potential students have to complete program as opposed to straight into the oil and gas workforce?

8. Financial aid can be a significant hurdle for students coming into higher education. What do you tell students to alleviate student fears of not being able to pay for college? Do oil and gas industry corporations assist with any funding for your programs through scholarships or grants?

9. What seems to be the most successful strategy/ies used for recruiting into your oil and gas program? How lucrative has social media been as a recruitment strategy?

10. Programs in oil and gas have recently begun expanding their recruitment campaigns to target more women, veterans, other minority populations. Is this ideology part of your current or future campaign strategy? How do you think recruitment needs to change in order to reach the best potential applicants?

11. What information resources do you give potential students interested in oil and gas programs so they can conduct their own research? Do you refer them to websites or social media for information? If so which ones and why? If you do not, why not?

12. The fracking industry, which is part of the oil and gas industry, has been under a lot of scrutiny for its effects, or perceived effects, on the environment. How do you respond to questions from recruits that involve these criticisms?

13. When recruiting locally in South Texas, what are some of the most significant challenges you come up against in qualified potential students?

14. How often do you recruit from outside the region and outside the State of Texas? How much interest from out of state has there been since the discovery of the Eagle Ford. How these applicants more/less qualified for these programs than South Texas applicants?

15. Participants will be asked to look at a series of job advertisements (see attachment) and answer the following questions related to their content: 
a. Consider the skill and education requirements listed in these ads. Of these jobs, which could a graduate of your program apply for and have a reasonable chance of an interview or job offer?

b. Does your program assist students in reading and interpreting job announcements like these?

c. The salary on many of these announcements are $\$ 60,000-\$ 80,000$ for entry level positions with a high school diploma. What do you tell potential students who are very much influenced by the money to be earned, but might not necessarily be aware of the instability of some of these contract positions?

\section{GROUP 6 - Recruiters for the Oil and Gas Industry will be asked the following questions:}

1. Please tell me about how you became a recruiter for XXX, and what specific positions you are currently recruiting for and/or are in high demand.

2. What skills are you looking for in potential new students for these programs? How do you communicate this skill set to potential applicants?

3. Women and Veterans have become a target demographic for oil and gas education programs over the last five years. What kind of increase in women and veterans, as well as other minority population applicants have you seen? What are some of the challenges in recruiting minority populations? How do you think recruitment needs to change in order to reach the best potential applicants?

4. When talking to potential applicants about these positions, what questions or concerns do they usually have regarding how their current skills can be utilized in the industry? How often do you refer to them a community college for a certification or training?

5. What demographics do you see enrolling in these programs, and if they are changing, how so?

6. Some potential applicants may be wavering on going to school or going straight into the oil and gas industry. What do you say to potential applicants who are in this position?

7. What are the potential incentives or benefits for applicants to go straight into the oil and gas industry, bypassing higher education? How and when would you persuade a potential applicant to go to school as opposed to entering the workforce without academic education?

8. The State of Texas and some oil and gas conglomerates have earmarked money to fund scholarships and grants for educational programs related to the oil and gas industry. How educated do potential applicants seem to be in this sponsored educational opportunity? How does your recruitment campaign work to foster an education of this sponsorship?

9. What seems to be the most successful strategy/ies used for recruiting into your oil and gas program? How lucrative has social media been as a recruitment strategy?

10. Programs in oil and gas have recently begun expanding their recruitment campaigns to target more women, veterans, other minority populations. Is this ideology part of your current or future campaign strategy? How do you think recruitment needs to change in order to reach the best potential applicants? 
11. What information resources do you give potential students interested in oil and gas programs so they can conduct their own research? Do you refer them to websites or social media for information? If so which ones and why? If you do not, why not?

12. The fracking industry, which is part of the oil and gas industry, has been under a lot of scrutiny for its effects, or perceived effects, on the environment. How do you respond to questions from recruits that involve these criticisms?

13. When recruiting locally in South Texas, what are some of the most significant challenges you come up against in qualified potential students?

14. How often do you recruit from outside the region and outside the State of Texas? How much interest from out of state has there been since the discovery of the Eagle Ford. How these applicants more/less qualified for these programs than South Texas applicants?

15. Participants will be asked to look at a series of job advertisements (see attachment) and answer the following questions related to their content:

a. Considering some of the language of these ads, why might a potential applicant be persuaded/dissuaded from applying?

b. An applicant may read job ads like the Field Service Technician position and see one of the qualifications is the ability to read, write, and speak English. Some applicants might think they meet this qualification; however, the level of their English ability may vary in fluency. How a qualification is like language ability measured exactly?

\section{GROUP 6 - Recruiters for the Oil and Gas Industry}

1. Please tell me about how you became involved with Texas Workforce Solutions. What specific positions related to the oil and gas industry are you are currently recruiting for and/or are in high demand.

2. What skills are you looking for in potential employees for these positions? How do you communicate this skill set to potential applicants?

3. Women and Veterans have become a target demographic for oil and gas education programs over the last five years. Have you seen an increase in women and veterans, as well as other minority population applicants, for oil and gas positions at Texas Workforce Solutions? What are some of the challenges in recruiting minority populations?

4. When talking to potential applicants about advertised positions, what questions or concerns do they usually have regarding how their current skills can be utilized in the industry? How often do you refer to them a community college for a certification or training?

5. Some temp agencies like Kelly Services, Inc., require their potential applicants to take standardized tests on Microsoft Word and Excel competency. What is the role of standardized testing or screening of applicants at Texas Workforce Solutions? 
6. Some potential applicants may be wavering on going to school or going straight into the oil and gas industry. What do you say to potential applicants who are in this position?

7. What are the potential incentives or benefits for applicants to go straight into the oil and gas industry, bypassing higher education? How and when would you persuade a potential applicant to go to school as opposed to entering the workforce without academic education?

8. What seems to be the most successful strategy/ies used for recruiting applicants for your oil and gas clients? Do you use social media as a marketing outlet? How lucrative has social media been as a recruitment strategy?

9. In what ways can Texas Workforce Solutions' recruitment strategies be revised in order to reach the best potential applicants for oil and gas industry positions?

10. What information resources do you give potential students interested in oil and gas positions so they can conduct their own research? Do you refer them to websites or social media for information? If so which ones and why? If you do not, why not?

11. The fracking industry, which is part of the oil and gas industry, has been under a lot of scrutiny for its effects, or perceived effects, on the environment. Has there been much concern about these issues from potential applicants? If so, how do you respond to questions from potential applicants that involve these criticisms?

12. When recruiting in South Texas, what are some of the most significant challenges you come up against in finding qualified potential applicants?

13. How often do you recruit from outside the region and outside the State of Texas? How much interest has Texas Workforce Solutions seen from out of state applicants since the discovery of the Eagle Ford? From your experience, are outof-state applicants more/less qualified for these programs than South Texas applicants?

14. Please look over the attached series of job advertisements and answer the following questions related to their content:

a. Considering some of the language of these ads, why might a potential applicant be persuaded/dissuaded from applying?

b. An applicant may read job ads like the Field Service Technician position and see one of the qualifications is the ability to read, write, and speak English. Some applicants might think they meet this qualification; however, the level of their English ability may vary in fluency. How is a qualification like language ability measured exactly? 


\section{APPENDIX 5}

\section{INFORMED CONSENT FORM}

\section{Introduction and Background Information}

You are invited to participate in a research study. The study is being conducted by Dr. Stephen Schneider, Ph.D., and Jennifer Marciniak, doctoral candidate in Rhetoric and Composition at the University of Louisville. The study is sponsored by University of Louisville, Department of English. The study will take place at different locations in South Texas. Approximately 15-18 subjects will be invited to participate.

\section{Purpose}

The purpose of this study is to investigate the strategies community colleges and fouryear universities in South Texas use to recruit students for oil and gas/ fracking industry related associates and certification programs. An analysis of these strategies, which include but are not limited to social media, job fairs, brochures and other physical texts, may illuminate possible trends in diversity recruitment for these programs. In addition, this study will also look at recruitment strategies utilized by the oil and gas/fracking companies in South Texas. Many of these companies are looking to hire workers with little or no education past high school, which puts them in somewhat direct competition with the educational institutions. This study looks at why some choose specialized education prior to entering the oil and gas workforce on one hand, and why others decide to forego higher education before taking an oil field position, on the other.

\section{Procedures}

In this study, you will be asked to provide feedback via series of interviews related to your position of student, potential student, former student, industry worker, or recruiter/admissions officer. Initial interviews will be conducted face to face in September of 2013. Follow-up interviews will be conducted as deemed necessary via email, telephone or Skype. Initial interviews will consist of a minimum of 10 questions regarding basic biographical questions, reasons behind your interest in the oil and gas field, perceptions about education and the workforce, and your higher education plans. Initial interviews will range from 1-2 hours. Follow-up interviews conducted over phone or Skype may last 1-2 hours depending on content. A 72-hour turnaround is requested for follow-up interviews conducted through e-mail. More than one follow-up interview may be needed over the course of the study. You may decline to answer any questions that make you feel uncomfortable.

\section{Potential Risks}


There are minimal risks associated with conducting interviews face-to-face, over the phone or Skype, or through email. Those risk(s) is/are potential hacking, loss, or undelivered email as well as unintentional loss of digital Skype or telephone recordings.

\section{Benefits}

The possible benefits of this study include certain changes in the way certain institutions recruit student for specific programs. The information collected may not benefit you directly. The information learned in this study may be helpful to others.

\section{Compensation}

You will not be compensated for your time, inconvenience, or expenses while you are in this study.

\section{Confidentiality}

Total privacy cannot be guaranteed. Your privacy will be protected to the extent permitted by law. If the results from this study are published, your name will not be made public. While unlikely, the following may look at the study records:

The University of Louisville Institutional Review Board, Human Subjects Protection Program Office.

Office for Human Research Protections (OHRP).

All information will be kept on a password protected computer. All notes will be coded, meaning names will be changed, for protection of your identity.

\section{Voluntary Participation}

Taking part in this study is voluntary. You may choose not to take part at all. If you decide to be in this study you may stop taking part at any time. If you decide not to be in this study or if you stop taking part at any time, you will not lose any benefits for which you may qualify.

\section{Research Subject's Rights, Questions, Concerns, and Complaints}

If you have any concerns or complaints about the study or the study staff, you have three options.

You may contact the principal investigator 502-852-2188. 
If you have any questions about your rights as a study subject, questions, concerns or complaints, you may call the Human Subjects Protection Program Office (HSPPO) (502) 852-5188. You may discuss any questions about your rights as a subject, in secret, with a member of the Institutional Review Board (IRB) or the HSPPO staff. The IRB is an independent committee composed of members of the University community, staff of the institutions, as well as lay members of the community not connected with these institutions. The IRB has reviewed this study.

If you want to speak to a person outside the University, you may call 1-877-852-1167. You will be given the chance to talk about any questions, concerns or complaints in secret. This is a 24-hour hot line answered by people who do not work at the University of Louisville.

This paper tells you what will happen during the study if you choose to take part. Your signature means that this study has been discussed with you, that your questions have been answered, and that you will take part in the study. This informed consent document is not a contract. You are not giving up any legal rights by signing this informed consent document. You will be given a signed copy of this paper to keep for your records.

Signature of Subject/Legal Representative

Signature of Person Explaining the Consent Form (if other than the Investigator)

Signature of Investigator
LIST OF INVESTIGATORS

Dr. Stephen Schneider

Jennifer Marciniak

\section{Date Signed}

Date Signed
PHONE NUMBERS

(502)-852-2188

(361)-207-1442 


\section{CURRICULUM VITA}

Name: $\quad$ Jennifer L. Marciniak

Contact: $\quad$ marciniakjl@gmail.com; (361) 207-1442

\section{Education}

Ph.D., Rhetoric and Composition, University of Louisville, December 2019

Dissertation: "Brokering Words and Work: Complexities of Literacy Sponsorship in the Oilfields of South Texas"

Committee: Bronwyn Williams (co-director), Stephen Schneider (codirector), Beth Boehm, Glynis Ridley, Michael Pennell

M.A., English, Rhetoric and Composition, Texas A\&M University-Corpus Christi, August 2009

B.A., Communications, Stephen F. Austin State University, May 2000

\section{Positions Held}

2016- : Director, Debby Ellis Writing Center, Southwestern University

2014-2016: Coordinator, Writing Resources, Berea College

2012-2014: Assistant Director, Virtual Writing Center, University of Louisville

2011-2012: Writing Center Consultant, University of Louisville

2010-2012: Graduate Teaching Assistant, University of Louisville

2009-2010: Adjunct, Del Mar College

2009-2012: Adjunct, Texas A\&M University - Corpus Christi

2009-2010: English Writing Lab Facilitator, Del Mar College

Sum 2009: English as a Second Language Instructor, ESL International School

2008-2009: Graduate Teaching Assistant, Texas A\&M University - Corpus

Christi

2008-2009: Writing Center Consultant, Texas A\&M University - Corpus Christi

2000-2002: English as a Second Language Instructor, Peace Corps Romania 


\section{Scholarship}

\section{PEER REVIEWED JOURNAL ESSAYS}

"Turning Theory into Practice: Breaking Ground with the Coastal Bend Writing Project." English in Texas 39.2 (Fall/Winter 2009): 31-40. Print.

"Teaching Composition at 'Harvard on the Guadalupe': The History of Writing and Social Contexts at Victoria College." Conference of College Teachers of English Studies 75 (2009): 44-52. Print.

\section{NATIONAL CONFERENCES}

"Visualizing Art-Based Reflection and Responses in Tutor Development Practices." Workshop. International Writing Center Association/National Council on Peer Tutoring in Writing, Columbus, OH., October 2019.

“"But My Clipboard Says You are Doing It Wrong:' Memes, Performance-Rhetoric, and Academic Resistance in Online Oil and Gas Worker Communities.” Individual Presentation. Conference on College Composition and Communication, Pittsburgh, PA, March 2019.

"The Migratory Patterns of Cross-Institutional Tutor Training: A Framework." Roundtable. National Conference on Peer Tutoring in Writing. South Padre Island, TX, October 2018.

"Using Assessment to Jump from Junior Spy to Covert Mission Impossible Identity Expert.” Panel. International Writing Center Association Conference. Chicago, Ill, November 2017.

"Sleuthing and Code-Breaking in Tutor Recruitment Practices." Panel. International Writing Center Association Conference. Chicago, Ill, November 2017.

"Writing Centers and Disciplinary Frontiers: Exploring Inventive Ways to Prepare Course-Embedded Tutors and Teaching Assistants for Adventurous Roles." Panel. International Writing Center Association 2016 Conference. Denver, CO, November 2016.

"The Dignity of Work: Writing Tutors and the Perception of Labor at Berea College." International Writing Center Association 2015 Conference. Pittsburgh, PA, October 2015.

"The Rhetoric of Recruitment: Eagle Ford Shale and the Fracking Industry as Literacy Sponsor in South Texas." Rhetoric Society of America 2014 Conference. San Antonio, TX, May, 2014. 
"The Social Center: Closing the Echo Chamber and Opening the Writing Center on Twitter." Panel. International Writing Center Association Collaborative at the Conference on College Composition and Communication. Indianapolis, IN, March 2014.

"Brokering Literacy Work: Education, Fracking, and Workforce Recruitment Strategies." Conference on College Composition and Communication. Indianapolis, IN, March 2014.

“'Just Grammar Please': Submission Forms and the Challenge of Learning About Client Need Prior to Consultation." National Conference on Peer Tutoring. Tampa, FL, November, 2013.

"Literacy on the Backside: The Complex Relationship between Corporate Sponsorship and Migrant Worker Education at Churchill Downs." Conference on College Composition and Communication, Las Vegas, NV, March 2013.

"Teaching as Translation: Caring as a Political Act.” College English Association National Conference. Richmond, VA. March 2012.

"The Farmhouse Online: The Rural/Urban Contact Zone of Cyber Education;" Research Network Forum: Conference on College Composition and Communication; Atlanta, GA, April 2011.

"The Personal is Political: Female Empowerment and Gender Borders in Alicia Gaspar de Alba's Desert Blood;" El Mundo Zurdo: The First International Conference on the Work and Life of Gloria E. Anzaldúa. University of Texas - San Antonio, May 2009.

"Progression of 'Evolution:' A New Critical Look at Sherman Alexie." Sigma Tau Delta International English Society Annual Conference. Louisville, KY. March 2008.

"Writing Centers: A Gateway to Promoting Latino/a Students' Academic Confidence at Hispanic-Serving Institutions." National Council of Teachers of English National Conference, San Antonio, TX, November 2008.

\section{REGIONAL CONFERENCES}

Fall 2019 Director's Day Out, South Central Writing Centers Association MicroRegional. Southwestern University, Georgetown, TX. Conference Host.

"Cross-Institutional Tutor Training: Creating and Revising Frameworks." South Central Writing Centers Association Conference, February 2019.

"Kairotic Diversity: The Challenge of Recruiting African American Tutors in the Writing Center at Berea College," 2016 Southeastern Writing Center Association Conference, Columbus, GA, February 2016. Roundtable. 
"De-Stressing with Stress-balls: The Multipurpose Use of Manipulatives in the Writing Center." 2015 Southeastern Writing Center Association - Kentucky Tutor Appreciation Conference, Eastern Kentucky University, Richmond, KY, October 2015.

"The Virtual Dissertation Writing Retreat: Building Community and Accountability Among Doctoral Students Writing from a Distance," 2014 Southeastern Writing Center Association Conference, East Carolina University. Greenville, NC, February 2014.

"The Invisible Writer: Approaches for Effective Online Tutoring." Southeastern Writing Center Association Fall Writing Center Tutor Appreciation Day and Creative Collaborative, Eastern Kentucky University, Richmond, KY, September 2013.

"Third Space and the Writing Center: Who Are We as Administration, Consultant, and Instructor?" Southeast Writing Center Association Conference, Eastern Kentucky State University. Richmond, KY, February 2012.

"Murderscapes: The Media and the Construct of the 'Imagined World' in Alicia Gaspar de Alba's Desert Blood." Conference of College Teachers of English. Lamar State University. Beaumont, TX, March 2010.

"Suns and Daughters: The Role of Marxism and Women in Khaled Hosseini's $A$ Thousand Splendid Suns." Southwest Texas Popular and American Culture Association Conference. Albuquerque, NM, February 2009.

\section{LOCAL CONFERENCES}

"Translation and Survival in Push and The Diving Bell and the Butterfly." Louisville Humanities Graduate Conference: The Phoenix Effect: Regeneration, Rebirth, Reformation. University of Louisville, Louisville, KY. March 2012.

"Teaching Composition at 'Harvard on the Guadalupe': The History of Writing and Social Contexts at Victoria College." Conference of College Teachers of English. University of Texas - Austin, March 2009.

"Parallels in Marxism and Feminism: Tracing the Roles of Gender and Class in Khaled Hosseini's A Thousand Splendid Suns." Graduate Student Association Scholarly Works Symposium. Texas A\&M University - Corpus Christi, April 2008.

"Linking Your Classroom to the World: Using Culturally Diverse Materials in the Classroom to Promote International Understanding." Center for Educational Development, Evaluation, and Research Conference: Education for Changing World. Texas A\&M University-Corpus Christi, December 2007. 


\section{Academic Writing Honors and Awards}

2019 South Central Writing Centers Association (SCWCA) Micro-Regional. Grant Recipient. Awarded June 2019.

2014 Southeastern Writing Center Association (SWCA) Tom Waldrep Scholarship. Awarded February 2014.

2014 Southeastern Writing Center Association (SWCA) Graduate Tutor Award. Awarded February 2014.

2013 Southeastern Writing Center Association (SWCA) and National Conference on Peer Tutoring in Writing Research Scholarship Winner. Awarded October 2013.

2013 Registration and Grub Travel Grant, National Conference on Peer Tutoring in Writing. Awarded October 2013.

The Dale T. Adams Student of the Month Award. Selected by University of Louisville Student Government Association Academic Policy Board. Awarded November 2012.

College English Association's Outstanding Graduate Student Paper for "Teaching as Translation: Caring as a Political Act." Nominee. College English Association National Conference; Richmond, VA. March 2012.

2010 Del Mar College Teacher of the Year. Nominee.

William B. Tanner Award for Best Rhetorical Paper by a Graduate Student; "Teaching Composition at 'Harvard on the Guadalupe:' The History of Writing and Social Contexts at Victoria College" Conference of College Teachers of English, University of Texas Austin. Awarded March 2009.

Diane Cox Images of Women Award; "Suns and Daughters: The Role of Marxism and Women in Khaled Hosseini's A Thousand Splendid Suns," Southwest Texas Popular and American Culture Association Conference, Albuquerque, NM. Awarded February 2009.

Haas Writing Award; "Suns and Daughters: The Role of Marxism and Women in Khaled Hosseini's A Thousand Splendid Suns," Texas A\&M University - Corpus Christi. Awarded March 2008.

Texas A\&M University - Corpus Christi College of Liberal Arts Competitive Academic Scholarship. Awarded yearly 2007-2009.

\section{Course Instruction and Design}

University Studies 124: Teaching and Tutoring Writing Across the Disciplines, 20192020, (1 section) 
English 286: Writing Center Theory and Practice, 2016 (1 section)

English 384: Teaching and Tutoring Peer Writing, 2015, (1 section)

English 101: Introduction to College Writing, 2009-2012 (4 sections)

English 102: Intermediate College Writing, 2009-2012 (5 sections)

English 1301: Introduction to Writing, 2008-2010 (4 sections)

English 1302: Intermediate Writing, 2008-2010 (6 sections)

English 101: Introduction to Composition, 2009-2010 (2 sections)

English as a Second Language Level 1: Basic Writing, English as a Second Language

International School, 2009 (1 section)

English as a Second Language Level 3: GRE/GMAT Prep, English as a Second

Language International School, 2009 (1 section)

5th-12th Grade English as a Second Language, Liceul Teoretic, Carei, Romania

\section{Service}

\section{COMMITTEES}

Sexual Misconduct Hearing Board, Southwestern University, 2019+

Academic Assessment Committee, Southwestern University, 2018+

SWCA Board - Kentucky State Representative, 2016

Christine Cozzens Grant Award Committee (SWCA) 2016

Learning Commons Committee, Berea College, 2014-15

Berea College Academic Coaching Coordinator Search Committee, 2014-15

International Writing Center Association Graduate Student Committee, 2013

University of Louisville Latino/Asian Studies Prof. Search Committee, 2012-13

University of Louisville Graduate Representative to English Faculty, $\quad$ 2012-13

University of Louisville Faculty Committee on Libraries, 2012-13

\section{DISSERTATION WORKSHOPS}

Virtual Dissertation Writing Retreat for Distance Learners, Director and Consultant, Dec. 2013

Dissertation Writing Retreat, Consultant, College of Education, July 2013

Dissertation Writing Retreat, Consultant, College of Education, Social Work, May 2013

Dissertation Writing Retreat, Consultant, J.B. Speed School of Engineering. May 2012

\section{FACULTY AND STAFF WRITING WORKSHOPS}

“Online Instructors and the Virtual Writing Center." Delphi U, Delphi Center for Teaching and Learning. University of Louisville - Shelby Campus. March 9, 2013; June 6, 2013. Facilitator.

“Tips for Writing Business Memos and Emails," University of Louisville Writing Center Presentation and Workshop. Hosted by College of Arts and Sciences, University of Louisville. October 2011. Facilitator. 


\section{PROFESSIONAL DEVELOPMENT FOR STUDENTS}

"Computer Literacy for Adult English Language Learners" Hispanic Outreach Project Tutor Training Workshop, Fall 2015 and Spring 2016. Facilitator.

"Part II: Teaching and Tutoring Research and Argumentative Writing." Writing Conference for Teaching Assistants and Imbedded Tutors. Berea College. Spring 2016. Director.

"Part I: Writing and Mentoring Strategies for Navigating the First-Year Experience" Writing Conference for Teaching Assistants and Imbedded Tutors. Berea College. Fall 2016. Director.

"Reading and Writing with Adult English Language Learners" Hispanic Outreach Project Tutor Training Workshop. Spring 2015. Facilitator.

\section{COMMUNITY VOLUNTEER WORK}

Technology Tutor, Backside Learning Center at Churchill Downs, Louisville, KY, 20122014

\section{PROFESSIONAL DEVELOPMENT}

Lavender Spaces Training, Southwestern University, 2019

Title IX Training, Berea College, 2016

Green Dot Training, Berea College, 2016

SafeZone Training, Berea College, 2016

University of Louisville Grant Writing Academy, 2013-2014

Career Colloquium for Graduate Students, Summer 2013.

University of Louisville Graduate Teaching Academy, 2011-2012

Building a Resume from a CV Workshop, Spring 2012.

Technology for Professional Development, Spring 2012.

Endnote Citation Management Software Workshop, Fall 2011

Technology for Effective Teaching Workshop, Spring 2011.

The IRB from the Inside Workshop, Spring 2011.

Blackboard Training (Advanced), Fall 2010.

Diversity in the Classroom Workshop, Fall 2010.

Finance 4 U Workshop. School of Interdisciplinary and Graduate Studies, 2010

\section{Professional Memberships}

National Council for Teachers of English (2014-present)

International Writing Center Association (2013-present)

Southeastern Writing Center Association (2014-2016)

Conference of College Teachers of English (2008-2011)

South Central Writing Centers Association (2016-present) 